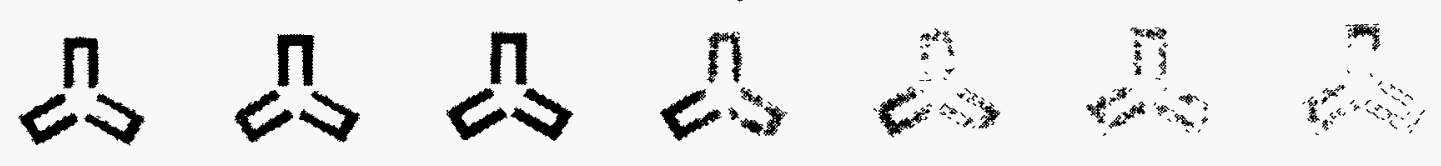

MLM-MU-90-66-0006

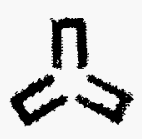

$\stackrel{n}{2}$

RELATIONAL GEISHA FORMAT

(RGF)

July 26, 1990

$\prod_{\infty}$

RECEIVED

JUL 22 หรSG

$\sum_{2}^{n}$

OSTI

$\stackrel{7}{7}$

¿ EGELG MOUND APPLIED TECHNOLOGIES

P.O. BOX 3000

MIAMISBURG, OHIO 45343-3000

$513-865-4020$

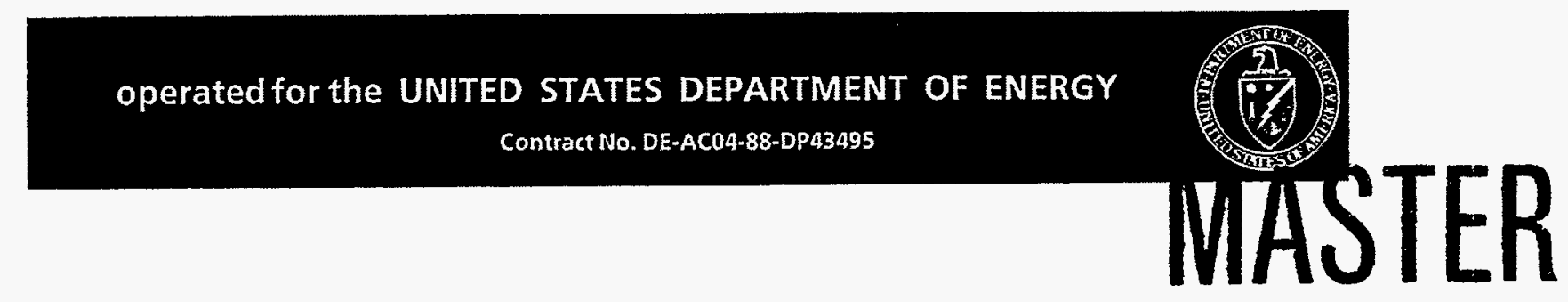

DSTRIBUTION OF THIS DOCUMENT IS UNLMMTED 
EG\&G Relational Geisha Format (RGF)

Analyst Reference Guide

\author{
Version 1.0 \\ June 15, 1990
}




\section{DISCLAIMER}

Portions of this document may be illegible in electronic image products. Images are produced from the best available original document. 


\title{
Relational Geisha Format
}

(RGF)

\section{Developed by : David I. Hegemann, EG\&G-MAT : Michael S. Hicks, EG\&G-MAT}

\author{
Documentation \\ written by : Carol Brunner, Ciber Inc. \\ : Suzanne Crabtree, EG\&G-MAT \\ : David L. Hegemann, EG\&G-MAT \\ : Pam Pugh, EG\&G-MAT
}

\section{DISCLAIMER}

This report was prepared as an account of work sponsored by an agency of the United States Government. Neither the United States Government nor any agency thereof, nor any of their employees, makes any warranty, express or implied, or assumes"any legal liability or responsibility for the accuracy, completeness, or usefulness of any information, apparatus, product, or process disclosed, or represents that its use would not infringe privately owned rights. Reference herein to any specific commercial product, process, or service by trade name, trademark, manufacturer, or otherwise does not necessarily constitute or imply its endorsement, recommendation, or favoring by the United States Government or any agency thereof. The views and opinions of authors expressed herein do not necessarily state or reflect those of the United States Government or any agency thereof. 
Table of Contents

Description

Page (s)

overview..............................

Background of RGF

Purpose of this Documentation

Who should use this Documentation

Suggestions on using this Documentation

PROCODE Data systems Configuration................

Automated Forkstation ( $\mathrm{AW}$ )

Diagram I, Figure 1 - Automated porkstation

Transaction Manager (TM)

Diagram 2, Figure 2 - Transaction Manager

Port Concentrator

Diagram 2, Figure 1 - Port Concentrator

Cell Supervisor

Diagram 3, Figure 1 - Cell supervisor

Diagram 4 - Procode volumes Schematic

Internetwork

Diagram 5 - Internetwork.

The RGF Record.......................... 14

RGE Record Description $\quad 14$

RGF Record Format 14

Example RGF Record 14

RGF Record Format Rules 14

RGE Field Descriptions.................... 15 - 18

Port $\quad 15$

Operation . 16

Part No./Serial No. (PN_SN) 16

Data Description 16

$\begin{array}{ll}\text { Data Value } & 17\end{array}$

TMDATE

$\begin{array}{ll}\text { CSDATE } & 17,18\end{array}$

CSTIME 18

PN_SN Field Contents......................19-31

Overview 19

PN_SN Field Contents Options 19

PN_SN Field Options Table 19

Table Constraints 19

PN_SN Field Containing the Reyword HDR 20

HDR Options Table $20-26$

PROD 
Table of Contents,

continued

Description

page(s)

PN_SN Field Contents, continued

$19-31$

HDR Options Table, continued

$20-26$

LOT

DRAFNO

21

DRAWIS

21

HP

21

22

GRPNAM

22

GRPVAL

23

DELETE

24

EXIT

CoMM (Comment)

24

25

COMPLETE

26

PN_SN Field Containing a PN or SN

27

PN or SN options Table

PN_SN Description

27

*ACCEPT , INITIAL

28

REJECT

28

*VERIFY

29,30

PN_SN Field Containing the Reyword DETAIL 31

DETAIL Options Table . 31

Production Description 31

OPERATION, PROCESSED 31

REJECT

RGF Database Files........................ 32

Overview $\quad 32$

Diagram 6 - Cell Supervisor Data Flow , 33

RGF Database File Structures 34

RGE Data Flow 35

RGF Database Files Utilization $\quad 36,37$

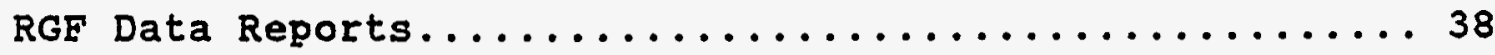

Reports Produced Using RGF Data 38

Database Maintenance Reports 38

RGF Data Collection Planning Process............. 39,40

Programming for RGF Data Collection.............41-44

Overview

Suggested Exhibits to Review

41.

List of Error Trapping Techniques 


\section{Table of Contents,}

continued

Description

Page (s)

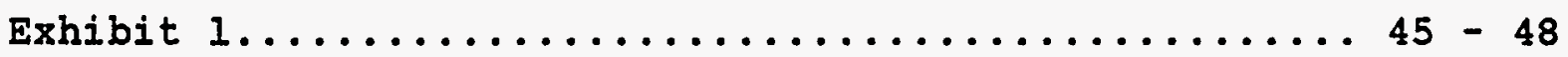

Sample A - RGF Data Blocks 46

Sample A - Electronic Traveler Report 47,48

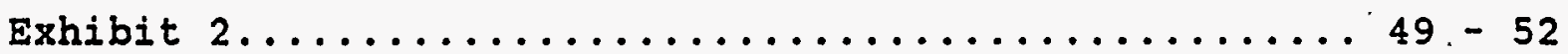

Sample B - RGF Data Blocks 50

Sample B - Electronic Traveler Report 51

Sample B - Operations Data Report 52

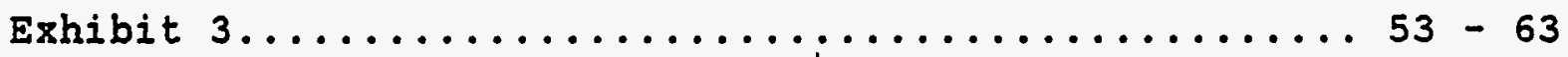

S/N Acceptance Report $\quad 54-58$

Status Verification Report $\quad 59,60$

Operation Upload Report 61

$\begin{array}{ll}\text { Detail Report } & 62,63\end{array}$

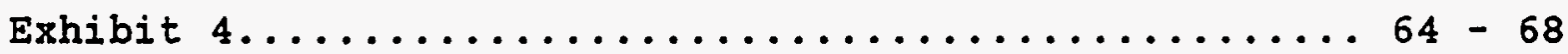

Sample Data Specification Document 65-68

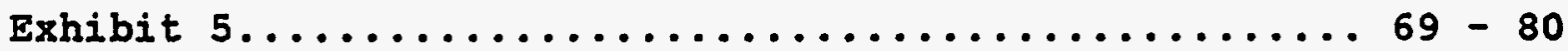

RGE Data Collection Program - written in IRL $70-80$

Exhibit $6 \ldots \ldots \ldots \ldots \ldots \ldots \ldots \ldots \ldots \ldots \ldots \ldots \ldots \ldots \ldots \ldots \ldots . \ldots \ldots \ldots$

RGF Data Collection Program TM Operator's Guide 82-86

(A portion of the MDS Tape User's Guide) 
EG\&G Relational Geisha Format (RGF) Analyst Reference Guide

OVERVIEW

Background of RGE

Purpose

of this

Documentation

Who should use this Documentation?
RGE was developed at EG\&G as an adaptation of the Universal Data Entry System called GEISHA (Generalized Edit Identification System Hollerith Assembly). GEISHA is a data system for external communication with DOE agencies within the weapons complex.

EG\&G production and test data is recorded in the RGE data format and computer processed into historical master files, where the production data is retained for reporting and analyses.

The purpose of this documentation is to provide instructional and reference material to the persons involved in RGF data maintenance and the systems analysis and programing for the collection of RGF data.

Programmers, Systems Analysts, Systems Managers, and the PROCODE Database Administrator should use this documentation.

Anyone involved in the RGE data collection planning process would also benefit from a review of portions of this documentation.

Suggestions. on using this Documentation

Programmers, Systems Analysts, Systems Managers and the PROCODE Database Administrator should initially review the entire document to learn about the RGF capabilities and options.

Once familiar with RGE, refer to the Table of Contents to find the page(s) where the information you need to reference is located in the document.

People involved in the RGF data collection planning process may benefit from a review of the following sections:

Section

The RGF Record

RGF Field Descriptions

PN_SN Field Contents

RGF Database Files Utilization

RGF Data Reports

RGE Data Collection Planning Process 39,40

\section{$\underline{\operatorname{Page}(s)}$}

14
$15-18$
$19-31$

36,37

38 
Following are descriptions and diagrams of the components of the PROCODE Data systems configuration.

The sequence in which the components of the configuration are presented illustrates the flow of the RGF data records through the PROCODE SYstem.

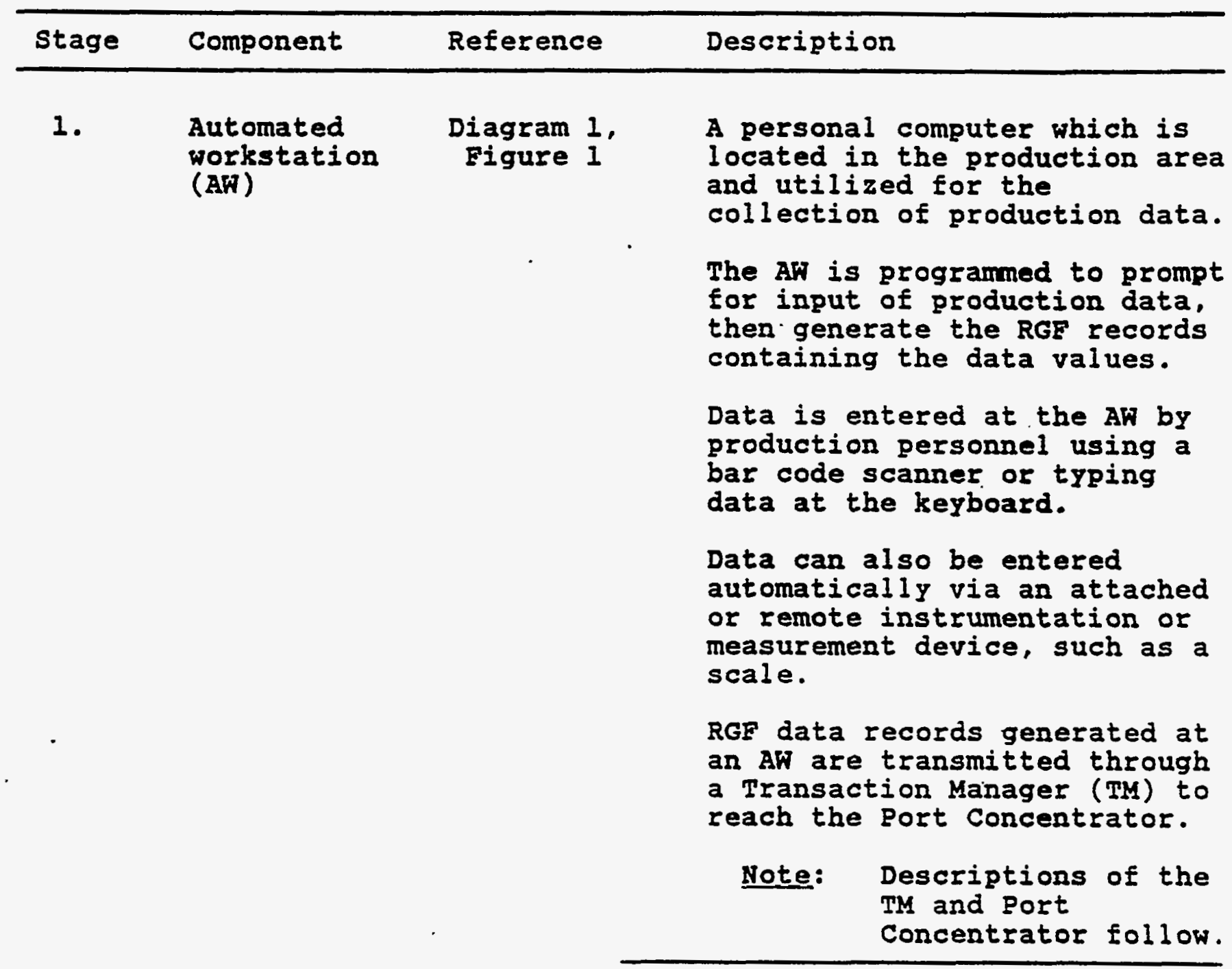




\section{PROCODE - HEMI \\ PETN WEIGH STATION SCHEMATIC}

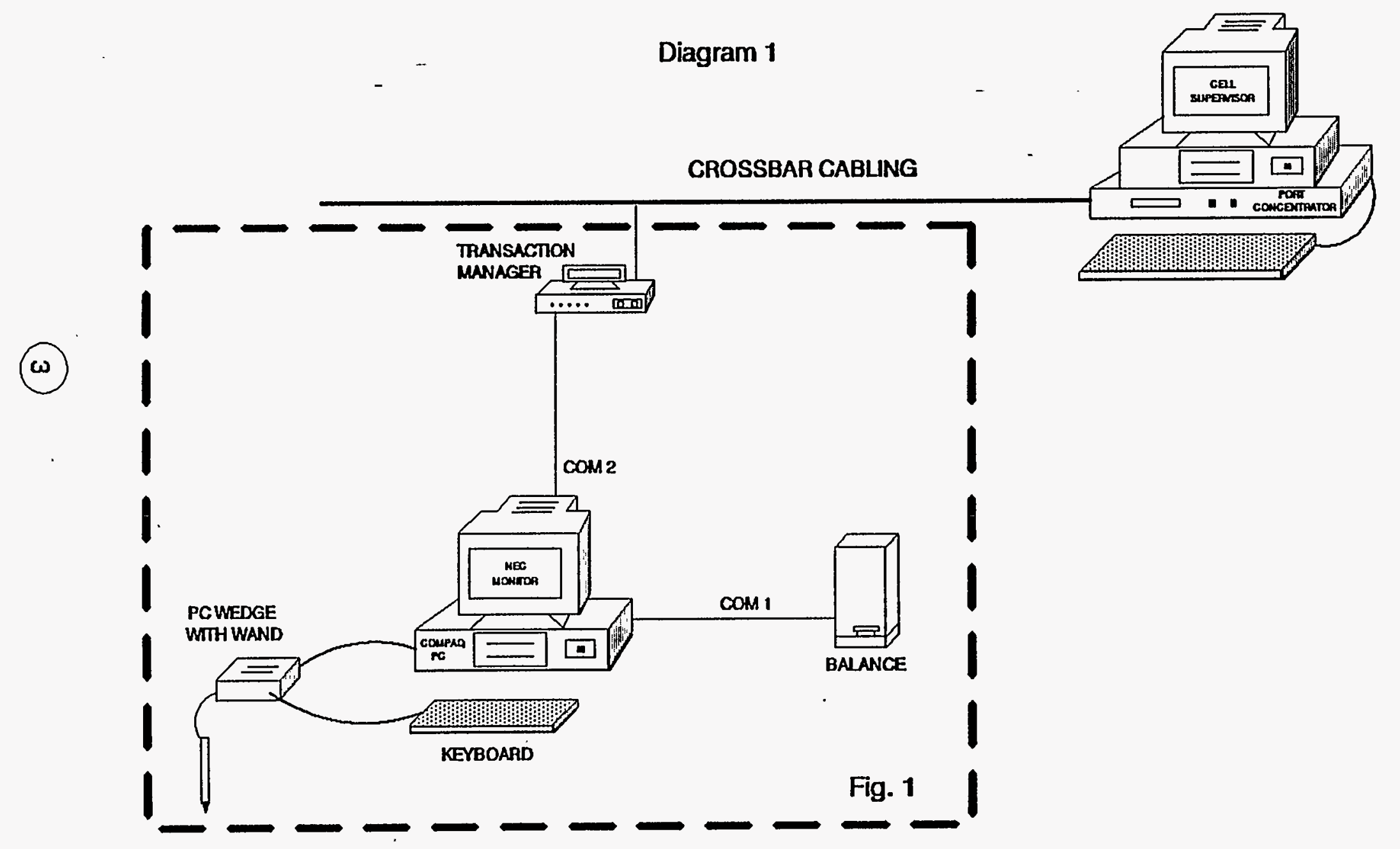


PROCODE DATA SYSTEMS CONFIGURATION, COntinued

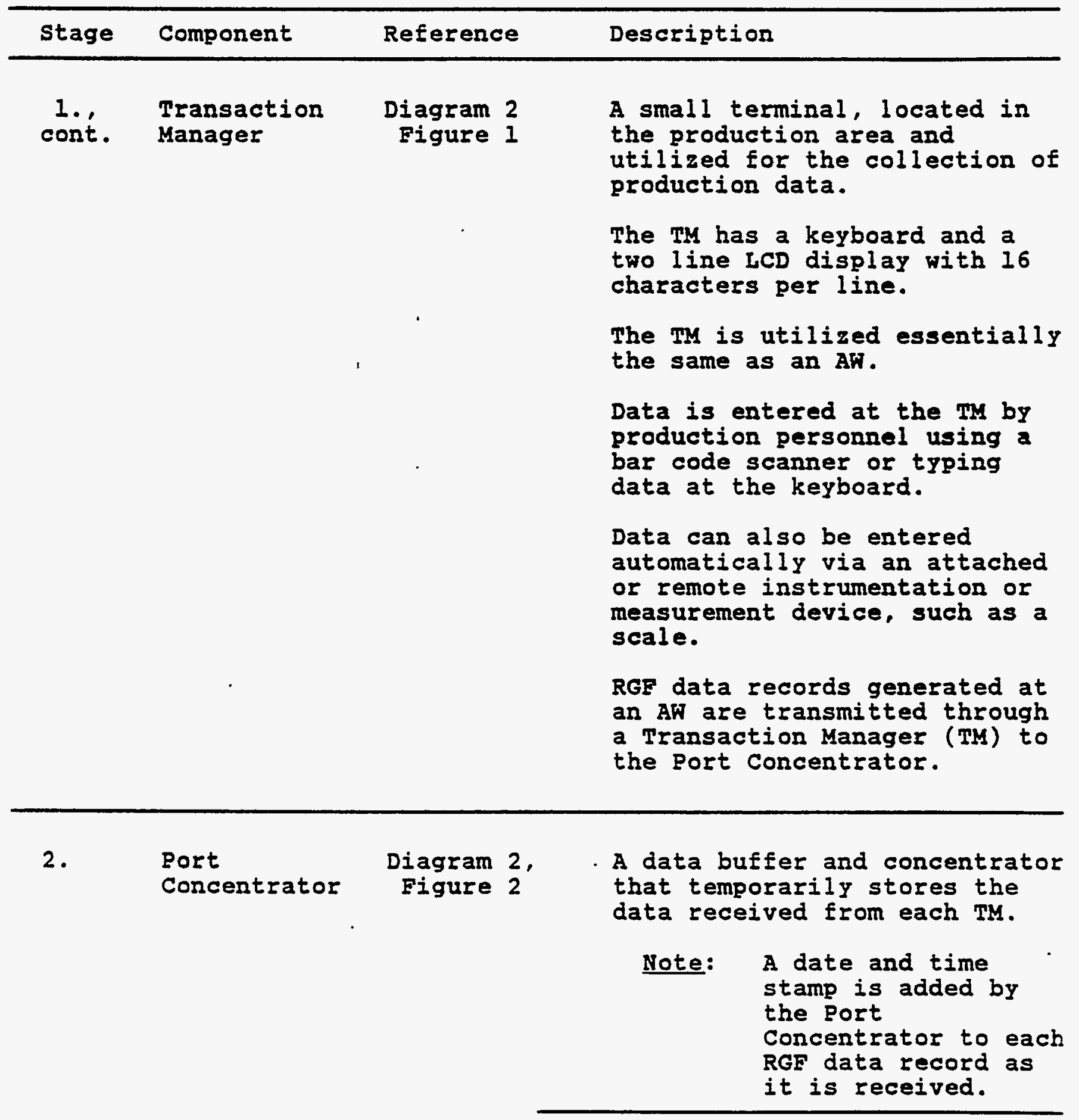




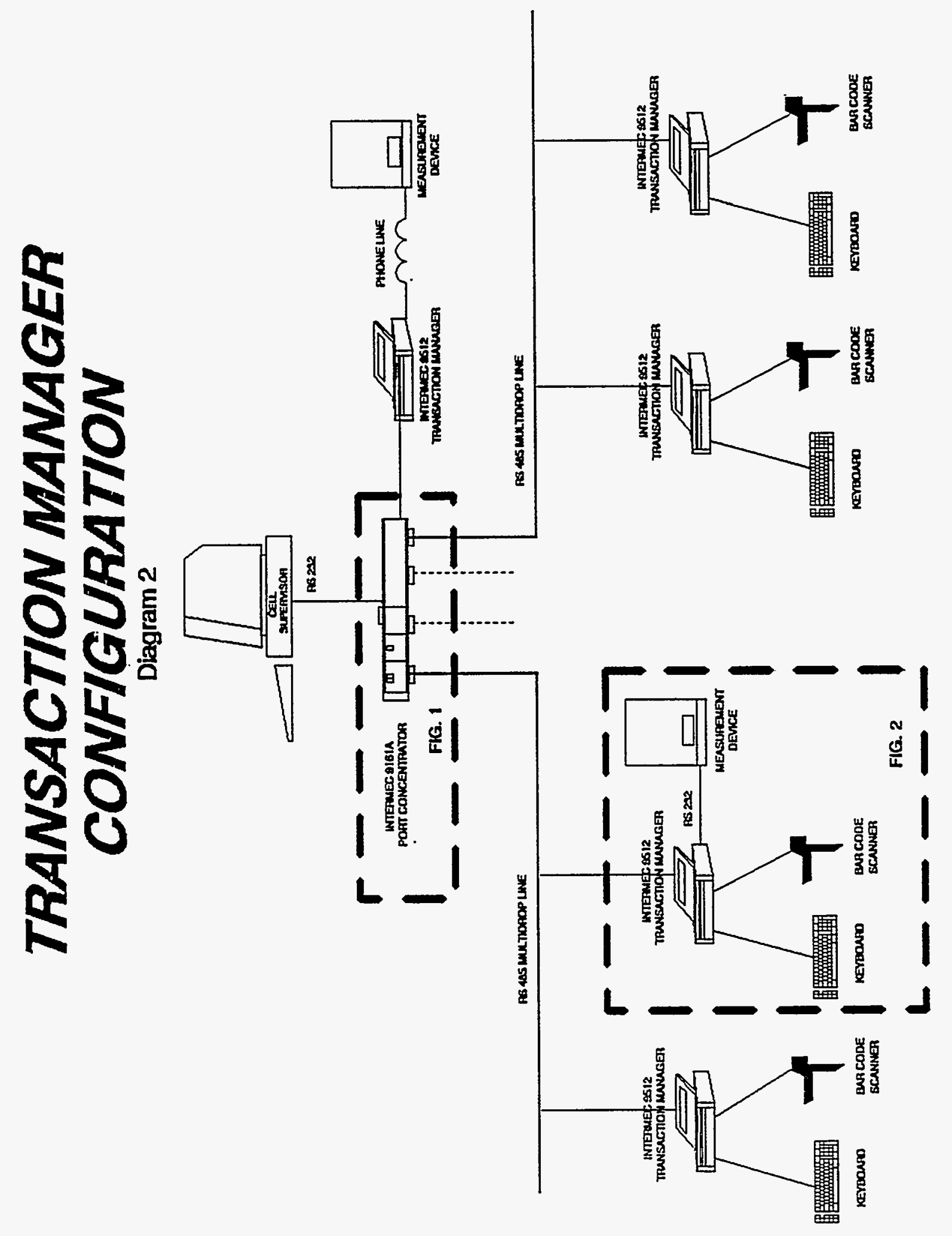

(5) 
PROCODE DATA SYSTEMS CONFIGURATION, Continued

\begin{tabular}{llll}
\hline Stage & Component & Reference & Description \\
\hline
\end{tabular}

Cell
Supervisor Fiagram 3,

The personal computer attached to the Port Concentrator and located in the production area where the RGF data is being collected.

The Cell Supervisor has two attached printers, a dot matrix log printer and an HP Laser for printing reports.

The PROCODE Data Systems functions to Receive Data, Upload Data, Print Reports and Maintain files are executed at the Cell Supervisor.

The Receive Data and Upload Data functions are described below.

\section{Receive Data}

a. Executes a program on the Procode Data system network.

The program does the following:

1. receives a batch of production data from the port. concentrator;

2. appends an additional date and time stamp to each RGF record; 


\section{PROCODE TAPE PROCESS}

Diagram 3

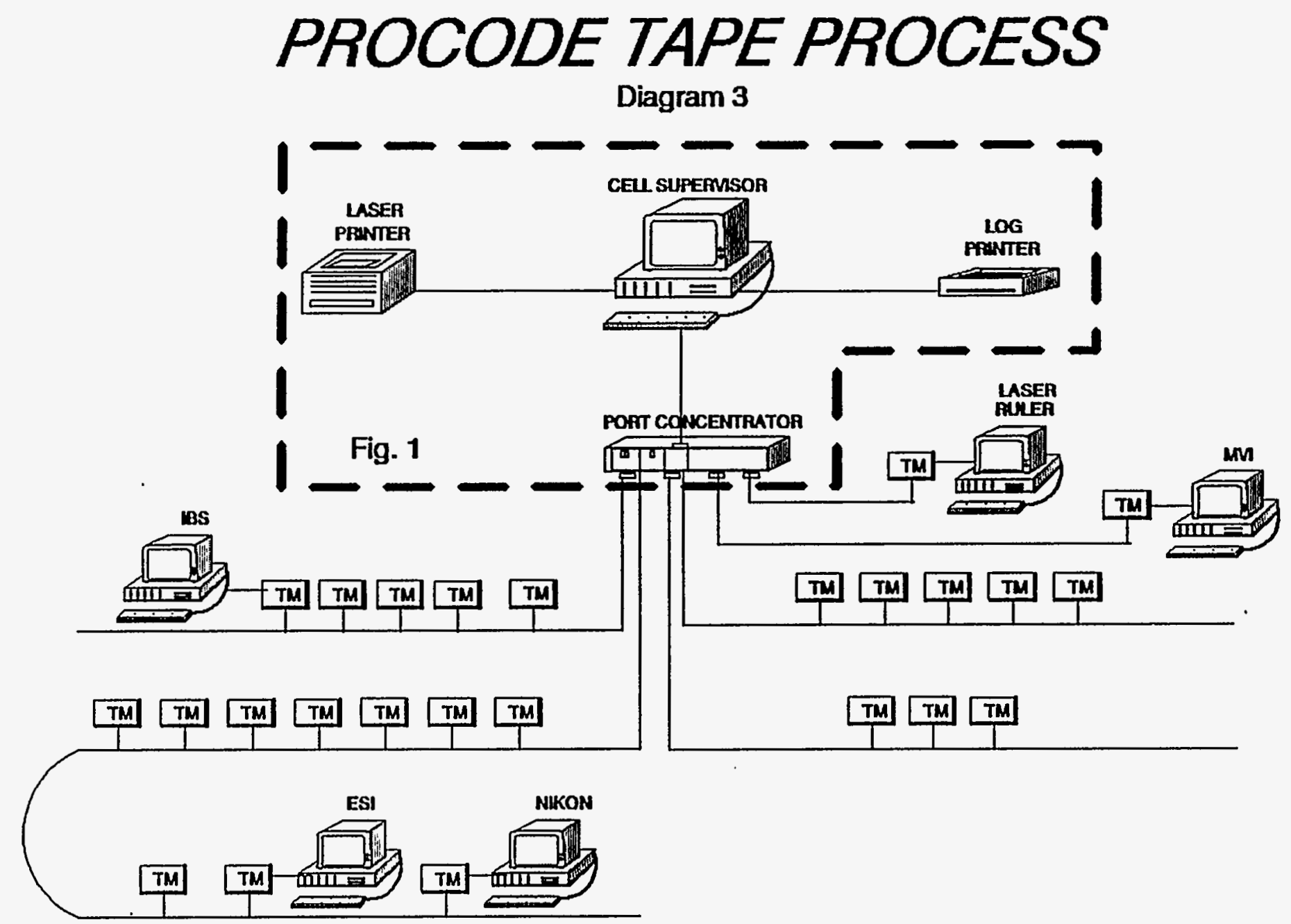

TM = TRANSACTON MANAGER 
PROCODE DATA SYSTEMS CONFIGURATION, COntinued

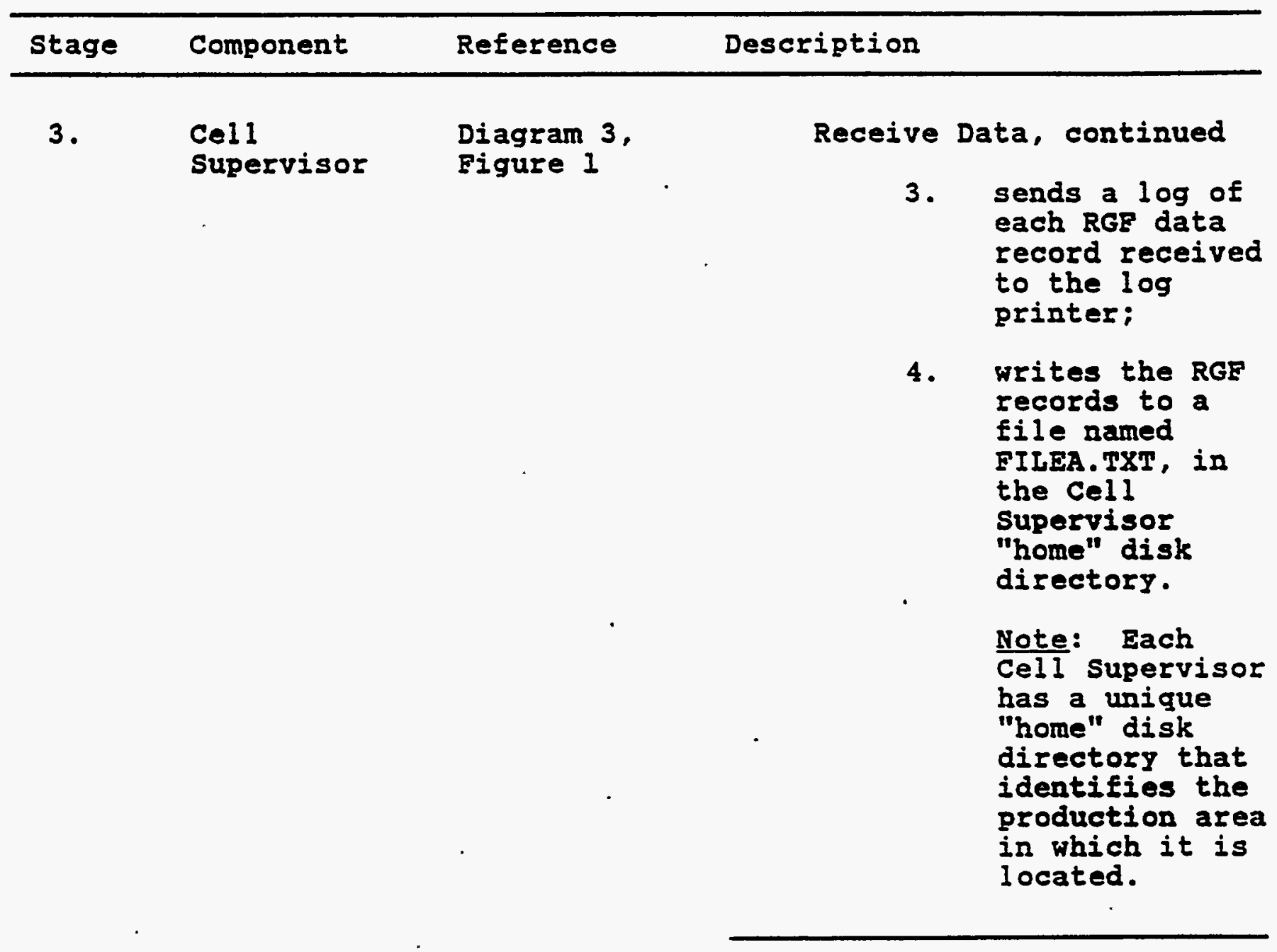




\section{PROCODE VOLUMES SCHEMATIC \\ Diagram 4}
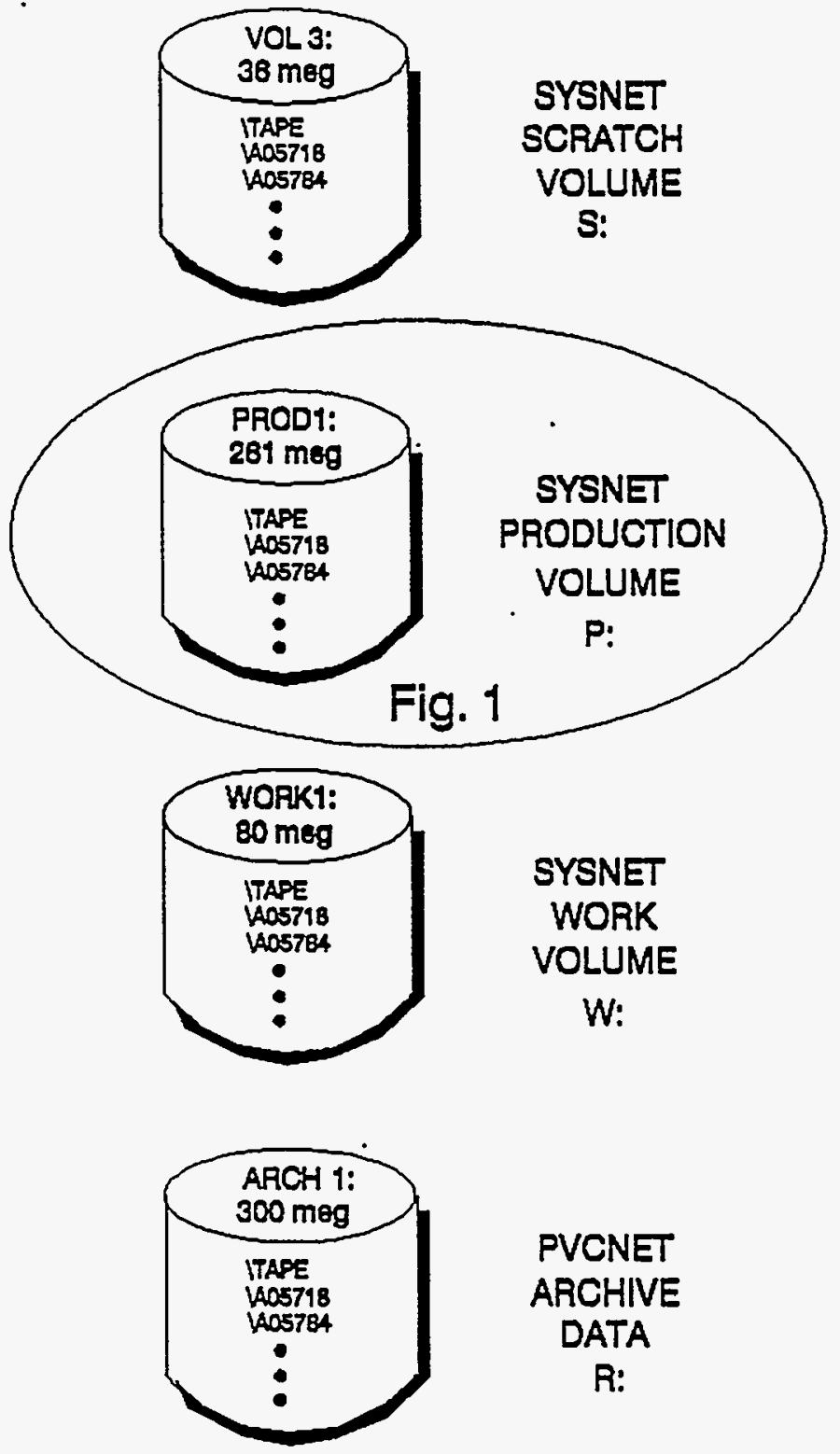

PVCNET

ARCHIVE

DATA

R: 
PROCODE DATA SYSTEMS CONFIGURATION, Continued

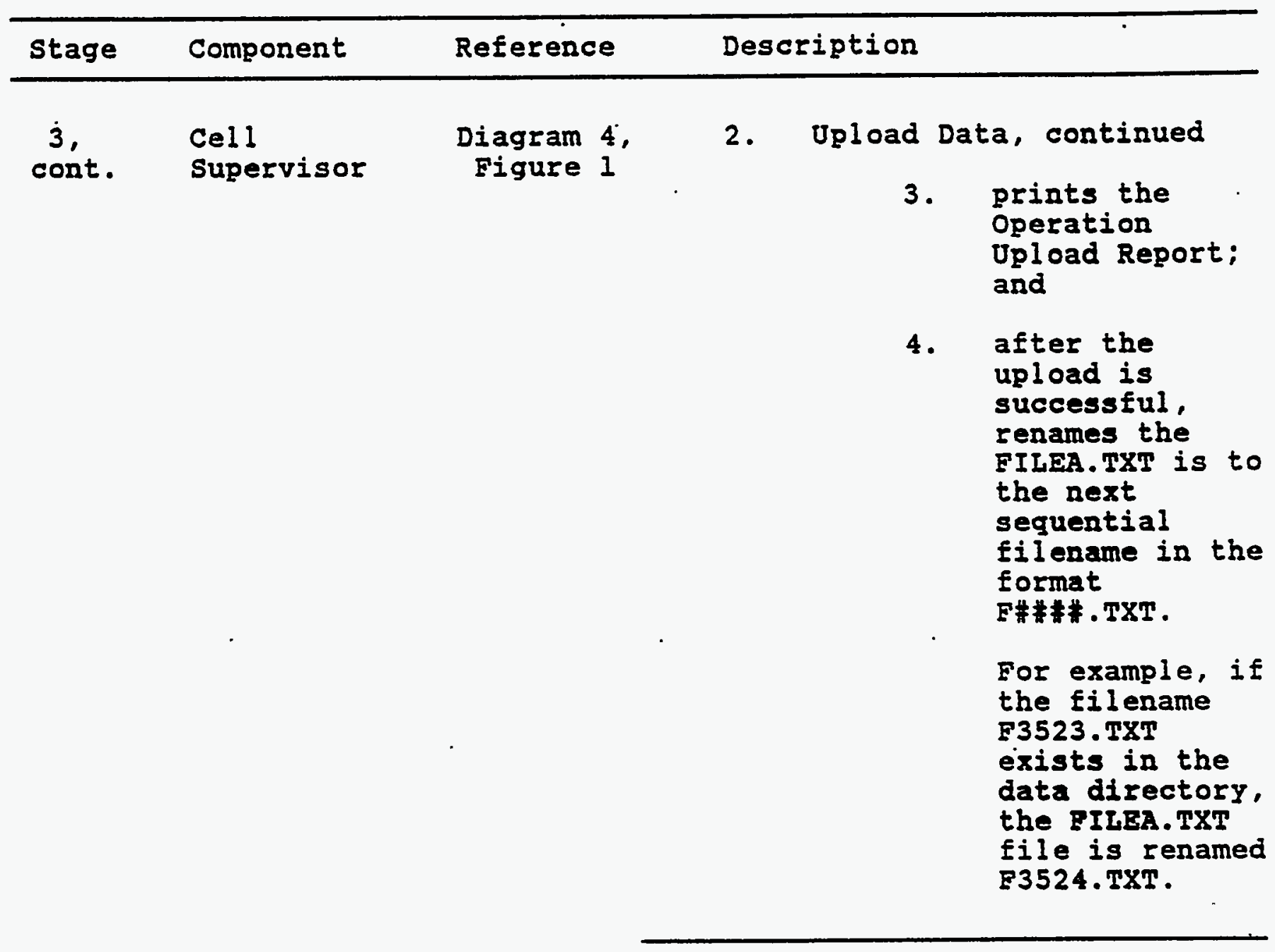


RROCODE DATA SYSTEMS CONFIGURATION, COntinued

\begin{tabular}{|c|c|c|c|}
\hline stage & Component & Reference & Description \\
\hline 4. & Internetwork & Diagram 5 & $\begin{array}{l}\text { Internetwork is a Novell } \\
\text { network of file servers. } \\
\text { It provides access via any } \\
\text { cell supervisor, network } \\
\text { server or network node, to the } \\
\text { RGF production data records } \\
\text { which were uploaded and } \\
\text { appended to the databases in } \\
\text { the network production volume. } \\
\text { RGg data reports can be } \\
\text { printed by selecting the } \\
\text { Report option from the procode } \\
\text { Data systems Main Menu. } \\
\text { Refer to the RGE Data Reports } \\
\text { section on page } 38 \text { for a } \\
\text { description of the reports. } \\
\text { Sample reports are provided on } \\
\text { pages 47 through } 63 \text { of this } \\
\text { documentation. }\end{array}$ \\
\hline
\end{tabular}



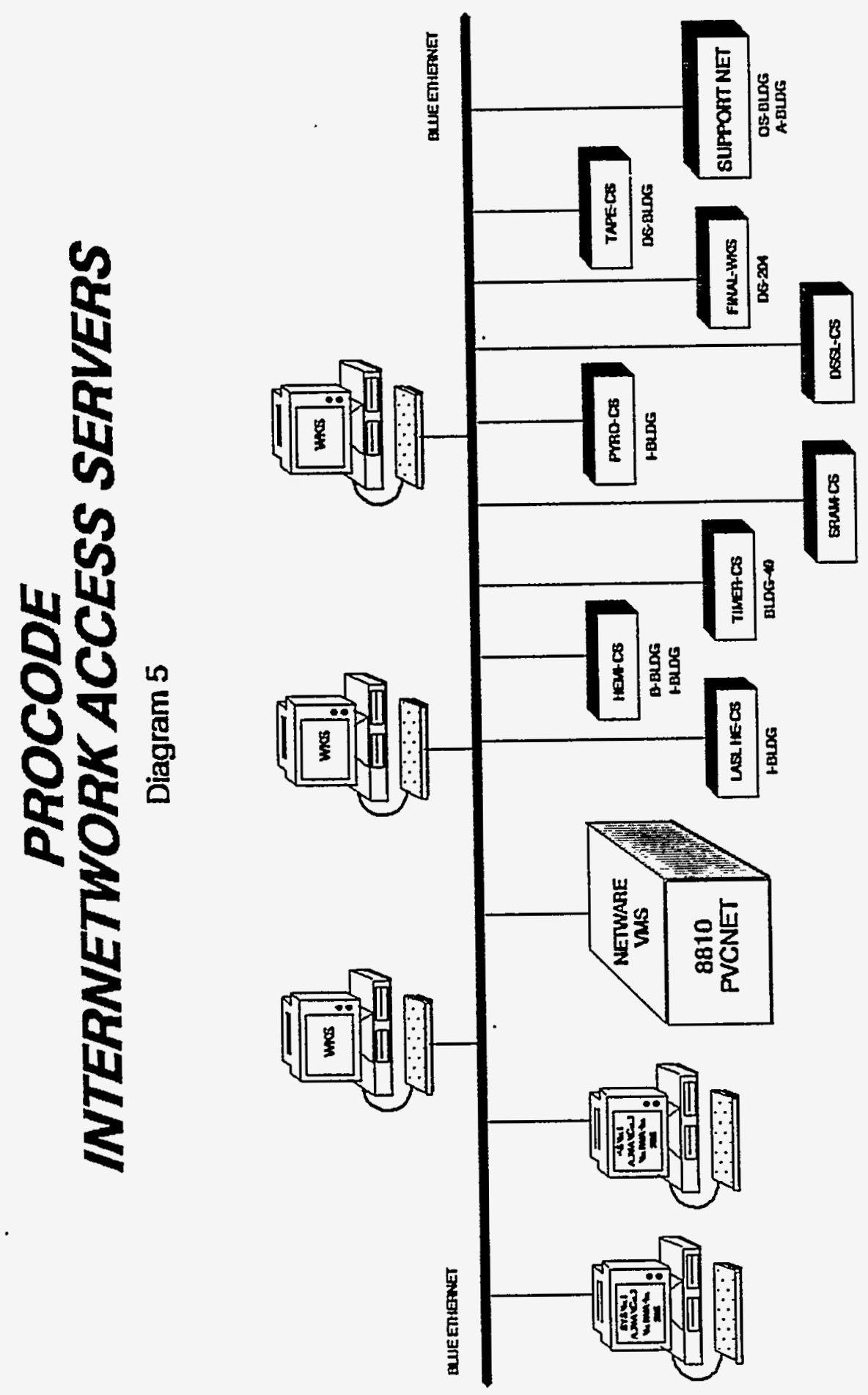

(13) 
THE RGE RECORD

RGF Record

Description
An RGF record consists of eight fields.

Four of the fields are automatically generated when the RGE record is transferred from the TM to the network storage volume.

The other four fields are programmed for inclusion in the RGF record by the programs that build RGF records.
RGF Record Format
RGF has a simple yet versatile record format.

The RGF record format is illustrated below.

Note: The number of characters in each field is defined using CHAR as an abbreviation for the word characters.

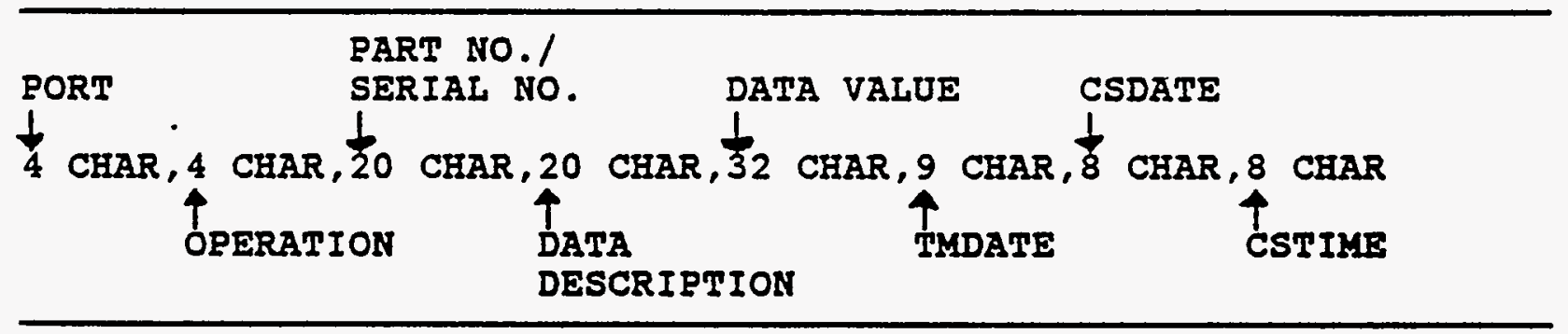

Example

RGF Record

An example of an actual RGF Record is shown below:

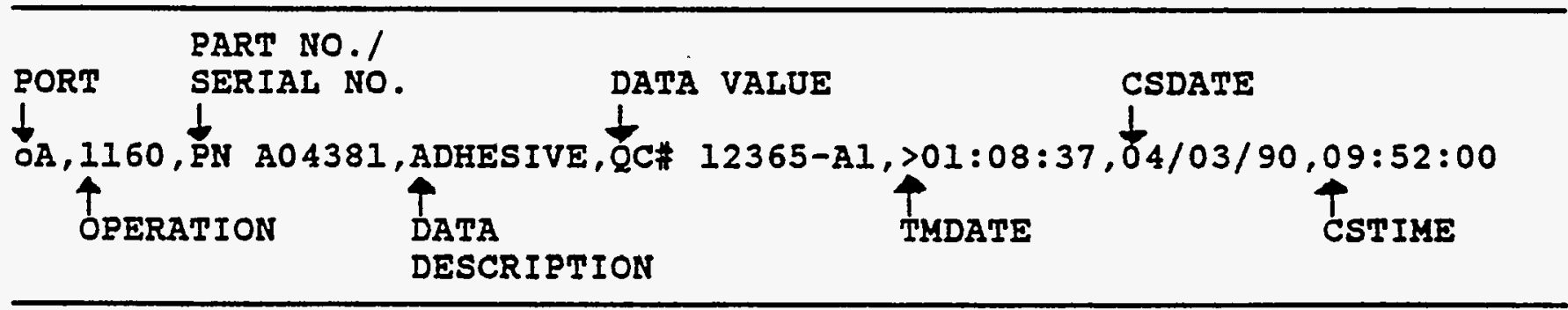

RGF Record Format Rules
Follow the RGF record format rules below:

1. Position fields only in the sequence shown.

2. Separate each field by a comma.

3. The PORT, TMDATE, CSDATE, and CSTIME fields are automatically appended to the RGF record and need not be considered when writing the programs that build the RGF records. 
The RGF Fields Descriptions Table below describes the contents of each field in an RGF record.

Note: All field contents are alphanumeric unless otherwise indicated.

RGF' Fields

Descriptions Table

\begin{tabular}{|c|c|c|c|}
\hline & Field & Name & Contents \\
\hline \multirow[t]{2}{*}{ PORT } & & 4 CHAR & $\begin{array}{l}\text { A one or two character code } \\
\text { that identifies the TM where } \\
\text { the production data was } \\
\text { collected. }\end{array}$ \\
\hline & & & $\begin{array}{l}\text { Note: The PORT can also } \\
\text { identify the TM that the AN is } \\
\text { connected to for transmitting } \\
\text { RGg data collected at the AM, } \\
\text { through the TM, to the port } \\
\text { concentrator. }\end{array}$ \\
\hline
\end{tabular}

The first Port code character identifies the main trunk line connected from the port concentrator to the TM.

The second character identifies the multidrop line connecting the TM to the main trunk line.

When the TM is connected directly to the main trunk line, the port code consists of only one character.

\section{Example: A}

When the TM is connected via a multidrop line to the main trunk line, the port code consists of two characters.

Example: pD

Note: The port code is automatically generated by the TM and appended to each RGE record as it is transmitted to the port concentrator. 
RGE FIELDS DESCRIPTIONS, Continued

RGF Fields

Descriptions

Table,

continued

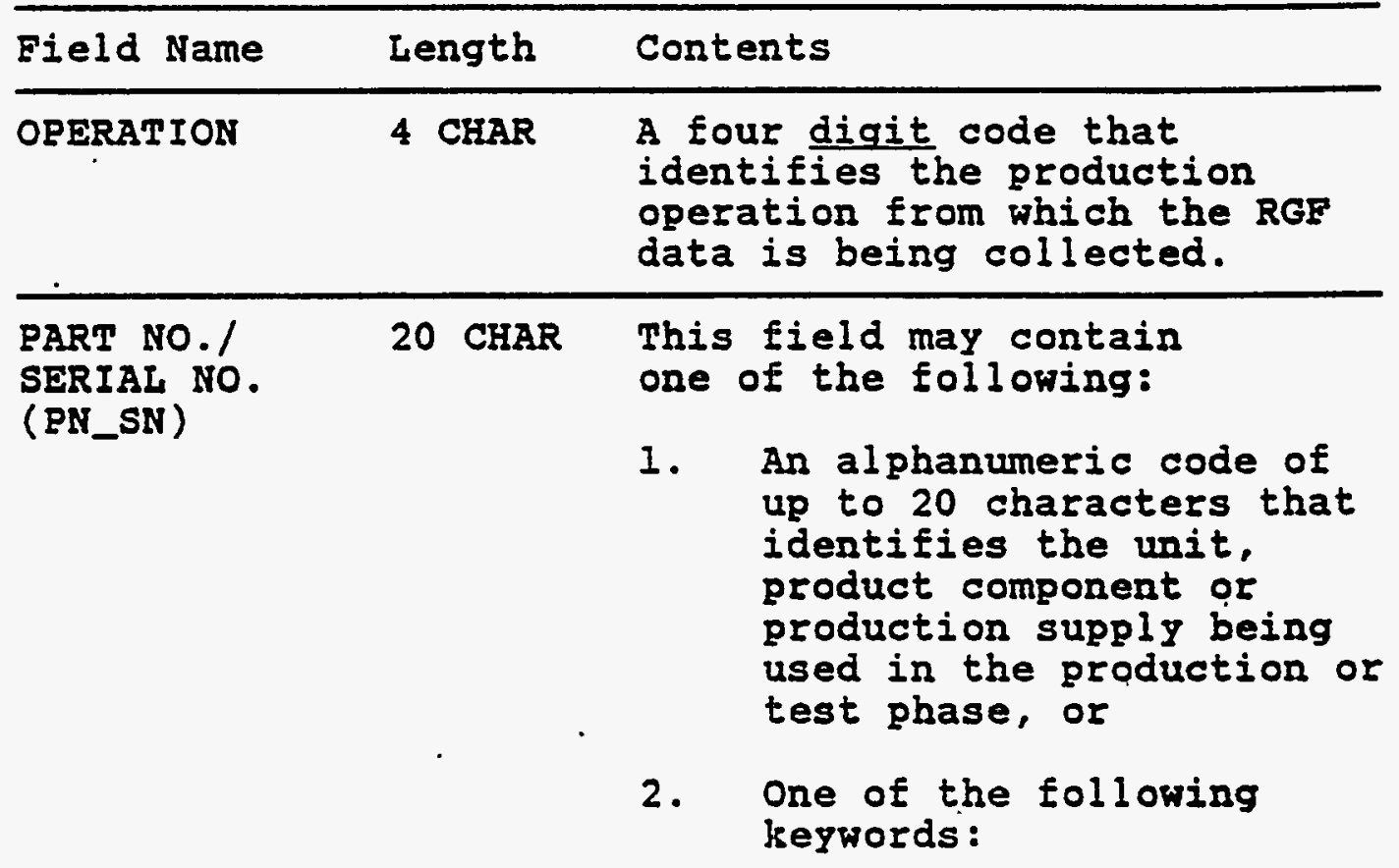

HDR

DETAIL

Note: Refer to the Options Tables beginning on page 19 for further explanation of the use of keywords in RGE.

$\begin{array}{ll}\text { DATA } & 20 \text { CHAR } \\ \text { DESCRIPTION }\end{array}$

A description of the contents of the Data value field.

This field may contain one of the following:

1. A keyword asso'iated with a specific PN_SN or Data Description keyword.

Note: Refer to the Options Tables below for further explanation of the use of keywords in RGE.

2. A description of the production or test data being collected. 
RGE Fields Descriptions Table, continued

\begin{tabular}{|c|c|c|}
\hline Field Name & Length & Contents \\
\hline $\begin{array}{l}\text { DATA } \\
\text { VALUEE }\end{array}$ & 32 CHAR & $\begin{array}{l}\text { The Data Value can range } \\
\text { from a temperature measurement } \\
\text { to a Product AO Code. } \\
\text { The data value contents } \\
\text { further defines the contents } \\
\text { of the Data Description and } \\
\text { Part No./Serial No. fields. } \\
\text { The data values are defined as } \\
\text { parameters in the build RGE } \\
\text { program or obtained via data } \\
\text { entry in response to programed } \\
\text { input prompts. }\end{array}$ \\
\hline TMDATE & 9 CHAR & $\begin{array}{l}\text { A nine character code that } \\
\text { indicates the real time and } \\
\text { date the RGF record was } \\
\text { generated. } \\
\text { The TMDATE format follows: } \\
\text { >DD:HR:MM } \\
\text { DD is the day of the month. } \\
\text { GR is the hour of the day. } \\
\text { MM is the minute of the hour. } \\
\text { Note: The TMDATE is } \\
\text { automatically } \\
\text { appended to the RGF } \\
\text { record when the } \\
\text { record is received } \\
\text { at the port } \\
\text { concentrator. }\end{array}$ \\
\hline
\end{tabular}

CSDATE

8 CHAR

The date the Receive Data function is executed at the Cell supervisor to transfer the RGF records from the port concentrator to the network storage volume. The CSDATE format follows:

$$
M M / D D / Y Y
$$

MM is the month.

$D D$ is the day of the month.

YY is the year. 
RGF FIELD CONTENTS, Continued

RGE Fields

Descriptions Table, continued
Example RGF Record

\begin{tabular}{|c|c|c|}
\hline Field Name & Length & Contents \\
\hline $\begin{array}{l}\text { CSDATE, } \\
\text { cont. }\end{array}$ & 8 CHAR & $\begin{array}{l}\text { Note: The CSDATE is } \\
\text { automatically appended to the } \\
\text { RGF record when the record is } \\
\text { received at the Cell } \\
\text { supervisor. }\end{array}$ \\
\hline CSTIME & 8 CHAR & $\begin{array}{l}\text { The time the RGg data record } \\
\text { is received at the Cell } \\
\text { Supervisor after the Receive } \\
\text { Data function is executed to } \\
\text { transfer the RGE records from } \\
\text { the port concentrator to the } \\
\text { network storage volume. } \\
\text { The CSTIME format follows: } \\
\text { HH:MM:Ss } \\
\text { HH is the hour. } \\
\text { MM is the minutes. } \\
\text { SS is the seconds. } \\
\text { Note: The cSTIME is } \\
\text { automatically } \\
\text { appended to the RGF } \\
\text { record when the } \\
\text { record is received } \\
\text { at the Cell } \\
\text { supervisor. }\end{array}$ \\
\hline
\end{tabular}

Below is an example of an actual RGF record, excluding the automatically generated fields:

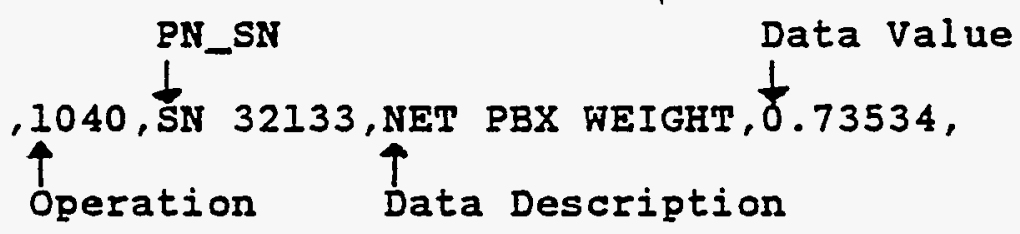


OVERVIEW

PN_SN Field Contents Options

The keyword HDR

The keyword DETAIL

PN_SH Field Options Tables
The PH_SN field may contain one of the following:

- the keyword HDR,

- the keyword DETAII, or

- the part number or serial number which identifies the unit, product component, or production supply being used in the production or test phase.

The contents of the PN_SN field influence the data contents available for use in the Data Description and Data value fields and the contents and format of the RGE data reports.

The' keyword EDR generally indicates that the Data value in that record is included in report headings.

The keyword DETAIL acts as place holder in the PN_SN field. When the contents of the PN_SN field is the keyword DETAIL, blank spaces print on the Electronic Traveler and Operations Data reports where the PN_SN field contents would have printed had there been $\bar{a}$ part number or serial number in the PN_SN field.

The PN_SN field content options and the related Data Description and Data Value field contents are defined in the Options Tables which follow.
Table Constraints

The \# Symbol

KEYWORDS

Asterisk (*)

RGE Record Examples
Follow the Options Tables Constraints below:

A \# symbol used in the syntax definition indicates that a numeric value is required.

Any field contents which are shown in all capital letters are keywords. Keywords must be spelled exactly the same as shown or normal processing at the cell supervisor level may not occur.

An asterisk (*) as the first character of a Data Description prevents the RGF record from printing on the Electronic Traveler Report.

Note: Records which include an asterisk (*) as the first character of the Data Description are uploaded to the Operations.DBF file.

The RGF record examples are shown exclusive of the PORT, TMDATE, CSDATE and CSTIME fields. 
PN_SN field Containing the Keyword HDR
The Data Description keywords, and Data Value contents and syntax, used when the PN_SN field contains the keyword HDR, are defined in the HDR Options Table below.

The HDR Data Description keywords are presented below in the sequence in which the related Data Value is normally prompted for input, by the program that builds the RGF records.

Comment: Each HDR Data Description keyword is a fieldname in the RGF database files, with the exception of the EXIT, DELETE and COMPLETE keywords.
HDR Options Table

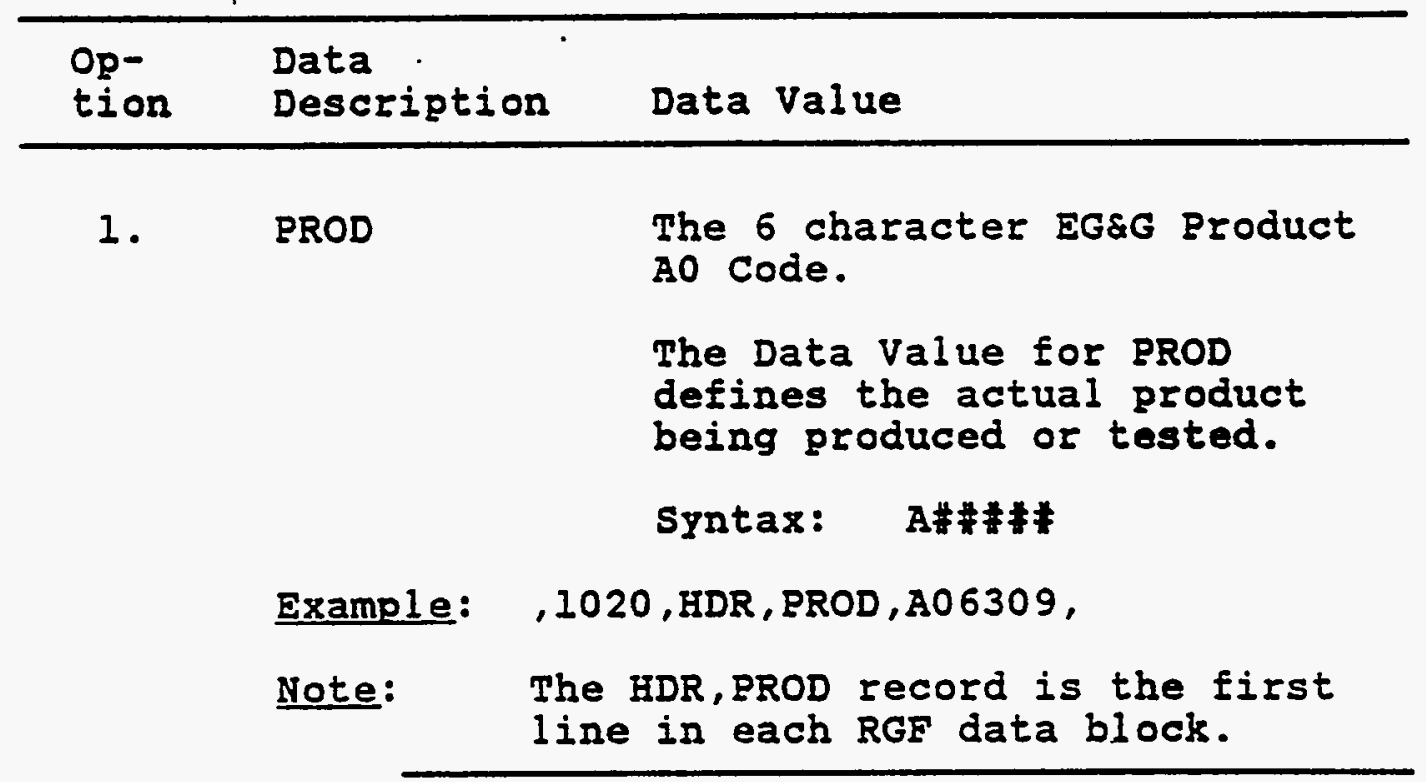


THE PN_SN FIELD CONTENTS, Continued

GDR Options

Table, continued

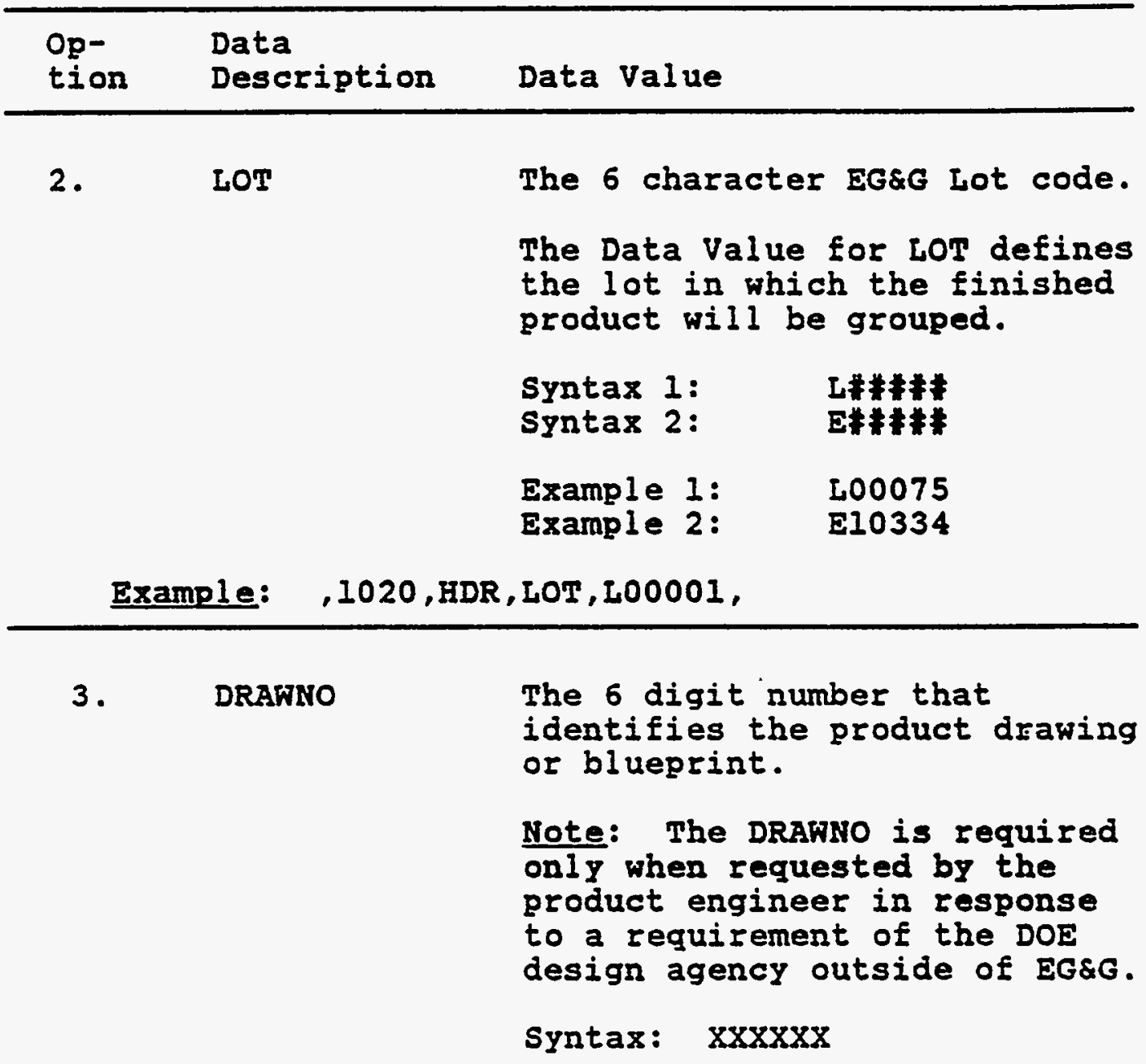

Example: $\quad 1020$, HDR, DRAKNO, 123456 ,

4. DRAWIS

The 2 or 3 digit issue or version number of the product drawing number.

Note: The DRAWIS is required only when a DRAWNO is required.

Syntax 1: $x x$

Syntax 2: $\mathrm{xxx}$

Example: , 1020,HDR, DRAW IS, 123, 
THE PN_SN FIELD CONTENTS, Continued

HDR Options Table, continued

\begin{tabular}{|c|c|c|}
\hline $\begin{array}{l}\text { Op- } \\
\text { tion }\end{array}$ & $\begin{array}{l}\text { Data } \\
\text { Description }\end{array}$ & Data Value \\
\hline \multirow[t]{2}{*}{5.} & $\mathrm{HP}$ & $\begin{array}{l}\text { A unique four digit code that } \\
\text { identifies the employee } \\
\text { operating the TM or AW where } \\
\text { the RGF data is being } \\
\text { collected. }\end{array}$ \\
\hline & & Syntax: \\
\hline
\end{tabular}

Example: , $1020, \mathrm{HDR}, \mathrm{HP}, 2422$,
A keyword that describes the product storage device used for storing a group of production parts to be processed, or a production run, in which a group of production parts are processed.

Syntax: The product storage device GRPHAMs are:

\section{REEL TRAY TUB}

The production run GRPNAMs are:

\section{PCRN PVD}

Note: PCRN stands for "Plasma Clean Run \#".

Note: PVD stands for Physical Vapor Deposition.

Example: , 1020,HDR, GRPNAM, TRAY ,

Note: The HDR, GRPNAM RGF record is predefined in the Build RGF program, and is not the result of operator input. 
THE PN_SN FIELD CONTENTS, Continued

HDR Options Table, continued

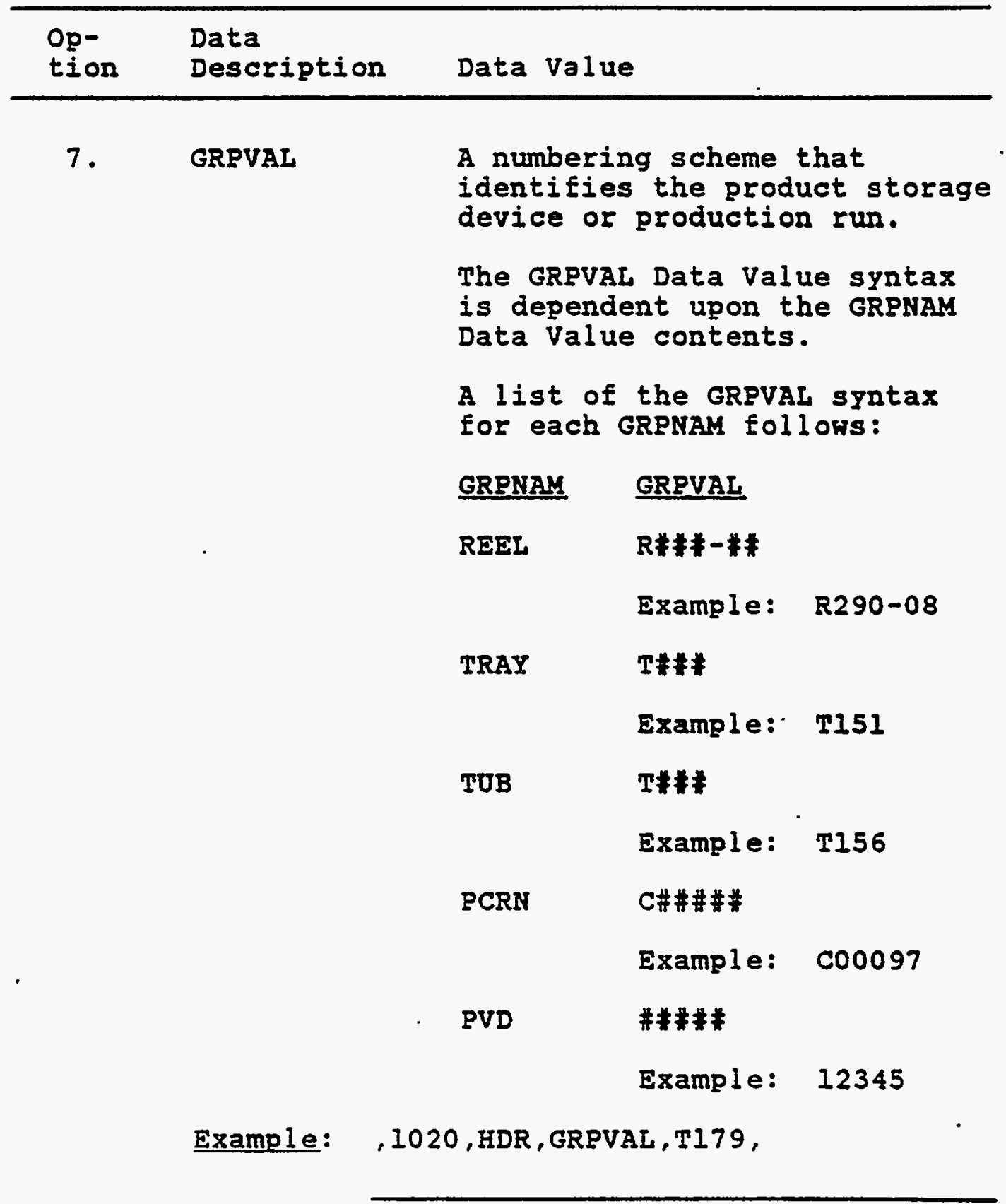


THE PN_SN FIELD CONTENTS, Continued

HDR Options

Table, continued

\begin{tabular}{|c|c|c|c|}
\hline $\begin{array}{l}\text { Op- } \\
\text { tion }\end{array}$ & $\begin{array}{l}\text { Data } \\
\text { Description }\end{array}$ & Dat: & Value \\
\hline \multirow[t]{7}{*}{8.} & \multicolumn{2}{|l|}{ DELETE } & $\Omega$ \\
\hline & \multicolumn{3}{|c|}{$\begin{array}{l}\text { Issue the DELETE, } \mathrm{R} \text { RGF record when the TM or } \\
\text { Ah operator types or scans "back" to delete } \\
\text { their previous data input. }\end{array}$} \\
\hline & \multicolumn{3}{|c|}{$\begin{array}{l}\text { The HDR, DELETE,n line marks n previous } \\
\text { records for deletion. N dictates the number } \\
\text { of previous records to delete as determined } \\
\text { by the number of "back" statements received } \\
\text { as a result of the operator typing or } \\
\text { scanning "back". }\end{array}$} \\
\hline & \multirow[t]{3}{*}{ Note: } & \multicolumn{2}{|c|}{$\begin{array}{l}\text { Used mainly when an invalid or } \\
\text { incorrect RC code is entered. }\end{array}$} \\
\hline & & \multicolumn{2}{|c|}{$\begin{array}{l}\text { May be used to delete records that } \\
\text { come after the initial HDR } \\
\text { information. }\end{array}$} \\
\hline & & nent: & $\begin{array}{l}\text { Any initial HDR } \\
\text { information should be } \\
\text { deleted by issuing the } \\
\text { EXIT,ALL record which is } \\
\text { explained below. }\end{array}$ \\
\hline & \multicolumn{3}{|c|}{ Example: , 1020, HDR, DELETE, 2 , } \\
\hline
\end{tabular}

9. EXIT ALL

Issue the EXIT, ALL RGF record when the TM or AW operator types EXIT or scans the "erase" bar code to abort the data collection operation.

Example: ,1020,HDR,EXIT,ALL，

Note: The EXIT,ALL record prevents the RGF records already collected during the operation, from being uploaded into the RGF database files, when the Upload function is executed. 
THE PN_SN FIELD CONTENTS, Continued

HDR Options Table, continued

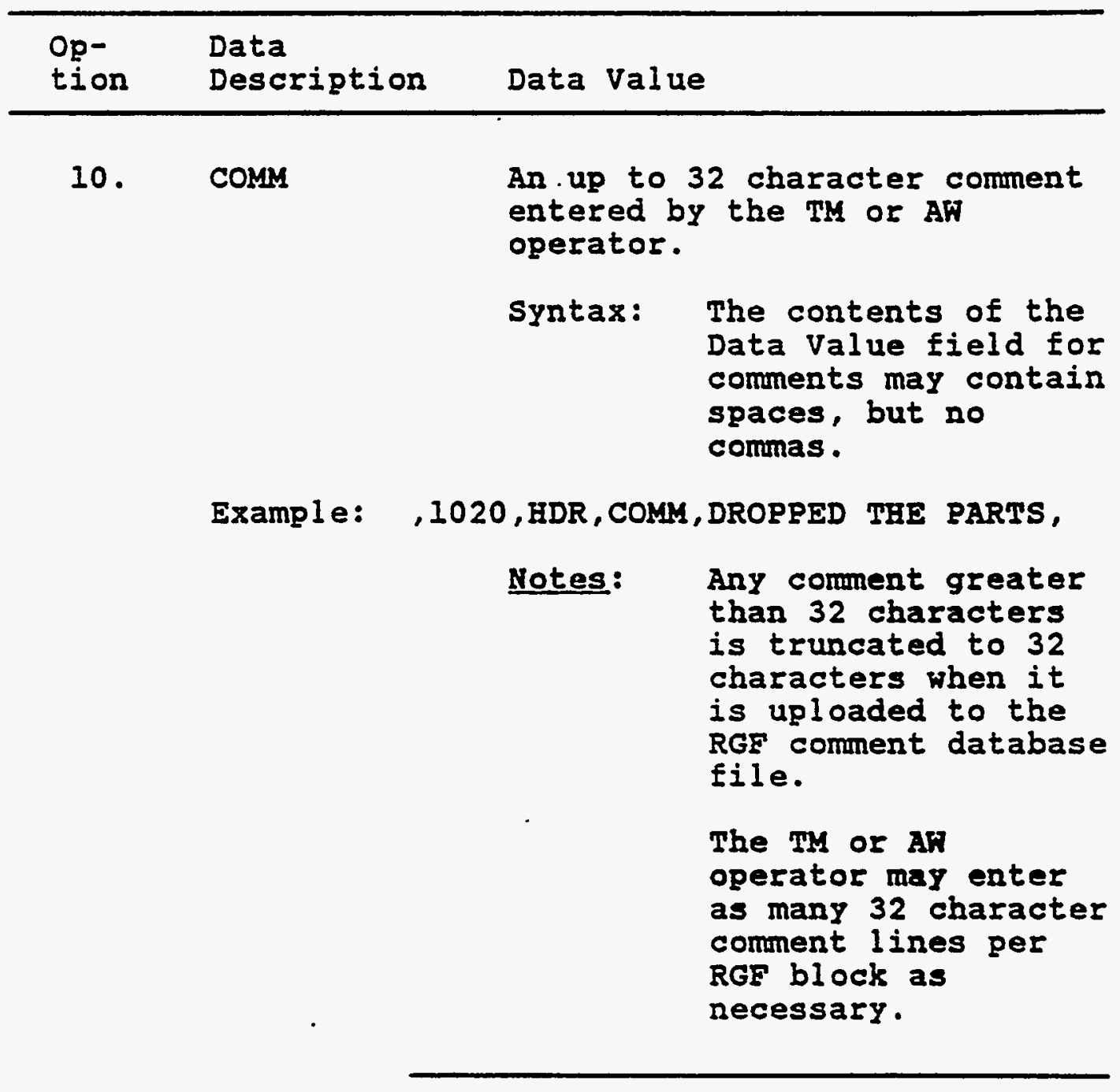


THE PN_SN FIELD CONTENTS, Continued

HDR Options

Table, continued

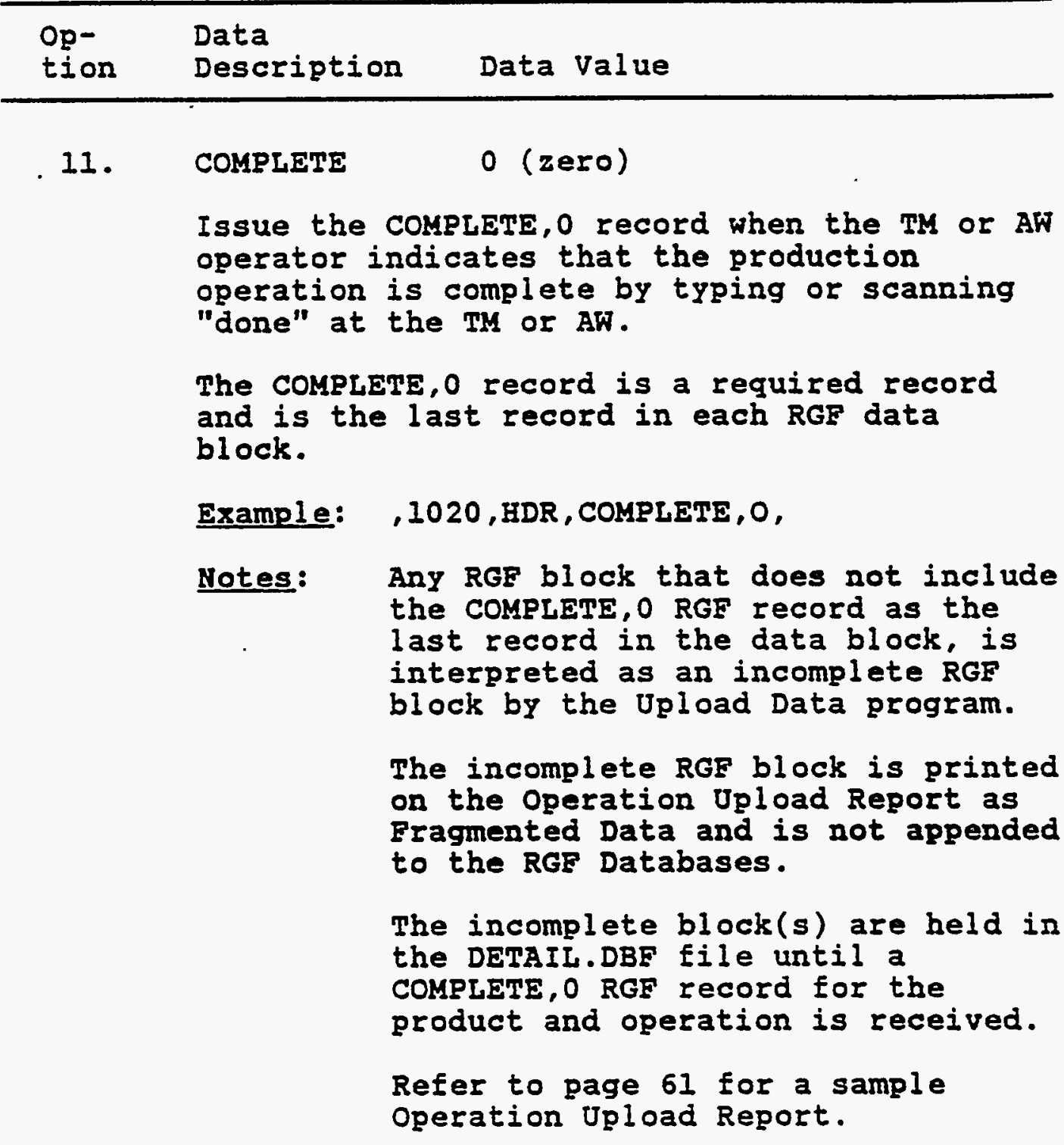


PN_SN field containing a PN or SN

PN or SN Options Table
The Data Description and Data Value contents and syntax used when the PN_SN field contains a part number or serial number, are defined in the PN or SN Options Table below.

Example 1: ,1015, TL 23, LOADED WT (GRAMS), .2713, Example 2: ,1160,PN A0805, HOUSING,QC\# 39407-A1, Example 3: ,1160,SN 12345,HEAD SN,SN 54321, 
THE PN_SN FIELD CONTENTS, Continued

PN or SN Options Table, continued

$$
\text { Op- Data }
$$

tion Description · Data Value

2. *ACCEPT

Initialize the RGF operation database with the component being produced, inspected or tested.

Note: The initilization data prints on the Operations Data Report but not the Electronic Traveler Report.

Therefore, the * is a required part of the keyword *ACCERT.

Example: , 1020,TL 03,*ACCEPT, INITIAL,
The Reject or Disposition code.

Can indicate one of the following:

a. Upon inspection it was determined that the part was bel ow standards.

Example: , 1020,TL 28,REJECT,RC 0342,

b. It was decided to use the part in a test.

The reject code describes why the component was rejected.

Syntax: RC 楼草

The disposition code describes how the part was disposed.

\section{INITIAL}

The keyword INITIAL is the required data value in an RGF record where the Data Description contents is the keyword *ACCEPT.

Syntax: DC \#\#\#\#

Example: ,1020,TL 29,REJECT,DC 0132, 
PN Or SN Options Table, continued

\section{Op- Data \\ tion Description Data Value \\ 4. *VERIFY REJECT OF ACCEPT \\ Some production procedures require that a verification of the status of the components, ACCEPT or REJECT, be performed before continuing to the next production phase.}

The VERIFY requirement is determined and requested by the product Engineer.

The verification procedure is always performed at an $A$ F. The component status previously collected and uploaded to the STAT.DBE RGE database file, for the product, must be downloaded to diskette then uploaded into the RAM memory at the AW PC for comparison during the verification procedure.

The steps in the verification procedure are listed below:

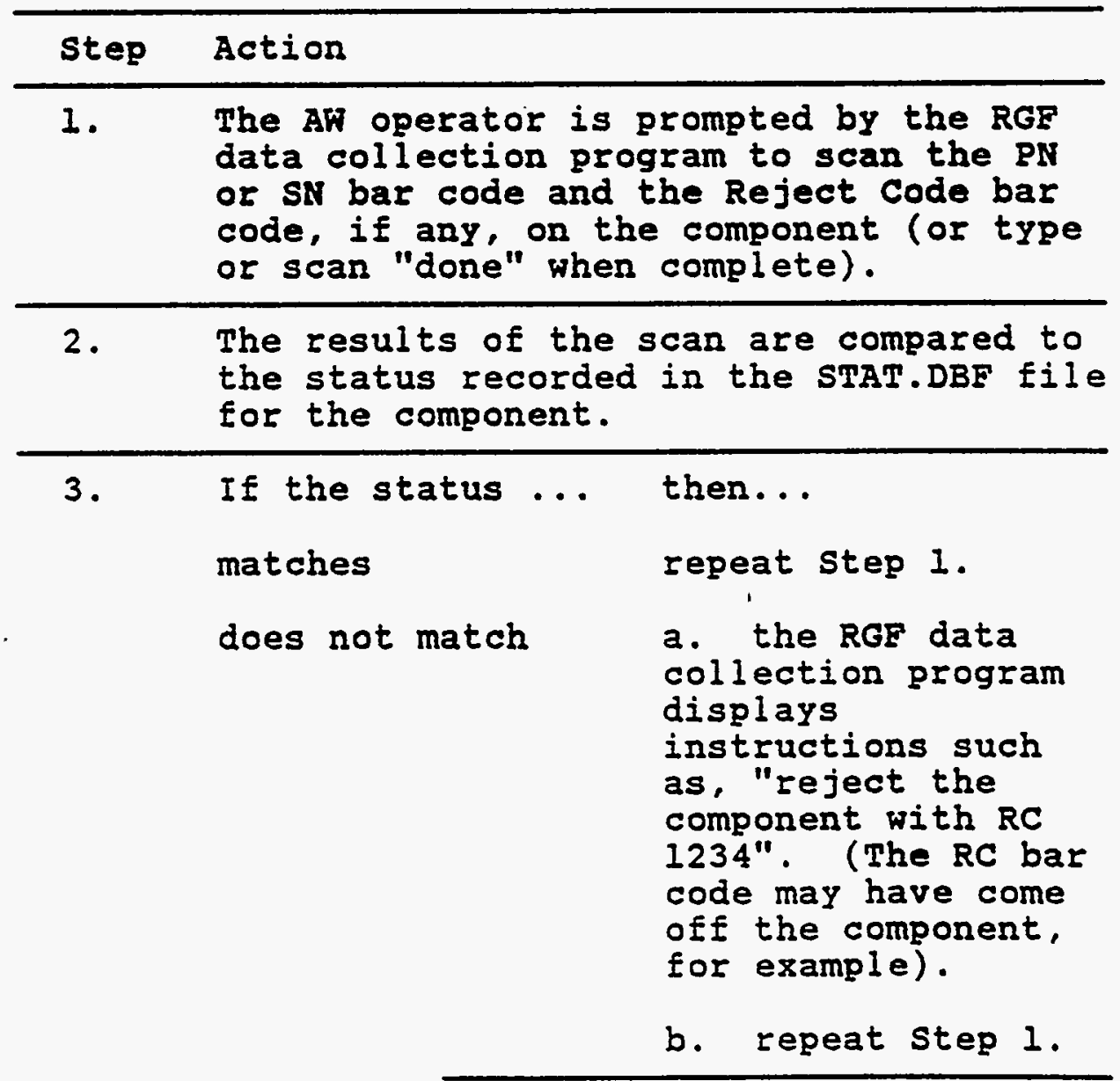


THE PN_SN EIELD CONTENTS, Continued

PN or $S N$ Options Table, continued

\section{Op- Data}

tion Description

Data Value

\section{4. *VERIFY, continued

Notes: The results of the verification procedure print on the Check/Verify Report. A sample of the Check/Verify Report is included on page of this document.

The asterisk (*) is a required part of the keyword *VERIFY because the verification data should not print on the Electronic Traveler Report.

Example: ,1020,TL 03, *VERIFY, ACCEPT,

Example: ,1020,TL 28,*VERIFY,REJECT, 
RN_SN EIELD CONTENTS, Continued

PN_SN Field Containing the Reyword DETAIL

DETAIL Options Table
The keyword DETAIL acts as place holder in the PN_SN field. When the PN_SN field contains the keyword DETAII, blank spaces print on the Electronic Traveler and Operations Data reports where the part number or serial number would have printed had there been a part number or serial number in the PN_SN field.

The Data Description and Data Value contents and syntax used when the PN_SN field contains the keyword DETAIL, are defined in the DETAIL Options Table below.

\begin{tabular}{|c|c|}
\hline $\begin{array}{l}\text { Op- } \\
\text { tion }\end{array}$ & $\begin{array}{l}\text { Data } \\
\text { Description }\end{array}$ \\
\hline \multirow[t]{3}{*}{1.} & $\begin{array}{l}\text { Production or An up to } 32 \text { character value } \\
\text { test detail } \\
\text { description } \\
\text { of description to the detail } \\
\text { characters. }\end{array}$ \\
\hline & ,1020, DETAIL, *Tooling Factor, 55, \\
\hline & $\begin{array}{l}\text { The method shown in the above } \\
\text { example is useful when the product } \\
\text { engineer requests that production } \\
\text { detail information be gathered and } \\
\text { stored, but not printed on the } \\
\text { Electronic Traveler Report (just } \\
\text { the operations Data Report, as } \\
\text { caused by the leading asterisk (*) } \\
\text { in the Data Description field). }\end{array}$ \\
\hline \multirow[t]{4}{*}{2.} & OPERATION \\
\hline & $\begin{array}{l}\text { Required as the second to last line in each } \\
\text { RGF block, preceding the HDR, COMPLETE,0 } \\
\text { record. }\end{array}$ \\
\hline & $\begin{array}{l}\text { This record indicates that the operation has } \\
\text { been successfully processed. }\end{array}$ \\
\hline & , I020, DETAIL, OPERATION, PROCESSED, \\
\hline \multirow[t]{3}{*}{3.} & RC 萧萧 \\
\hline & $\begin{array}{l}\text { Used when a part that is included in a bulk } \\
\text { group of non serialized parts is rejected. } \\
\text { It is useful for recording how many of the } \\
\text { parts were rejected and why, even though the } \\
\text { specific parts rejected cannot be tracked. }\end{array}$ \\
\hline & Example: $\quad$ 1475,DETAIL,REJECT,RC 0800 \\
\hline
\end{tabular}


RGE DATABASE FILES

OVERVIEW

Introduction

The Upload Data function executed from the Cell

Supervisor appends RGF data to the RGF database files.

Note: The Upload Data function is described in detail on page 9 of this documentation.

The RGF database files are utilized to generate the RGE Data Reports. (Refer to the RGE Data Reports section on page 38 for a description of the RGE Data Reports.)

Data' Flow

The Cell Supervisor Flow diagram, Diagram 6 on page 33 , shows all of the database files to which RGE data is appended by the Uploạ Data function.

The RGE Data Flow section on page 35 explains the data flow process.

File

Structure

The RGF database file structures are shown on page 34.

File

Utilization

Descriptions of the utilization of each file begin on page 36 . 


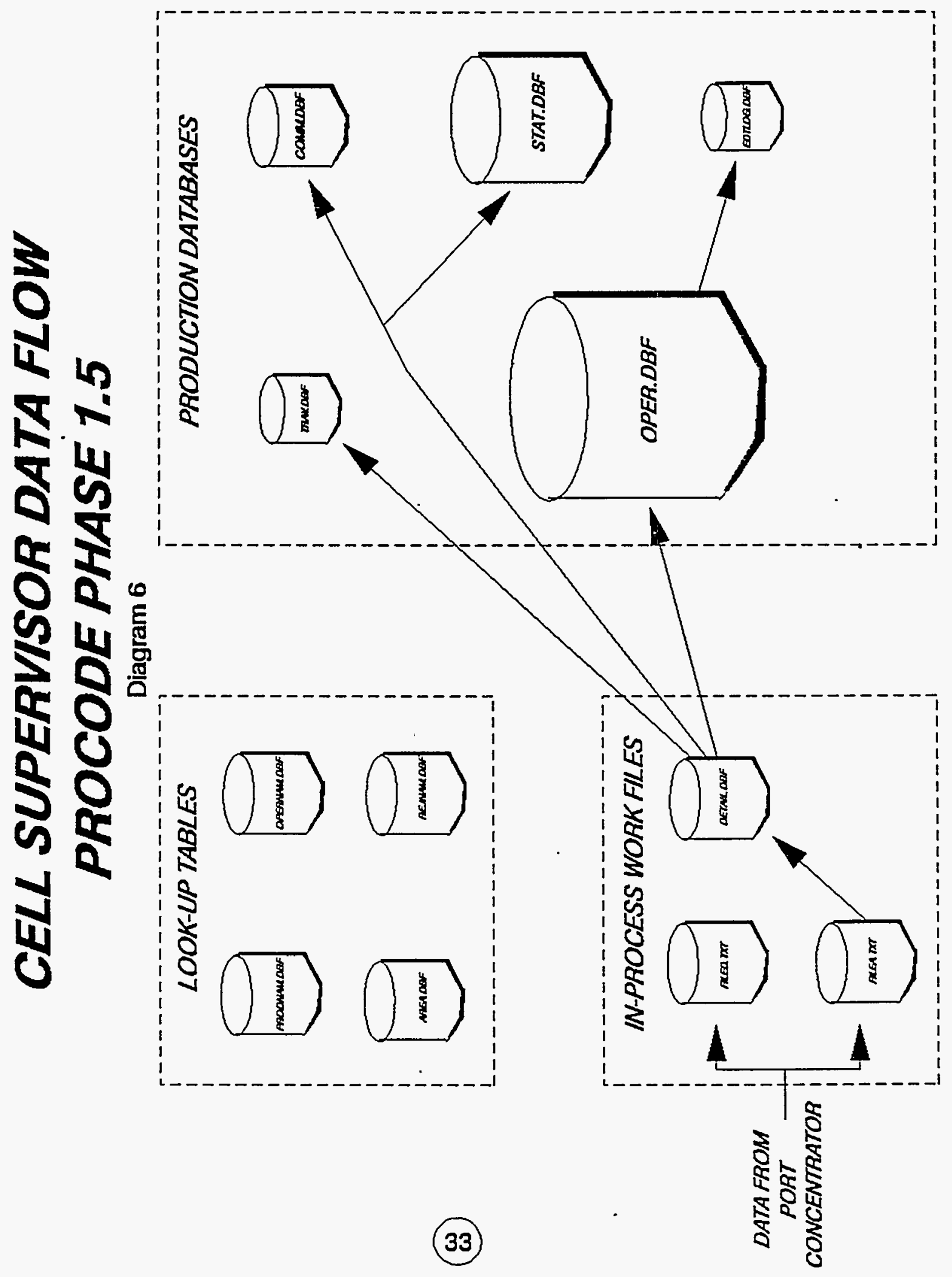


The structures of the main RGF database files accessed to print the RGF Data Reports are defined below.

\begin{tabular}{|c|c|c|c|}
\hline Filename & Field Name & Type & Length \\
\hline DETAIL.dbf & $\begin{array}{l}\text { PORT } \\
\text { OPER } \\
\text { PN_SN } \\
\text { DATADESC } \\
\text { VALUE } \\
\text { TMDATE } \\
\text { CSDATE }\end{array}$ & $\begin{array}{l}\text { Character } \\
\text { Character } \\
\text { Character } \\
\text { Character } \\
\text { Character } \\
\text { Character } \\
\text { Character }\end{array}$ & $\begin{array}{r}4 \\
4 \\
20 \\
20 \\
32 \\
9 \\
8\end{array}$ \\
\hline TRAV . dbf & $\begin{array}{l}\text { TRAV } \\
\text { PROD } \\
\text { DRAFHO } \\
\text { DRAKIS } \\
\text { LOT } \\
\text { GRPNAM } \\
\text { GRPVAL }\end{array}$ & $\begin{array}{l}\text { Character } \\
\text { Character } \\
\text { Character } \\
\text { Character } \\
\text { Character } \\
\text { Character } \\
\text { Character }\end{array}$ & $\begin{array}{r}6 \\
6 \\
10 \\
6 \\
6 \\
6 \\
9\end{array}$ \\
\hline OPER.dbf & $\begin{array}{l}\text { PROD } \\
\text { LOT } \\
\text { GRPVAL } \\
\text { TRAV } \\
\text { ORER } \\
\text { HP } \\
\text { PN_SN } \\
\text { DATADESC } \\
\text { VALUE } \\
\text { CSDATE } \\
\text { TMDATE }\end{array}$ & $\begin{array}{l}\text { Character } \\
\text { Character } \\
\text { Character } \\
\text { Character } \\
\text { Character } \\
\text { Character } \\
\text { Character } \\
\text { Character } \\
\text { Character } \\
\text { Character } \\
\text { Character }\end{array}$ & $\begin{array}{r}6 \\
6 \\
7 \\
6 \\
4 \\
4 \\
20 \\
20 \\
32 \\
8 \\
9\end{array}$ \\
\hline COMM. dbf & $\begin{array}{l}\text { PROD } \\
\text { LOT } \\
\text { GRPVAL } \\
\text { TRAV } \\
\text { OPER } \\
\text { COMM } \\
\text { CSDATE } \\
\text { TMDATE }\end{array}$ & $\begin{array}{l}\text { Character } \\
\text { Character } \\
\text { Character } \\
\text { Character } \\
\text { Character } \\
\text { Character } \\
\text { Character } \\
\text { Character }\end{array}$ & $\begin{array}{r}6 \\
6 \\
7 \\
6 \\
4 \\
32 \\
8 \\
8\end{array}$ \\
\hline STAT.dbE & $\begin{array}{l}\text { PROD } \\
\text { LOT } \\
\text { GRPVAL } \\
\text { TRAV } \\
\text { LOPER } \\
\text { PN_SN } \\
\text { DISP } \\
\text { DISP_REASON }\end{array}$ & $\begin{array}{l}\text { Character } \\
\text { Character } \\
\text { Character } \\
\text { Character } \\
\text { Character } \\
\text { Character } \\
\text { Character } \\
\text { Character }\end{array}$ & $\begin{array}{r}6 \\
6 \\
7 \\
6 \\
4 \\
20 \\
6 \\
32\end{array}$ \\
\hline
\end{tabular}


The RGF data flow process initiated by the Upload Data function is explained below. (Refer to the Cell Supervisor Flow diagram, diagram 6 on page for an illustration of the data flow).

\begin{tabular}{|c|c|}
\hline Stage & Description \\
\hline 1. & $\begin{array}{l}\text { Data is read from EILEA. TXT in the Cell } \\
\text { Supervisor home directory and copied to the } \\
\text { Detail.DBE file in the product subdirectory } \\
\text { on the network storage volume PRODI. }\end{array}$ \\
\hline \multirow[t]{8}{*}{2.} & $\begin{array}{l}\text { A Traveler ID is assigned to each RGF data } \\
\text { block. }\end{array}$ \\
\hline & $\begin{array}{l}\text { a. Each RGF data block is read from the } \\
\text { Detail.DBF file. }\end{array}$ \\
\hline & $\begin{array}{l}\text { The PROD, LOT, and GRPVAL data values in } \\
\text { each block are compared to the PROD, LOT } \\
\text { and GRPVAL data values in the } \\
\text { Traveler.DBF file. }\end{array}$ \\
\hline & Then... \\
\hline & $\begin{array}{l}\text { the matching } \\
\text { traveler ID is } \\
\text { assigned to the RGF } \\
\text { block. }\end{array}$ \\
\hline & $\begin{array}{l}\text { 1. the next } \\
\text { sequential traveler } \\
\text { ID is assigned to } \\
\text { the RGF block. }\end{array}$ \\
\hline & $\begin{array}{l}2 \text { the new traveler } \\
\text { ID is added to the } \\
\text { Traveler.DBE file. }\end{array}$ \\
\hline & $\begin{array}{l}\text { The Traveler ID is used as the } \\
\text { database key. }\end{array}$ \\
\hline 3. & The Traveler ID is appended to the RGF block. \\
\hline 4. & $\begin{array}{l}\text { The RGF records in each block are appended to } \\
\text { the appropriate RGF database files according } \\
\text { to the File Utilization description below. }\end{array}$ \\
\hline
\end{tabular}


RGE DATABASE FILES UTILIZATION

File

Utilization
A description of the utilization of each of the RGF database files follows.

Fil ename

File Utilization

LOGEILE.txt Captures a $10 \mathrm{~g}$ of the RGE records as they are received by the Cell

Supervisor.

Contains the same RGF record information that prints at the cell supervisor log printer during the Receive Data process.

This is a historical file which is archived periodically.

\begin{tabular}{|c|c|}
\hline FILEA.txt & $\begin{array}{l}\text { Stores the RGF records as they are } \\
\text { received at the cell supervisor from the } \\
\text { port concentrator. (Refer to the } \\
\text { explanation of the Receive Data and } \\
\text { Upload Data functions on pages } 7 \text { through } \\
\text { Il for details.) }\end{array}$ \\
\hline \multirow[t]{2}{*}{ EDTLOG . dbf } & $\begin{array}{l}\text { Provides an audit trail of all of the } \\
\text { RGE records modified by the system } \\
\text { Manager. }\end{array}$ \\
\hline & $\begin{array}{l}\text { When any record in an RGF database file. } \\
\text { is modified, the original record is } \\
\text { appended to the Edtlog.DBF. }\end{array}$ \\
\hline \multirow[t]{4}{*}{ DETAIL.dbf } & $\begin{array}{l}\text { The RGF records are stored in the } \\
\text { Detail.DBF file before being appended to } \\
\text { the other RGF database files. }\end{array}$ \\
\hline & $\begin{array}{l}\text { Any incomplete RGF data blocks (blocks } \\
\text { missing the HDR, COMPLETE, } 0 \text { record) are } \\
\text { not appended to the other RGE database } \\
\text { files. }\end{array}$ \\
\hline & $\begin{array}{l}\text { Incomplete data blocks remain in the } \\
\text { Detail.DBE file until the HDR, COMPLETE } \\
\text { record is received, or the Detail.DBF } \\
\text { Eile is maintained by the system } \\
\text { Manager. }\end{array}$ \\
\hline & $\begin{array}{l}\text { The Detail Report can be printed to lis } \\
\text { each record in the Detail.DBF file, } \\
\text { sorted by port. }\end{array}$ \\
\hline
\end{tabular}


RGE DATABASE FILES UTILIZATION, Continued

\begin{tabular}{|c|c|}
\hline Filename & File Utilization \\
\hline TRAV . dbf & $\begin{array}{l}\text { Stores the RGF block records that make } \\
\text { up the Report Header information. }\end{array}$ \\
\hline OPER . dbE & $\begin{array}{l}\text { stores the RGF block records that make } \\
\text { up the information shown in the body of } \\
\text { the Electronic Traveler and operation } \\
\text { Data reports. }\end{array}$ \\
\hline \multirow[t]{2}{*}{ COMM.dbf } & $\begin{array}{l}\text { stores selected records from the RGF } \\
\text { data blocks that contain the keyword } \\
\text { com (comments) in the Data Description } \\
\text { field. }\end{array}$ \\
\hline & $\begin{array}{l}\text { The contents of the Comm.DBF print on } \\
\text { the Electronic Traveler Report. }\end{array}$ \\
\hline \multirow[t]{2}{*}{ STAT.dbf } & $\begin{array}{l}\text { Contains a snapshot of the status } \\
\text { (ACCEPT or REJECT) of all of the } \\
\text { serialized parts that have been } \\
\text { initialized into the RGF database with } \\
\text { the *ACCEPT, INITIAL record. }\end{array}$ \\
\hline & $\begin{array}{l}\text { The contents of the stat.DBF file print } \\
\text { on the Serial Number Acceptance Report } \\
\text { (sometimes referred to as the status } \\
\text { Report). }\end{array}$ \\
\hline \multirow[t]{3}{*}{ PRODNAM . dbE } & $\begin{array}{l}\text { Stores the text descriptions of the EG\&G } \\
\text { Product AO codes. }\end{array}$ \\
\hline & $\begin{array}{l}\text { This database is updated as needed, by } \\
\text { the Procode Database Administrator. }\end{array}$ \\
\hline & $\begin{array}{l}\text { The text descriptions of the Product AO } \\
\text { codes print on the Report Headers. }\end{array}$ \\
\hline \multirow[t]{3}{*}{ OPERNAM.dbE } & $\begin{array}{l}\text { Stores the text descriptions of the EG\&G } \\
\text { Operation codes. }\end{array}$ \\
\hline & $\begin{array}{l}\text { This database is updated as needed, by } \\
\text { the Procode Database Administrator. }\end{array}$ \\
\hline & $\begin{array}{l}\text { The text descriptions of the operation } \\
\text { codes print on the Report Headers. }\end{array}$ \\
\hline
\end{tabular}


Reports Produced using RGF Data
Traveler Report

Operation Data Report

S/N Acceptance Report

Check/Verify Status Report

Database

Maintenance Reports

Sample Reports
Several reports are produced using RGF data. The RGF data reports are available for each product and are accessed via the Print Reports option on the Procode Data Systems Menu.

The RGF data reports are used by production workers and supervisors, Engineers, Technicians and Procode System Managers.

The main RGF Data Reports which are accessed via the PROCODE Data Systems menu are listed and described bel ow:

- Traveler Report (or Electronic Traveler)

- Operation Data Report

- S/N Acceptance Report (or Status Report)

- Check/Verify Status Report

The Traveler Report includes all RGF data collected for a product, exclusive of the records which contain an asterisk (*) in the Data Description field, such as the *ACCEPT, INITIAL records.

The Operation Data Report includes all RGF data collected for a product, exclusive of the operator comments.

The S/N Acceptance Report shows the status, (ACCEPT or REJECT) at the time of the report, of the serialized parts that were initialized into the database with an *ACCEPT, INITIAL record.

The Check/Verify status Report shows the results of the verification procedure performed to verify the status of the serialized parts. (Refer to page 29 for an explanation of the verification procedure.)

Two additional reports, the Detail Report and the Upload Data Report are printed by the System Manager to aid in maintaining the integrity of the RGF database files. These reports are accessed via commands issued at the operating system prompt.

Samples of each of the reports listed above are included with this documentation on pages through 
Data

Collection

Planning

Guidelines
Follow the guidelines below to determine the data collection requirements for the production or testing process being automated for data collection.

3. Review the technical manual to obtain
information on the product production process
and valid product AO codes and product
component oc\#'s.
Meet with key production personnel.
a. Technicians, product engineers and
production managers can answer any
questions related to the Technical
Manual and data collection requirements.
Meet with other programmer analysts writing
code for data collection for the same
production process.
a. plan the production beginning and ending
points for each data collection program.
verify that all data collection
requirements are met by the combined
data collection programs, in the proper
sequence.




\begin{tabular}{ll}
\hline Stage & Description \\
\hline 6. & $\begin{array}{l}\text { Document the data collection requirement } \\
\text { specifications for review by the sey } \\
\text { production personnel and the Procode Database } \\
\text { Administrator. } \\
\text { Note: } \\
\text { An example of a data specifications } \\
\text { document is provided in Exhibit } 4, \\
\text { Sample Data specifications for the } \\
\text { Electrical Measurement station, } \\
\text { beginning on page 65. }\end{array}$ \\
\hline 7. & $\begin{array}{l}\text { Once the data specifications are approved, } \\
\text { programming for RGF data collection may } \\
\text { begin. }\end{array}$
\end{tabular}


PROGRAMMING FOR RGE DATA COLLECTION

OVERVIEW

Building

RGE Records

RGE Data

Entry

RGF Record

Description

RGF Block

Description

Programing

Standards

Suggested

Exhibits to

Review

The software programs that build the RGF records at the TMs are written in the IRL programming language. The programs that build RGF records at the AFs are written in either the C, Clipper or BASIC programming languages. The programs are loaded. locally on the TM or AF where they will run.

The production procedures performed at each TM or AW are unique to the product being produced or tested there. Therefore, the programs that build RGP records are unique to the product and the production phase or test being performed at each TM or AF location.

RGE data entry is accomplished by production personnel typing entries or scanning bar codes with bar code wands.

Data is also obtained from automated testing equipment. Either way, the data entry is in response to data input prompts issued by the program being executed at the TM or AW.

An RGF record consists of eight fields.

Four of the fields are automatically generated when the RGF record is transferred from the TM to the network storage volume.

The other four fields are programmed for inclusion in the RGF record by the programs that build RGF records.

A variable number of RGF records make up an RGF block.

The block begins with the RGF record that specifies the EG\&G Product AO code being produced or tested, and ends with the RGE record that contains the keyword COMPLETE in the Data Description field.

Certain programming standards must be followed to ensure that accurate, complete RGF production data is collected and processed.

The programming standards and guidelines for fulfilling the standards are described in this section.

A review of Exhibits 5 and 6 beginning on page 65 may provide you with some programming ideas and a better understanding of programming for RGF data collection. 
Programming standards, continued
List of Error Trapping Techniques
A sample IRL program written for RGF data collection is included as Exhibit 5, which begins on page 70 .

The programming standards described here are utilized in the sample IRL program.

You may want to review the specific programming methods of error trapping used in the sample IRL program.

Verification of valid data entry using the error trapping techniques listed below is an important part of programing for RGF Data Collection.
Compare the data entry received in response to the current prompt with the previous data entries received for the current RGF data block.

- The product (PROD) data value must be valid based on the operation code entered.

- the data value for the LOT must be valid based on the product (PROD) entered,

- the data value for the group name (GRPNAM) must be valid based on the data value received for the product (PROD), and

- the data value for the group value (GRPVAL) must be valid based on the group name (GRPHAM).

Note: The GRPNAM is always programmed into the RGF Data Collection program and does not require operator input.

The GRPVAL entered by the TM or AW operator is compared for validity to the GRPNAM programmed into the RGF Data Collection Program. 
PROGRAMMING FOR RGE DATA COLLECTION, Continued

List of Error Trapping Techniques, continued

Check the syntax of each data value entry based on the contents of the Data Description field.

Note: A \# symbol used in the syntax column indicates that a numeric value is required.

Data Description Data Value Syntax

PROD

LOT

DRAFNO

DRAFIS

HP

GRPNAM

GRPVAL

Description of a component or production supply

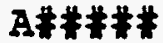

し莱井\#

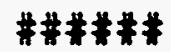

\#\#\#

\#\#\#\#

REEL

TRAY

TUB

PCRN

PVD

R\#\#\#-\#\# (for GRPNAM REEL) TH\#\# (for GRPNAM TRAY) T\#\#\# (for GRPNAM TUB) C\#\#\#\# (for GRPNAM PCRN) \#\#\#\# (for GRPNAM PVD)

A QC\# may be used in the data value field when the PN_SN field contains a part number or serial number and the data description field contains a description of a component or a production supply.

Syntax： QC\# \#\#-AI

Note: QC\# is a literal. DO NOT replace the single \# following the QC with a digit. 
PROGRAMMING FOR RGE DATA COLLECTION, Continued

List of Error Trapping Techniques, continued

Check for the reasonableness of the number of rejects entered in response to the "Any Rejects?" prompt.

Note: The number of rejects will normally be less than 1000 except in Tape processing.

Check the comment (COMM) entries to verify that

- the comment is 'less that 33 characters, and

- does not include embedded commas

Note: If commas are embedded, replace them with blank spaces.

Check for a COMPLETE record.

Provide for a DELETE record option after the operator has completed entering the report header information, and especially when REJECT codes are being input.

Provide for an EXIT, ALL option at any time during data entry.

Note: Issue a prompt asking the operator for verification of the EXIT,ALL function before exécuting it.

Verify that the Data Descriptions used in the RGF Data Collection program do not exceed 20 characters.

Check that the spelling of the keywords used in the RGF Data Collection program is correct. 


\section{EXHIBIT 1}

Description

Sample A RGF Data Blocks

Sample A Electronic Traveler Report
Page(s)

46

47,48 
PA, 1251, HOR , PRDO, A04236, 007:10:43,02/07/90, 10:44:25 PA, 1251, HDR , LOT , L99999, >07: 10:43, 02/07/90, 10:44:26 $P A, 1251$, HDR , HP, $2635,>07: 10: 43,02 / 07 / 90,10: 44: 27$ PA, 1251, HDR , GRPVAL, C99999, >07:10:44, 02/07/90, 10:44:29 PA, 125?, HDR , GRPHAM, PCRH , >07:10:44, 02/07/90, 10:44:29 PA, 1251, SH 12541, *UNIT, PROCE5SED,>07:10:44,02/07/90, 10:44:40 PA, 1251, SN 12542, *UNIT, PROCESSED , >07:10:44, 02/07/90, 10:44:53 PA, 1251, SN 12543, *UHIT, PROCESSED, >07:10:44, 02/07/90, 10:45:02 PA, 1251, SN 12544, *UNIT,PRDCESSED, >07:10:44, 02/07/90, 10:45:08 PA, 1251, SH 12545, «UN1T, PROCESSED, >07:10:44, 02/07/90, 10:45:12 PA, 1251,SN 12544,REJECT COOE,RC 0258,>07:10:45,02/07/90, 10:45:28 PA, 1251, DETAIL, OPERATIOH, PROCESSED, >07:10:45, 02/07/90, 10:45:39 PA, 1251, HDR , COMPLETE, 0,>07:10:45, 02/07/90, 10:45:39 PA, 1295, HDR , PRDO, A04236, >07:10:45, 02/07/90, 10:46:04 PA, 1295, HDR, LOT, LS9999, >07:10:45, 02/07/90,10:46:04 PA, 1295, HDR , HP, 2635, >07:10:45, 02/07/90, 10:46:05 PA, 1295, HDR, GRPVAL, C99999, 207:10:45, 02/07/90, 10:46:07 PA, 1295, HDR, GRPHAM , PCRK, >07: 10:45, 02/07/90, 10:46:08 PA, 1295, PN AO4380, KAPTOH, QC\# 22222-A1, >07:10:46,02/07/90,10:46:29 PA, 1295, SN 12545,REJECT COOE,RC 0236,>07:10:46,02/07/90,10:46:39 PA, 1295, HDR, COMH, THIS IS A TEST, >07:10:46, 02/07/90, 10:46:54 PA, 1295, DETAIL, OPERATIOH, PROCESSED, >07:10:46, 02/07/90, 10:46:58 PA, 1295, HOR , CONPLETE, 0, >07:10:46, 02/07/90, 10:46:59 $P A, 1400, H D R, P R C 0, A 04236,>07: 10: 46,02 / 07 / 90,10: 47: 22$ PA, 1400, HDR , LOT, L99999, >07: 10:46, 02/07/90, 10:47:23 PA, 1400, HDR, HP, 2635, >07:10:46,02/07/90,10:47:23 PA, 1400, HDR, GRPVAL, C99999, 207:10:47,02/07/190, 10:47:29 PA, 1400, HDR, GRPHAN, PCRH, >07: 10:47, 02/07/90, 10:47:30 PA, 1400, SH 12365, *UHIT, PROCESSED,>07:10:47, 02/07/90, 10:47:48 PA, 1400,SH 12365, "UNIT, PROCESSED,>07:10:47, 02/07/90, 10:47:52 PA, 1400, SH 14526, *UHIT, PROCESSED,>07:10:47, 02/07/90, 10:47:55 PA, 1400, DETAIL, OPERATIOH, PROCESSED, >07:10:47, 02/07/90, 10:48:08 PA, 1400, HDR, COMPLETE, 0,>07:10:47, 02/07/90, 10:48:08 $P A, 1401, H D R, P R O 0, A 04236,>07: 10: 48,02 / 07 / 90,10: 48: 29$ PA, 1401, HDR , LOT, L99999, >07:10:48, 02/07/90, 10:48:30 PA, 1401, HDR , HP , 2635, >07:10:48, 02/07/90, 10:48:31 PA, 1401, HDR, GRPVAL, C99999, >07:10:48, 02/07/90, 10:48:35 PA, 1401, HDR, GRPHAH, PCRH, >07: 10:48, 02/07/90, 10:48:36 PA, 1401, SN 14526, "UHIT, PROCESSED, >07:10:48, 02/07/90, 10:48:43 PA, 1401, SN 12547, UUNIT, PROCESSED, >07:10:48,02/07/90, 10:48:46 PA, 1401, SN 12587, *UHIT,PROCESSED, >07:10:48,02/07/90, 10:48:49 PA, 1401, DETAIL, OPERATIOH, PROCESSED , 007:10:48, 02/07/90, 10:49:01 PA, 1401, HDR , COMPLETE, 0,>07:10:48,02/07/90, 10:49:02 PA, 1345, HDR , PRCO , A04236,>07:10:48, 02/07/90, 10:49:22 PA , 1345, HDR , LOT , LS9999, >07: 10:48, 02/07/90, 10:49:23 PA, 1345, HOR , HP, 2635, >07:10:48, 02/07/90, 10:49:23 PA, 1345, HDR , GRPVAL, C99999,>07:10:48, 02/07/90, 10:49:26 PR, 1345, HOR, GRPHAK, PCRH, >07:10:48, 02/07/90, 10:49:27 PA, 1345,SN 14526,REJECT COOE,RC 0258,>07:10:49,02/07/90,10:49:37 PA, 1345, SM 14587,REJECT COOE,RC 0145,>07:10:49,02/07/90,10:49:44 PA, 1345, DETAIL, OPERATIOK, PROCESSED, >07:10:49, 02/07/90, 10:49:53 PA, 1345, HDR , COMPLETE, 0,>07:10:49,02/07/90, 10:49:54 PA, 1200, HDR , PROD, A04236, >07:10:49,02/07/90, 10:50:15 PA, 1200, HDR, LOT, L99999, >07:10:49,02/07/90, 10:50:15 $P A, 1200, H O R, H P, 2635,>07: 10: 49,02 / 07 / 90,10: 50: 16$ PA, 1200, HDR, GRPVAL, C99999, >07:10:49,02/07/90, 10:50:18 PA, 1200, HDR, GRPHAM, PCRH, >07:10:49,02/07/90, 10:50:19 PA, 1200, DETAIL, OPERATION, PROCESSED , 007:10:50, 02/07/90, 10:50:27 EA, 1200, HDR , COMPLETE , 0,>07:10:50,02/07/90, 10:50:28 $P A, 1250, H D R, P R D O, A 04236,>07: 10: 50,02 / 07 / 90,10: 50: 47$ PA, 1250, HDR , LOT , L99999, >07: 10:50,02/07/90, 10:50:48 $P A, 1250, H D R_{2} H P, 2635,>07: 10: 50,02 / 07 / 90,10: 50: 49$ PA , 1250, HDR, GRPVAL, C99999, >07:10:50,02/07/90, 10:50:51 PA, 1250, HDR, GRPHAH, PCRH, >07:10:50,02/07/90, 10:50:51 PA, 1250, SN 23698,REJECT COOE,RC 0256,>07:10:50,02/07/90,10:50:59 PA, 1250, DETAIL, OPERATIOH, PROCESSED , >07:10:50, 02/07/90, 10:51:06 PA, 1250, HDR , COMPLETE, $0,>07: 10: 50,02 / 07 / 90,10: 51: 07$ 


\section{$\star \star \star \star \star$ UNCLASSIFIED \\ PROCODE Electronic Traveler}

$\begin{array}{llll}\text { PRCOUCT }: \text { LOHG CABLE } & & \text { FRIDAY, FEBRUARY } 9,1990 & 3: 26 \text { PM } \\ \text { PROOUCT AO } & : \text { A04236 } & \text { LOT : L99999 } & \text { PAGE NO: } 1 \text { TRAVELER ID: } 38 \\ \text { ORAHING HO. : } & \text { SUFFIX: } & \text { SYSTEM: SYSTEM UTILITY } \\ \text { PCRH } & : \text { C9999 } & & \text { DSA\# TEST VERSION DEVELOPMENT VERSION }\end{array}$

OPERATIOH: 1200 LASER WELD CABLE

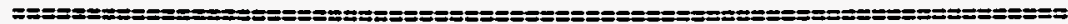

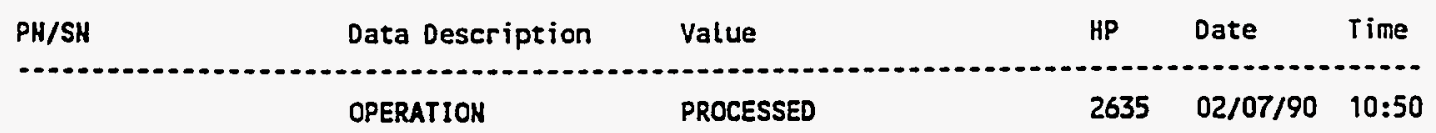

OPERATION: 1250 CLEAN \& IHSPECT WELD

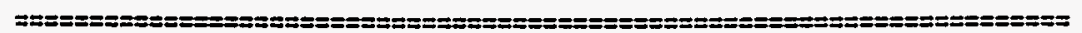

\begin{tabular}{llllll} 
PH/SH & Data Description & Value & HP & Date & Time \\
\hline SH 23698 & OPERATIOH & PROCESSED & 2635 & $02 / 07 / 90$ & $10: 50$ \\
& REJECT CDOE & RC 0256 & 2635 & $02 / 07 / 90$ & $10: 50$
\end{tabular}

OPERATIOH: 1251 QC INSPECT HELD

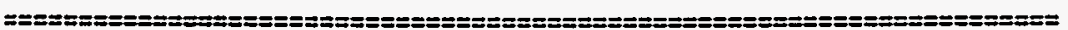

$\begin{array}{llllll}\text { PH/SH } & \text { Data Description } & \text { Value } & \text { HP } & \text { Date } & \text { Time } \\ & \text { OPERATIOH } & \text { PROCESSED } & 2635 & 02 / 07 / 90 & 10: 45 \\ \text { SH } 12544 & \text { REJECT COOE } & \text { RC } 0258 & 2635 & 02 / 07 / 90 & 10: 45\end{array}$

OPERATIOH: 1295 APPLY KAPTON

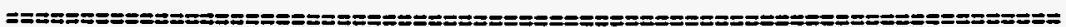

\begin{tabular}{|c|c|c|c|c|c|}
\hline PH/SH & Data Description & Value & HP & Date & Time \\
\hline & OPERATIOH & PROCESSED & 2635 & $02 / 07 / 90$ & $10: 46$ \\
\hline PH A04380 & KAPTOH & QC\# 222222-A1 & 2635 & $02 / 07 / 90$ & $10: 46$ \\
\hline SH 12545 & REJECT CODE & RC 0236 & 2635 & $02 / 07 / 90$ & $10: 46$ \\
\hline
\end{tabular}

COMMENTS: THIS IS A TEST

OPERATIOH: 1345 VISUAL CURED KAPTON COVER

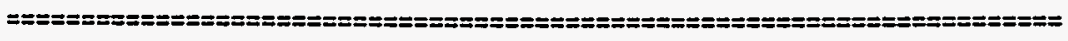

$\begin{array}{lllrrr}\text { PH/SH } & \text { Data Description } & \text { Value } & \text { HP } & \text { Date } & \text { Time } \\ & \text { OPERATION } & \text { PROCESSED } & 2635 & 02 / 07 / 90 & 10: 49 \\ \text { SH } 14526 & \text { REJECT COOE } & \text { RC } 0258 & 2635 & 02 / 07 / 90 & 10: 49 \\ \text { SH } 14587 & \text { REJECT COOE } & \text { RC } 0145 & 2635 & 02 / 07 / 90 & 10: 49\end{array}$




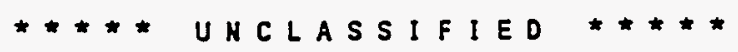

\section{PROCODE Electronic Traveler}

PROOUCT : LONG CABLE

PROOUCT AO : A04236

DRAHIKG KO. :

PCRH

: 699999
FRIDAY, FEBRUARY 9, $1990 \quad 3: 26$ PM

LOT : 199999

SUFFIX:
PAGE NO: 2 TRAVELER I0: 38 SYSTEM: SYSTEM UTILITY DSA\# TEST VERSIOH DEVELOPMEHT VERSION

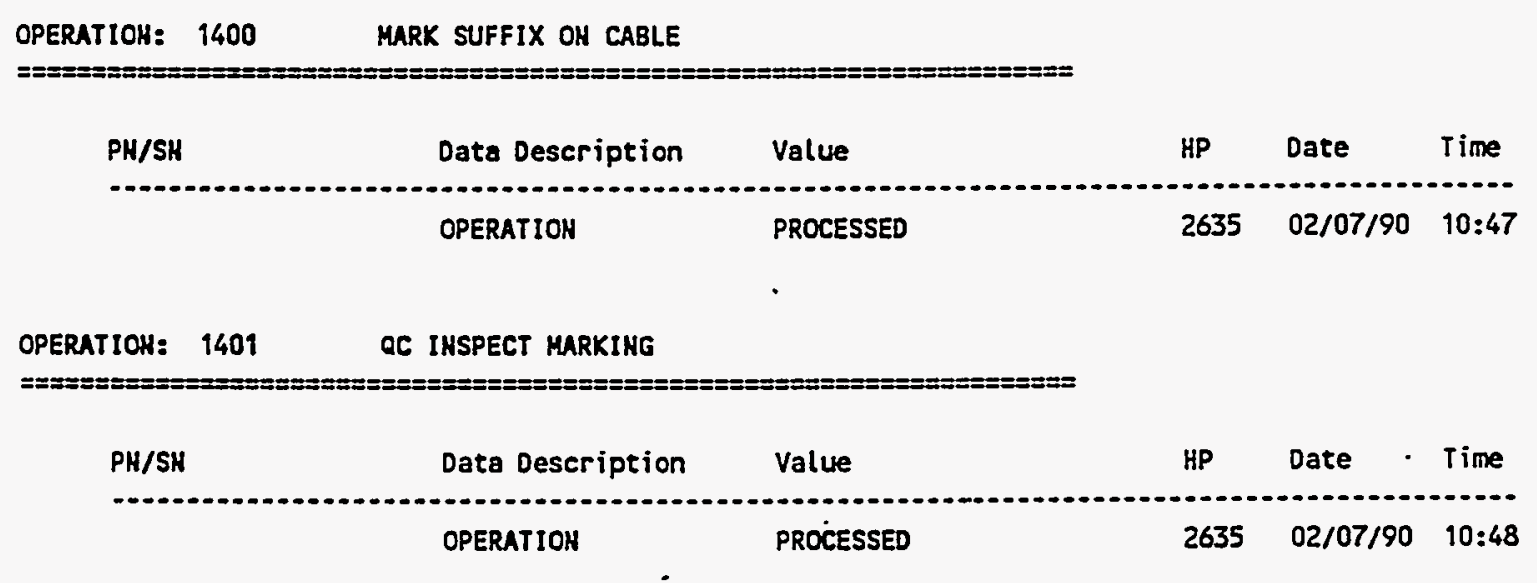




\section{EXHIBIT 2}

Description

Sample B RGF Data Blocks

Sample B Electronic Traveler Report

Sample B Operations Data Report

\section{Page(s)}

50

51

52 
RA, 1160, HDR , PRO0 , A04235, 04/30/90, 10:03:15

$>01: 00: 00,04 / 30 / 90,10: 03: 15$

NA, 1160, HDR , LOT , L88888, , 04/30/90, 10:03:16

$n A, 1160$, HDR , HP , 2635, 04/30/90, 10:03:16

nA , 1160, HDR , GRPVAL, C88888,>30:09:51,04/30/90, 10:03:17

nA, 1960, HDR , GRPNAM, PCRN, >30:09:51,04/30/90, 10:03:17

NA, 1160, PH A04381, ADHESIVE, OC\# 12365-A1,>30:09:51,04/30/90, 10:03:18

MA, 1160, DETAIL,PVD RUN\#,88888,>30:09:51,04/30/90,10:03:18

MA, 1960, SN TT7T7, “ACCEPT, INITIAL, ,>30:09:51, 04/30/90, 10:03:19

$M A, 1160$, SH 7TT77, HEADER SH,SH 02589,>30:09:51,04/30/90,10:03:19

$\mathrm{NA}, 1160$, SN 77777 , *PVD RUN\#,88888,>30:09:51,04/30/90, 10:03:20

nA, 1960, SH 88888, "ACCEPT, IHITIAL, ,>30:09:51,04/30/90, 10:03:20

NA, 1160, SN 88888, HEADER SN, SN 02586,>30:09:51,04/30/90,10:03:21

$M A, 1160$, SH 88888, ॠPVO RUN\#,88888,>30:09:51,04/30/90, 10:03:21

$M A, 1160$, SH 99999, *ACCEPT, INITIAL, , >30:09:52,04/30/90, 10:03:22

$\mathrm{MA}, 1160$, SH 99999, HEADER SH, SH 01254,>30:09:52,04/30/90,10:03:22

MA, 1160, SN 99999, "PVD RUN",88888,>30:09:52,04/30/90, 10:03:23

MA, 1160, DETAIL, OPERATION, PROCESSED, >30:09:52, 04/30/90, 10:03:23

$\mathrm{MA}, 1160$, HDR , COMPLETE, $0,>30: 09: 52,04 / 30 / 90,10: 03: 24$

NA, 1862, HOR , PROO , A04242, >30:09:52, 04/30/90, 10:03:24

$\mathrm{MA}, 1862$, HOR , LOT , L88888, >30:09:52, 04/30/90, 10:03:25

$\mathrm{MA}, 1862$, HDR , HP , 2635, >30:09:52, 04/30/90, 10:03:25

$\mathrm{MA}, 1862$, HOR , GRPVAL, 88888, >30:09:52, 04/30/90, 10:03:26

$\mathrm{MA}, 1862$, HOR , GRPHAM, PVO, >30:09:52, 04/30/90, 10:03:26

AA, 1862, SH 01236, REJECT COOE, RC 0012,>30:09:53,04/30/90,10:03:27

MA , 1862, DETAIL, OPERATIOK, PROCESSED , >30:09:53,04/30/90, 10:03:27

$\mathrm{MA}, 1862$, HDR , COMPLETE, $0,>30: 09: 53,04 / 30 / 90,10: 03: 28$

$\mathrm{MA}, 1476, \mathrm{HDR}$, PRCO, A04242,>30:09:57, 04/30/90, 10:03:28

NA, 1476, HDR , LOT , L88883, >30:09:57, 04/30/90, 10:03:29

NA, 1476, HDR , HP , 2635, >30:09:57, 04/30/90, 10:03:29

$\mathrm{MA}, 1476$, HDR , GRPVAL, $88888,>30: 09: 57,04 / 30 / 90,10: 03: 30$

NA, 1476, HDR , GRPHAK, PVO, >30:09:57,04/30/90, 10:03:30

MA, 1476, DETAIL, AMOUNT Fe (PPM), 12,>30:09:57,04/30/90, 10:03:31

NA, 1476, DETAIL, AMOUNT Ni (PPN), 05,>30:09:57,04/30/90, 10:03:31

nA, 1476, DETAIL, AMOUNT Cr (PPD), 03,>30:09:57,04/30/90,10:03:32

MA, 1476, DETAIL,AMOUNT Cl (PPM), 04,>30:09:57,04/30/90,10:03:32 MA, 1476, DETAIL, AMOUNT CU (PPD), 23,>30:09:57,04/30/90,10:03:33

MA, 1476, DETAIL, AMOUNT C (ppm), 21,>30:09:57,04/30/90, 10:03:33

กA', 1476, DETAIL, AMOUNT AL (\%),89,>30:09:58,04/30/90,10:03:34

NA, 1476, DETAIL, AKOUNT OTHERS (PPM), 30,>30:09:58,04/30/90, 10:03:34

NA, 1476, DETAIL, SAMPLE ID, 012345,>30:09:58,04/30/90, 10:03:35

nA, 1476, DETAIL, PVD RUN DISPOSITIOH,PASS, >30:09:58, 04/30/90, 10:03:35

$\mathrm{NA}, 1476$, DETAIL, OPERATION ,PROCESSED , >30:09:59,04/30/90, 10:03:36

IA, 1476, HDR , COMPLETE, $0,>30: 09: 59,04 / 30 / 90,10: 03: 36$ 
PROCODE Electronic Traveler

PROOUCT : SHORT CABLE

PROOUCT AO : A04235

DRAHIHG HO. :

PCRH
MONDAY, APRIL 30, 1990 10:30 AM

PAGE NO: 1 TRAVELER ID: 87

SYSTEM: SYSTEM UTILITY

DSA\# TEST VERSIOH DEVELOPMENT VERSION

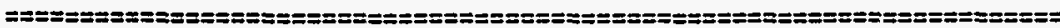

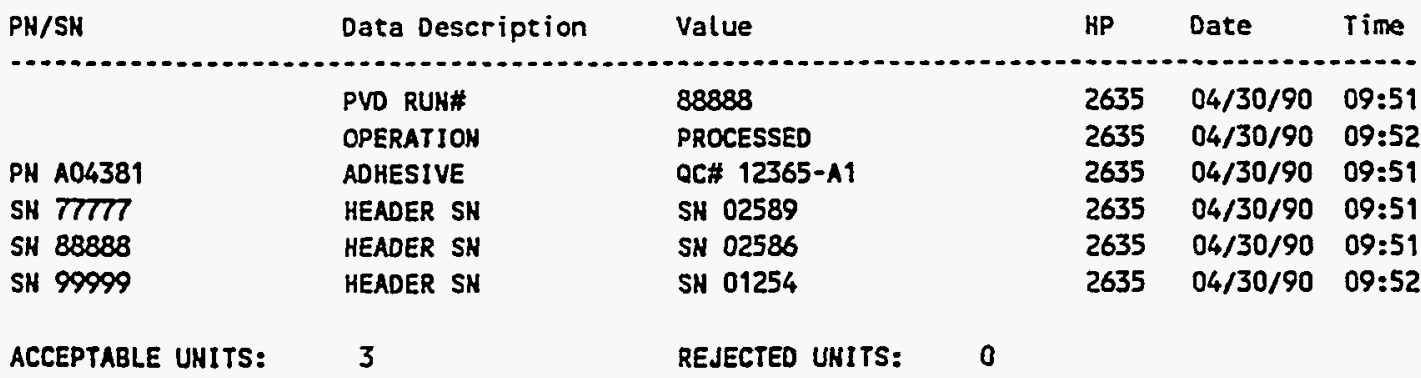




\section{Operation Data}

PROOUCT : SHORT CABLE

PRCOUCT AO : A04235

DRAHING NO. : PCRN
MONDAY, APRIL 30, 1990 10:29 AM PAGE NO: 1 TRAVELER ID: SYSTEM: SYSTEM UTILITY DSA\# TEST VERSION OEVELOPMENT VERSIOH

OPERATION: 1160 SHAGE PIN \& INSPECT

\begin{tabular}{|c|c|c|c|c|c|}
\hline PH/SH & Data Description & Value & HP & Date & Time \\
\hline 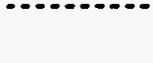 & PVD RUNA & 88888 & 2635 & $04 / 30 / 90$ & $09: 51$ \\
\hline & OPERATION & PROCESSED & 2635 & $04 / 30 / 90$ & $09: 52$ \\
\hline PN 104381 & ADHESIVE & QC\# 12365-A1 & 2635 & $04 / 30 / 90$ & $09: 51$ \\
\hline SN 77777 & -ACCEPT & INITIAL & 2635 & $04 / 30 / 90$ & $09: 51$ \\
\hline SH $77 T 7$ & HEADER SH & SN 02589 & 2635 & $04 / 30 / 90$ & $09: 51$ \\
\hline sH $7 m T$ & \#PVD RUN\# & 88888 & 2635 & $04 / 30 / 90$ & $09: 51$ \\
\hline SH 88888 & *ACCEPT & IHITIAL & 2635 & $04 / 30 / 90$ & $09: 51$ \\
\hline SH 88888 & HEADER SH & SH 02586 & 2635 & $04 / 30 / 90$ & $09: 51$ \\
\hline SH 88888 & *PVO RUN\# & 88888 & 2635 & $04 / 30 / 90$ & $09: 51$ \\
\hline SH 99999 & *ACCEPT & IHITIAL & 2635 & $04 / 30 / 90$ & $09: 52$ \\
\hline SH 99999 & HEADER SN & SH 01254 & 2635 & $04 / 30 / 90$ & $09: 52$ \\
\hline SH 99999 & *PVO RUN\# & 88888 & 2635 & $04 / 30 / 90$ & $09: 52$ \\
\hline
\end{tabular}




\section{EXHIBIT 3}

\section{Sample Reports}

Description

S/N Acceptance Report

Status Verification Report

Operation Upload Report

Detail Report
Page (s)

$54-58$

59,60

61

62,63 


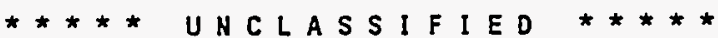

Serial Number Acceptance Report

PRODUCT : MC3926 BRIDGE

PRODUCT AO : A05764 LOT : E10235

DRAWING HO. :

REEL : R377-02
TUESDAY, JUNE 5, 1990 3:09 PM

PAGE NO: 1 TRAVELER ID: 1227

SYSTEM: PROCODE SYSTEM

DSA\# 871860-G Version 5.0

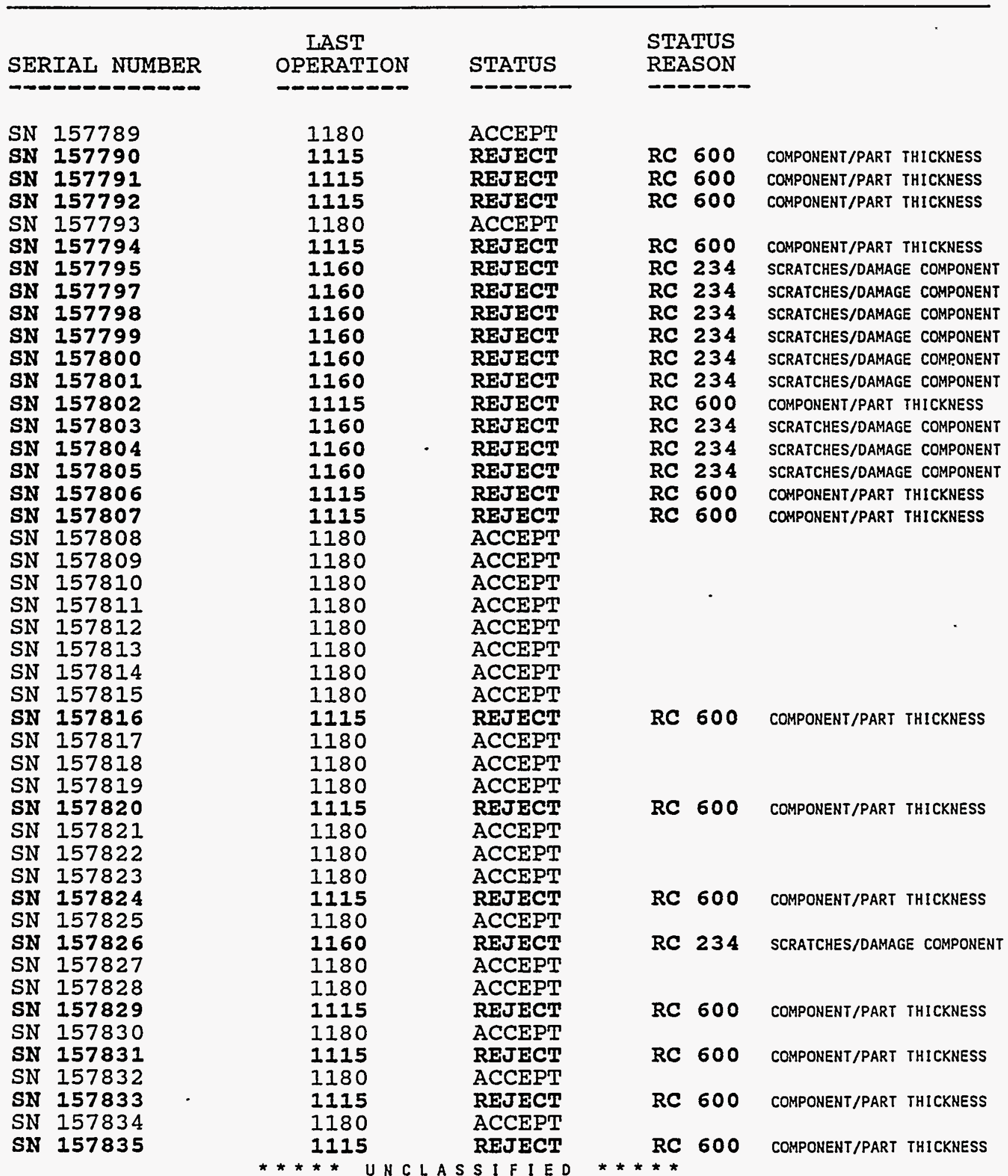


Serial Number Acceptance Report

PROOUCT : MC3926 BRIDGE

PRODUCT AO : A05764

DRAHING HO. :

REEL
LOT : E10235

SUFFIX:
TUESDAY, JUNE 5, $1990 \quad 3: 09$ PM

PAGE NO: 2 TRAVELER ID: 1227

SYSTEM: PROCOOE SYSTEM

DSA\# 879860-G Version 5.0

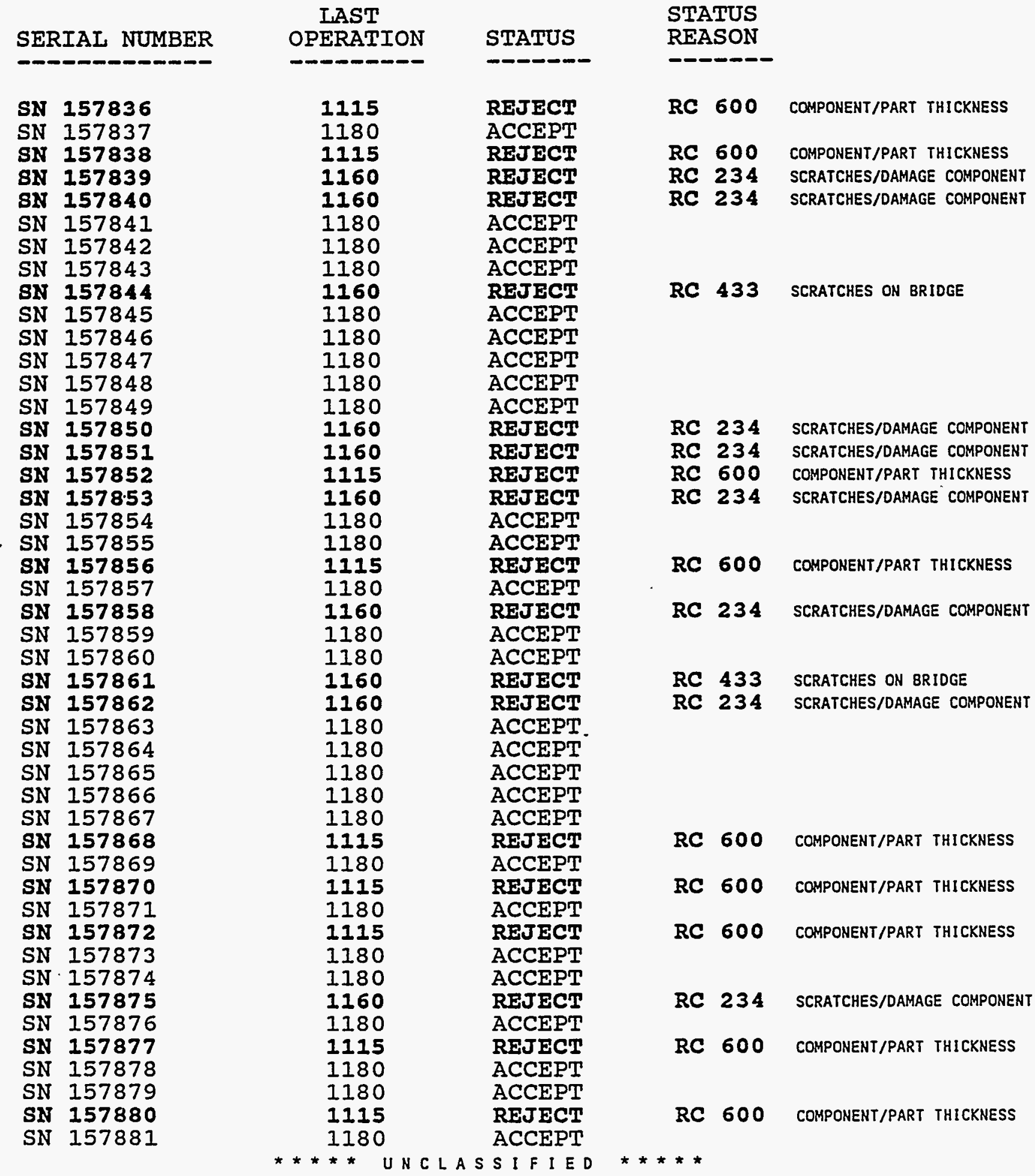


Serial Number Acceptance Report

PRODUCT : MC3926 BRIDGE

PRODUCT AO : A05764 DRAWING HO. : REEL
LOT : E10235

SUFFIX:
TUESDAY, JUHE 5, $1990 \quad 3: 09$ PM

PAGE NO: 3 TRAVELER ID: 1227

SYSTEM: PROCOOE SYSTEM

OSA\# 871860-G Version 5.0

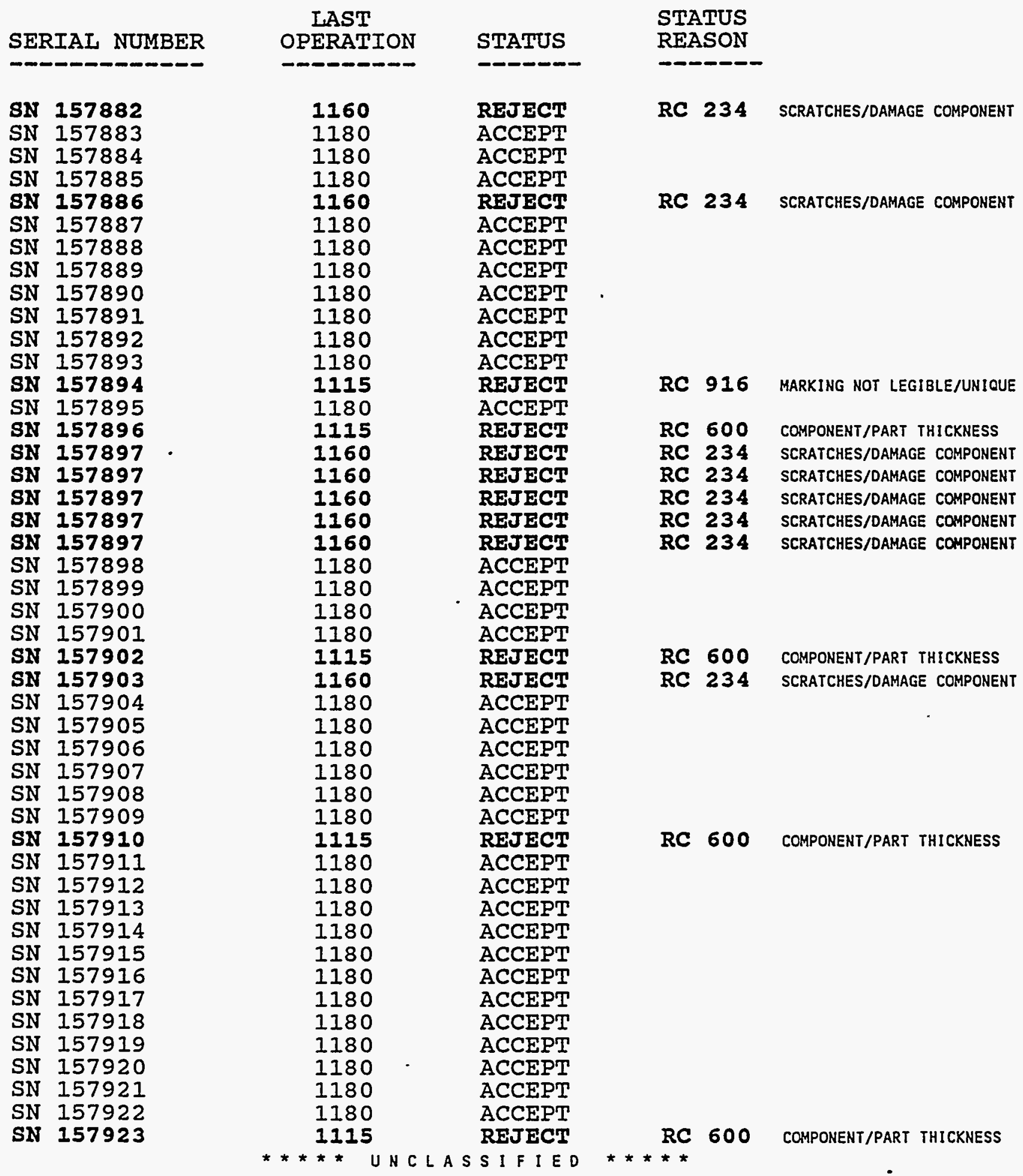


Serial Number Acceptance Report

PRODUCT : MC3926 BRIDGE

PRODUCT AO : A05764

DRAWING NO. :

REEL : R377-02
LOT : E10235

SUFFIX:
TUESDAY, JUNE 5, 1990 3:09 PH

PAGE NO: 4 TRAVELER ID: 1227

SYSTEM: PROCOOE SYSTEM

DSA\# 871860-G Version 5.0

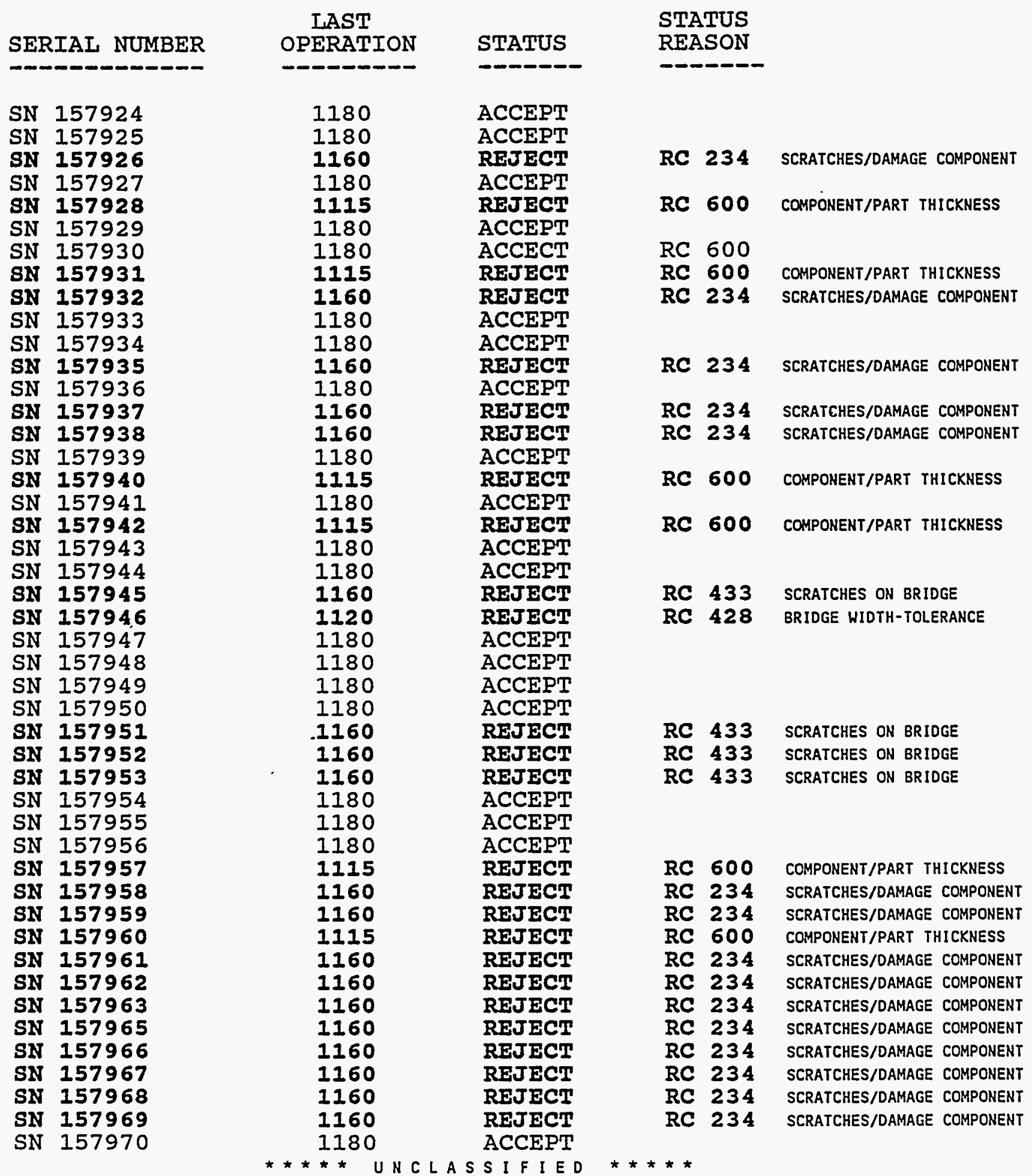




\section{Serial Number Acceptance Report}

PRODUCT : HC3926 BRIDGE

PRODUCT AO : A05764

ORAWING HO. :

REEL
: R377-02
LoT : E10235

SUFFIX:
TUESDAY, JUNE 5, 1990 3:09 PM *

PAGE NO: 5 TRAVELER ID: 1227

SYSTEM: PROCODE SYSTEM

DSA\# 871860-G Version 5.0

\section{SERIAL NUMBER}

- - - - - - - -

SN 157971

SN 157972

SN 157973

SN 157974

SN 157975

SN 157976

SN 157977

SN 157978

SN 157979

SN 157980

SN 157981

SN 157982

SN 157983

SN 157984

SN 157985

SN 157986

SN 157987

SN 157988

\section{LAST}

OPERATION

- - - - -

1160

1160

1180

1160

1160

1160

1180

1180

1160

1160

1115

1115

1115

1115

1160

1160

1115

1115

\section{STATUS}

REJECT

REJECT

ACCEPT

REJECT

REJECT

REJECT

ACCEPT

ACCEPT

REJECT

REJECT

REJECT

REJECT

REJECT

REJECT

REJECT

REJECT

REJECT

REJECT
STATUS

REASON

- - - -

RC 234 SCRATCHES/DAMAGE COMPONENT

RC 234 SCRATCHES/DAMAGE COMPONENT

RC 234 SCRATCHES/DAMAGE COMPONENT

RC 234 SCRATCHES/DAMAGE COMPONENT

RC 234 SCRATCHES/DAMAGE COMPONENT

RC 234 SCRATCHES/DAMAGE COMPONENT RC 234 SCRATCHES/DAMAGE COMPONENT

RC 600 COMPONENT/PART THICKNESS

RC 600 COMPONENT/PART THICKNESS

RC 600 COMPONENT/PART THICKNESS

RC 600 COMPONENT/PART THICKNESS

RC 234 SCRATCHES/DAMAGE COMPONENT

RC 234 SCRATCHES/DAMAGE COMPONENT

RC 600 COMPONENT/PART THICKNESS

RC 600 COMPONENT/PART THICKNESS

Serial Number Summary:

\begin{tabular}{lrrr} 
Good & $:$ & 105 & $51.98 \%$ \\
Rejected & $:$ & 97 & $48.02 \%$ \\
Dispositioned : & 0 & $0.00 \%$ \\
\hline Total & 202 &
\end{tabular}




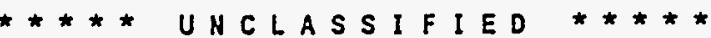

\section{Status Verification Report}

PRODUCT : MC3926 BRIDGE

PRODUCT AO : A05764

ORAWING NO. :

REEL
LOT : E10235

SUFFIX:
TUESDAY, JUNE 5, $1990 \quad 3: 24$ PM

PAGE NO: 2 TRAVELER ID: 1227

SYSTEH: PROCOOE SYSTEH

DSA\# 871860-G Version 5.0

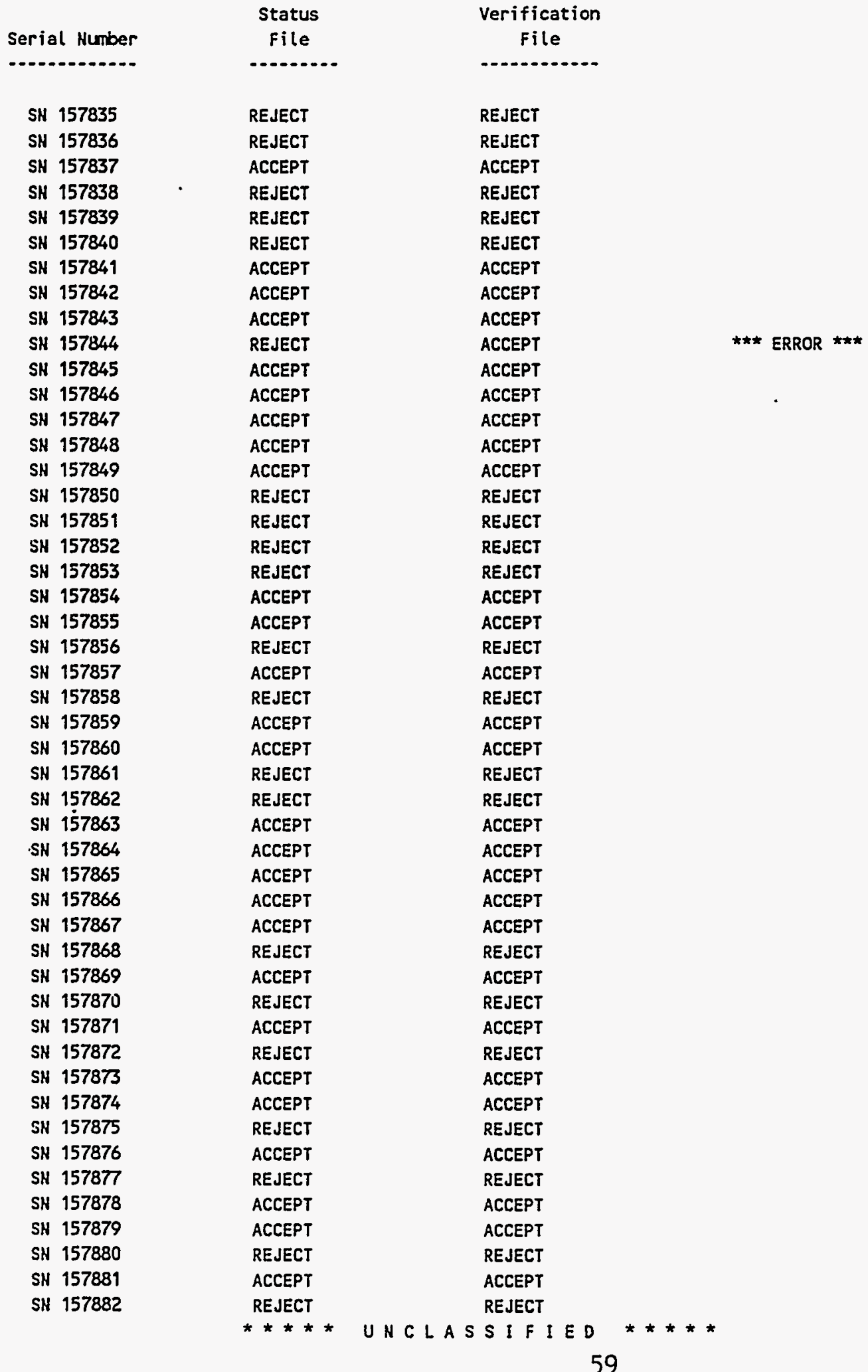




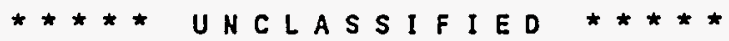

Status Verification Report

PRODUCT : MC3926 BRIDGE

PRODUCT AO : $A 05764$

DRAWING HO.:

REEL
TUESDAY, JUNE 5, $1990 \quad 3: 12$ PM

PAGE NO: 1 TRAVELER ID: 1227

SYSTEM: PROCOOE SYSTEM

DSA\# 871860-G Version 5.0

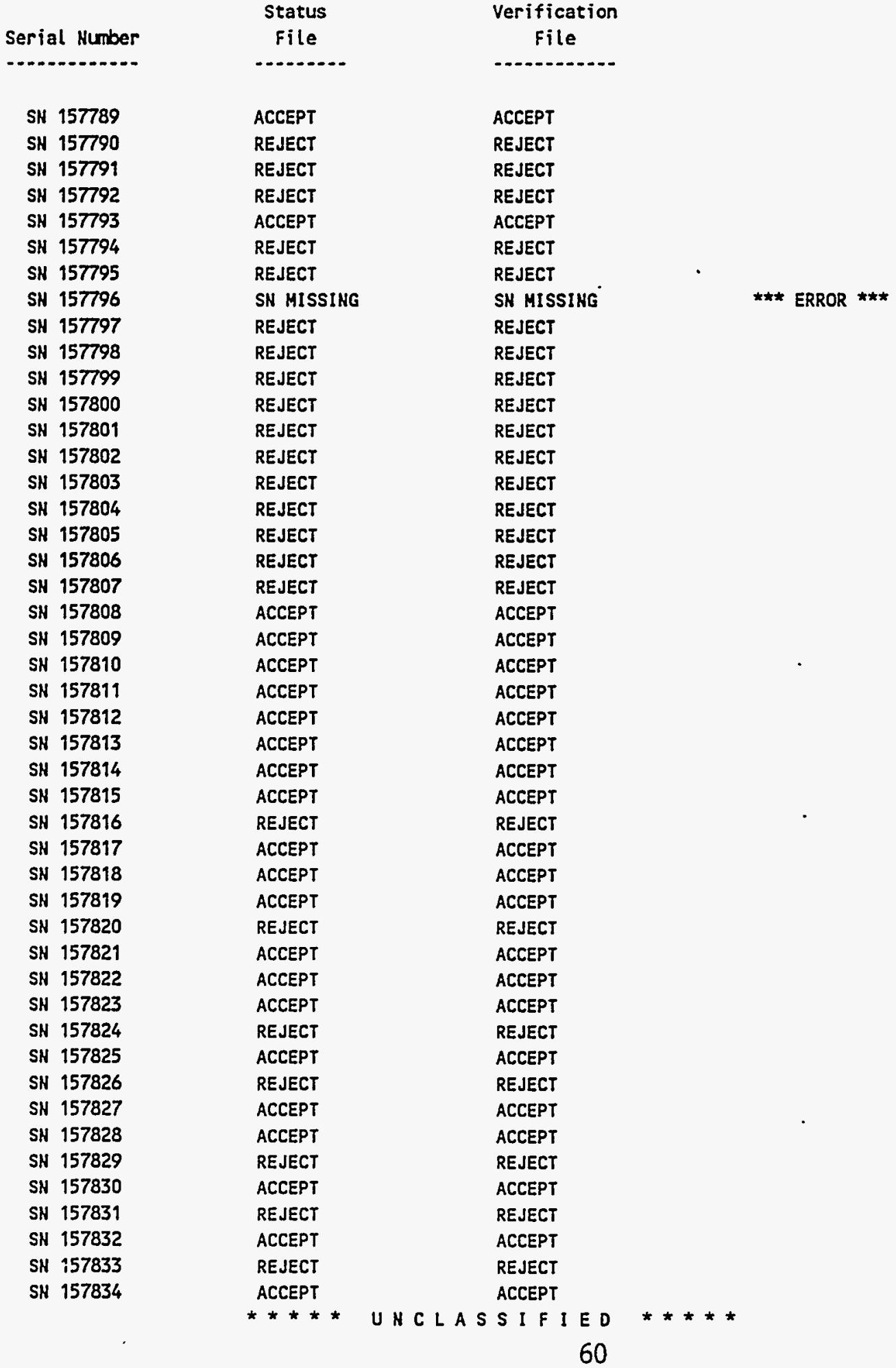


Upload Filename: P: \TAPE\F3754,TXT

\section{OPERATIONS OPLOADED}

$\begin{array}{llll}\text { A06303 } & \text { L00005 } & \text { R744-02 } & 1155 \\ \text { A05764 } & \text { L00007 } & \text { R397-04 } & 1190 \\ \text { A05764 } & \text { I00007 } & \text { R397-04 } & 1190 \\ \text { A05764 } & \text { L00007 } & \text { R397-04 } & 1190 \\ \text { A05764 } & \text { L00007 } & \text { R397-04 } & 1190 \\ \text { A05764 } & \text { L00007 } & \text { R397-04 } & 1190 \\ \text { A05764 } & \text { L00007 } & \text { R397-04 } & 1190 \\ \text { A05716 } & \text { L00007 } & \text { R009-0 } & 1300 \\ \text { A05716 } & \text { L00007 } & \text { R009-00 } & 1300\end{array}$

\section{OPERATIONS NOT UPLOADED AND MISC. ERRORS}

** FRAGMENTED DATA RECOPIED FROM: OG , 1155 .

A05716 L00007 R021-00 1275

A05716 L00007 R021-00 1275

A05716 L00007 R022-00 1275

A05716 L00007 R009-00 1300 SH C16448 *** ERROR *** A05716 L00007 R009-00 1300 SH C16411 *** ERROR *** A05716 L00007 R009-00 1300 SH C16433 *\# ERROR *** A05716 L00007 R009-00 1300 SH C16454 * ERROR ** A05716 L00007 R009-00 1300 SH C16443 *\#* ERROR *** A05716 L00007 R009-00 1300 SH C16446 ERROR *\#* A05716 L00007 R009-00 1300 SH C16452 ** ERROR *** A05716 L00007 R009-00 1300 SH C16410 *** ERROR *\#* A05716 L00007 R009-00 1300 SN C16422 *** ERROR *** A05716 L00007 R009-00 1300 SH C16407 *** ERROR *** A05716 L00007 R009-00 1300 SN C16451 *** ERROR *** A05716 L00007 R005-00 1400

SERIAL NUMBER REJECTED THICE SERIAL NUMBER REJECTED THICE SERIAL NUMBER REJECTED THICE SERIAL NUMBER REJECTED THICE SERIAL NUMBER REJECTED THICE SERIAL NUABER REJECTED THICE SERIAL NUMBER REJECTED TUICE SERIAL NUMBER REJECTED THICE SERIAL NUMBER REJECTED TWICE SERIAL NUMBER REJECTED THICE SERIAL NUMBER REJECTED THICE 


\begin{tabular}{|c|c|}
\hline PROD & A05716 \\
\hline LOT & $\llcorner 00007$ \\
\hline HP & 2522 \\
\hline GRPVAL & $R 021-00$ \\
\hline GRPHAM & REEL \\
\hline RUBBER $1 / 8$ & QC\# 52158-A1 \\
\hline RUB8ER ST & QC\# 52194-A1 \\
\hline RUBBER $1 / 32$ & $Q C \# 51501-A 1$ \\
\hline PROD & A05716 \\
\hline LOT & 100007 \\
\hline HP & 5530 \\
\hline GRPVAL & $R 021-00$ \\
\hline GRPNAM & REEL \\
\hline RUBBER $1 / 8$ & QC\# 52158-A1 \\
\hline RUBBER ST & QC\# 52194-A1 \\
\hline RUBBER $1 / 32$ & OC\# 51501-A1 \\
\hline PROO & A05716 \\
\hline LOT & L00007 \\
\hline HP & 5530 \\
\hline GRPVAL & $\mathrm{R} 022-00$ \\
\hline GRPHAM & REEL \\
\hline RUBBER $1 / 8$ & OC\# 52158-A1 \\
\hline RUBBER ST & QC\# 52194-A1 \\
\hline RUBBER $1 / 32$ & QC\# 51501-A1 \\
\hline EXIT & $A L L$ \\
\hline RES.LOWER.LIMIT & .051 \\
\hline RES.UPPER . LIMIT' & .059 \\
\hline PROD & A05716 \\
\hline LOT & L00007 \\
\hline GRPNAM & REEL \\
\hline GRPVAL & R005-00 \\
\hline HP & 2252 \\
\hline OPERATOR \#2 & 2522 \\
\hline PART SN & SN 204340 \\
\hline *FIXTURE\# & A \\
\hline PART SN & SH 204337 \\
\hline *FIXTURE\# & B \\
\hline PART SN & SN 204335 \\
\hline
\end{tabular}

$>18: 13: 24 \quad 05 / 18 / 90$ $>18: 13: 2405 / 18 / 90$ $>18: 13: 2405 / 18 / 90$ $>18: 13: 24 \quad 05 / 18 / 90$ $>18: 13: 24 \quad 05 / 18 / 90$ $>18: 13: 24 \quad 05 / 18 / 90$ $>18: 13: 24$ 05/18/90 $>18: 13: 24 \quad 05 / 18 / 90$ $>18: 14: 22 \quad 05 / 18 / 90$ $>18: 14: 22 \quad 05 / 18 / 90$ $>18: 14: 22 \quad 05 / 18 / 90$ $>18: 14: 22 \quad 05 / 18 / 90$ $>18: 14: 22 \quad 05 / 18 / 90$ $>18: 14: 22 \quad 05 / 18 / 90$ $>18: 14: 23 \quad 05 / 18 / 90$ $>18: 14: 23 \quad 05 / 18 / 90$ $>18: 14: 24 \quad 05 / 18 / 90$ $>18: 14: 24 \quad 05 / 18 / 90$ $>18: 14: 24 \quad 05 / 18 / 90$ $>18: 14: 24 \quad 05 / 18 / 90$ $>18: 14: 24 \quad 05 / 18 / 90$ $>18: 14: 24 \quad 05 / 18 / 90$ $>18: 14: 2405 / 18 / 90$ $>18: 14: 24 \quad 05 / 18 / 90$

$>31: 10: 25 \quad 05 / 31 / 90$

$>30: 15: 43 \quad 05 / 30 / 90$ $>30: 15: 43 \quad 05 / 30 / 90$

$>05: 08: 08 \quad 06 / 05 / 90$ $>05: 08: 08 \quad 06 / 05 / 90$ $>05: 08: 08 \quad 06 / 05 / 90$ $>05: 08: 08 \quad 06 / 05 / 90$ $>05: 08: 08 \quad 06 / 05 / 90$ $>05: 08: 08 \quad 06 / 05 / 90$ $>05: 08: 18 \quad 06 / 05 / 90$ $>05: 08: 18 \quad 06 / 05 / 90$ $>05: 08: 20 \quad 06 / 05 / 90$ $>05: 08: 20 \quad 06 / 05 / 90$ $>05: 08: 24 \quad 06 / 05 / 90$ 


\begin{tabular}{|c|c|c|}
\hline & & \\
\hline$c^{2}$ & 1400 & SH C \\
\hline & 400 & ( \\
\hline & 400 & 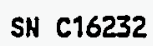 \\
\hline & 400 & 433 \\
\hline & 400 & 623 \\
\hline & 400 & 20433 \\
\hline & 400 & N $C 1623$ \\
\hline & 400 & N 20433 \\
\hline & 400 & N Cं1623 \\
\hline & 1400 & iN 20432 \\
\hline & 1400 & SH C1623 \\
\hline & 1400 & SH 204327 \\
\hline & 1400 & N C16237 \\
\hline & 1400 & SN 204320 \\
\hline & 1400 & SH C1623 \\
\hline & 1400 & SN 20432 \\
\hline & 1400 & SH C1623S \\
\hline & 1400 & SN 20432 \\
\hline & 1400 & SH C16240 \\
\hline & 1400 & SH 204314 \\
\hline & 1400 & - \\
\hline & 1400 & SN 20431 \\
\hline & 1400 & SH C1624 \\
\hline & 1400 & SN 20431 \\
\hline & 1400 & SH C16243 \\
\hline & 1400 & SH 20430 \\
\hline & 1400 & SH C1624 \\
\hline & 1400 & SH 204308 \\
\hline & 1400 & SH $C 1624$ \\
\hline of & 1400 & SN 20430 \\
\hline & 1400 & SN C1624 \\
\hline & 1400 & SH 20426 \\
\hline o & 1400 & SH C16245 \\
\hline oF & 1400 & SH 20426 \\
\hline of & 1400 & SH C1625 \\
\hline of & 1400 & SH 20426 \\
\hline pr & 1400 & SN $C 1625$ \\
\hline pF & 1400 & SH 204262 \\
\hline r & 1400 & 1625 \\
\hline 6 & 1400 & 0426 \\
\hline & 1400 & 1625 \\
\hline & 1400 & \\
\hline
\end{tabular}

\begin{tabular}{|c|c|}
\hline *FIXTURE\# & C \\
\hline PART SN & SH 204334 \\
\hline *FIXTURE\# & A \\
\hline PART SH & SN 204333 \\
\hline *FIXTURE\# & B \\
\hline PART SH & SH 204331 \\
\hline *FIXTURE\# & C \\
\hline PART SN & SH 204330 \\
\hline *FIXTURE\# & A \\
\hline PART SN & SN 204329 \\
\hline *FIXTURE\# & B \\
\hline PART SH & SH 204327 \\
\hline \#FIXTURE\# & C \\
\hline PART SH & SH 204326 \\
\hline *FIXTURE\# & A \\
\hline PART SH & SN 204325 \\
\hline *FIXTURE\# & B \\
\hline PART SH & SH 204321 \\
\hline •FIXTURE\# & C \\
\hline PART SH & SH 204314 \\
\hline "FIXTURE\# & A \\
\hline PART SK & SH 204312 \\
\hline \#FIXTURE\# & B \\
\hline PART SH & SH 204311 \\
\hline •FIXTURE\# & C \\
\hline PART SN & SN 204309 \\
\hline *FIXTURE\# & A \\
\hline PART SN & SN 204308 \\
\hline *FIXTURE\# & 8 \\
\hline PART SN & SH 204307 \\
\hline *FIXTURE\# & A \\
\hline PART SH & SN 204267 \\
\hline *FIXTURE\# & C \\
\hline PART SN & SN 204266 \\
\hline *FIXTURE\# & A \\
\hline PART SN & SH 204264 \\
\hline *FIXTURE\# & C \\
\hline PART SN & SH 204262 \\
\hline *FIXTURE\# & A \\
\hline PART SN & SH 204264 \\
\hline \#FIXTURE\# & C \\
\hline PART SH & SN 204262 \\
\hline *FIXTURE\# & A \\
\hline
\end{tabular}

$>05: 08: 24 \quad 06 / 05 / 90$ $>05: 08: 3406 / 05 / 90$ $>05: 08: 34$ 06/05/90 $>05: 08: 4306 / 05 / 90$ $>05: 08: 43$ 06/05/90 $>05: 08: 46 \quad 06 / 05 / 90$ $>05: 08: 4606 / 05 / 90$ $>05: 09: 4706 / 05 / 90$ $>05: 09: 4706 / 05 / 90$ $>05: 09: 59$ 06/05/90 $>05: 09: 59 \quad 06 / 05 / 90$ $>05: 10: 00 \quad 06 / 05 / 90$ $>05: 10: 00 \quad 06 / 05 / 90$ $>05: 10: 03$ 06/05/90 $>05: 10: 03$ 06/05/90 $>05: 10: 06 \quad 06 / 05 / 90$ $>05: 10: 06 \quad 06 / 05 / 90$ $>05: 10: 09 \quad 06 / 05 / 90$ $>05: 10: 0906 / 05 / 90$ $>05: 10: 1206 / 05 / 90$ $>05: 10: 12 \quad 06 / 05 / 90$ $>05: 10: 1406 / 05 / 90$ $>05: 10: 14$ 06/05/90 $>05: 10: 18 \quad 06 / 05 / 90$ $>05: 10: 18 \quad 06 / 05 / 90$ $>05: 10: 3506 / 05 / 90$ $>05: 10: 3506 / 05 / 90$ $>05: 10: 3906 / 05 / 90$ $>05: 10: 39$ 06/05/90 $>05: 10: 4606 / 05 / 90$ $>05: 10: 46 \quad 06 / 05 / 90$ $>05: 10: 4906 / 05 / 90$ $>05: 10: 4906 / 05 / 90$ $>05: 10: 55 \quad 06 / 05 / 90$ $>05: 10: 5506 / 05 / 90$ >05:12:45 06/05/90 $>05: 12: 45 \quad 06 / 05 / 90$ $>05: 12: 47$ 06/05/90 $>05: 12: 4706 / 05 / 90$ $>05: 12: 4506 / 05 / 90$ $>05: 12: 45 \quad 06 / 05 / 90$ $>05: 12: 47$ 06/05/90 $>05: 12: 47$ 06/05/90 
EXHIBIT 4

Description

Page (s)

Sample Data Specifications Document

$65-68$ 


\section{SYSTEM DATA}

\subsection{ELECTRICAL MEASUREMENT DATA}

The ELECTRICAL MEASUREMENT station will supply the iollow data to the Cell supervisor:

operation number

$\square$ cable product number

$\square$ cable lot number

$\square$ HP number of the operator

$\square$ cable serial number

$\square$ specification limits

$\square$ uncorrected resistance

$\square$ corrected resistance

$\square$ inductance

room temperature

$\square$ §-32 character lines for comments

\subsection{DATA FORMAT}

ELECTRICAL MEASUREMENT station data format for communications with the PROCODE System.

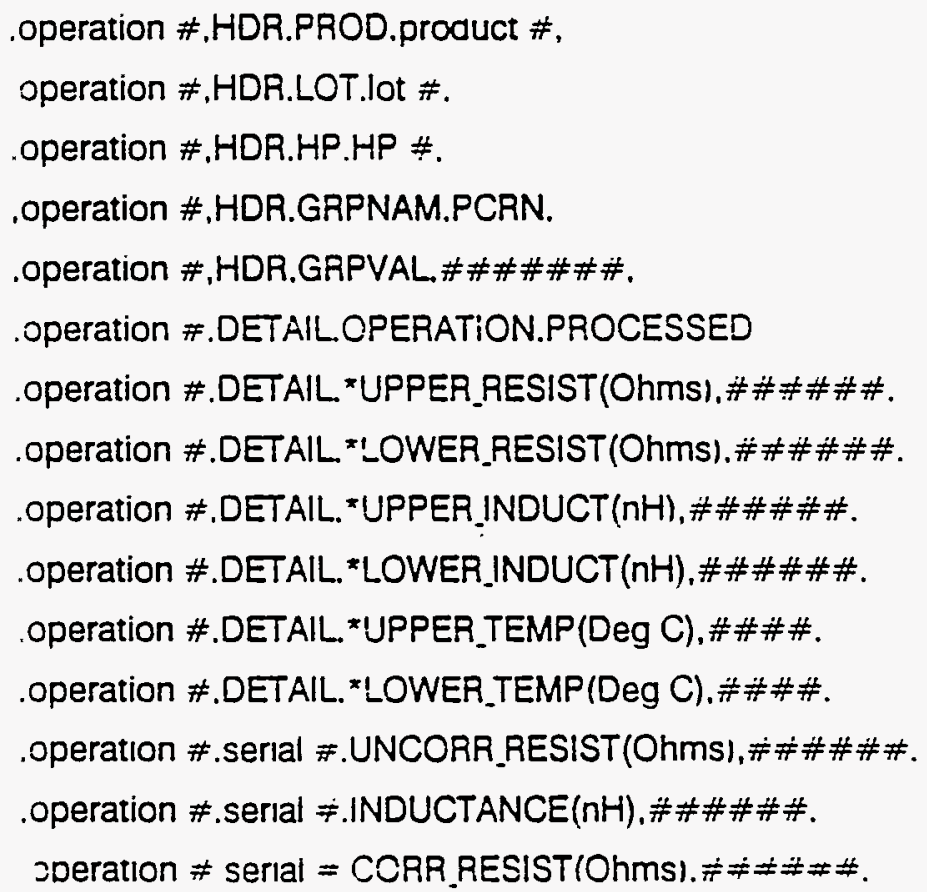


.operation \#,serial \#,ROOM_TEMP(Deg C),

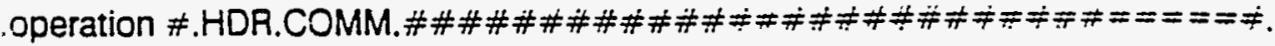
operation \#.HDR.COMPLETE.O,

Yote:

operation \# cable product \# cable lot \# $\mathrm{HP}$ \#
$=1757$

$=$ A04235 or AOCALB (Calibration)

$=\mathrm{L} 00123$ or E00123 (e-order)

= operator's HP number

\subsection{PROCESS PARAMETERS}

Three upper and lower specification limits are used by the automated workstation to determine the fitness of the part being tested. They are as follows.

\begin{tabular}{|c|c|c|c|c|c|c|c|}
\hline Product & Reaistance & Ind & verance & & Tected To & Alpha & $\begin{array}{c}\text { Room } \\
\text { Temperature }\end{array}$ \\
\hline Actuator (MC 3738) & $3.870-4.280 \Omega$ & & MA & $\vdots$ & $25^{\circ} \mathrm{C}$ & .003850 & $20-27^{\circ} \mathrm{C}$ \\
\hline Det Assembly (MC 3739) & $55.000-85.000 \mathrm{~m} \Omega$ & $6.0-$ & $120 \eta H$ & $i$ & $23^{\circ} \mathrm{C}$ & .003800 & $20-27^{\circ} \mathrm{C}$ \\
\hline Det Assembly (MC 3740) & $|105.000-135.000 \mathrm{~m} \Omega|$ & 25.0 & $31.0 \eta \mathrm{H}$ & & $23^{\circ} \mathrm{C}$ & .003800 & $20 \cdot 27^{\circ} \mathrm{C}$ \\
\hline Hemi-Det (MC3510) & $0.071 \cdot 0.187 \Omega$ & $30.0-$ & $38.0 \eta \mathrm{H}$ & & $23^{\circ} \mathrm{C}$ & $! .003746$ & $20 \cdot 27^{\circ} \mathrm{C}$ \\
\hline Hem1-Det (MC3510) & $0.151 \cdot 0.180 \Omega$ & 60.0 & $75.0 \eta \mathrm{H}$ & & $23=C$ & .003746 & $20 \cdot 27^{\circ} \mathrm{C}$ \\
\hline MC 4094 & & & & & & ' & \\
\hline MC 4096 & & & & & & . & \\
\hline
\end{tabular}

Tüble i. Electrical Measurement Specirication Limits.

The above process parameters are controiled under the DSA rension number and are stored in an ASCII file (EL.M.PRM).

\subsubsection{MODIFYING PROCESS PARAMETERS}

\section{YOTE:}

The following procedure is valid only when the sysiem is in non "WR" mode. (The header information indicates calibration or engineering evaluation mode. see secrion 3.2 and 3.3.)

The electrical measurement specification limits mav be modified if the process requires. The parameters may be changed by pressing the $F 2$ key while the command line is displayed. When ine $F \geq$ key is pressed. a left arrow may be seen to the right of the command menu. This must be followed by pressing $P$ within six seconds or 
the systems goes back to command mode. Enter the password at the prompt.

A screen is displayed. allowing the entry of new parameters.

When input is complete the new parameters may be saved and the parameter file updated or the changed ignored (see figure 7).

A prompt will be displayed after the last parameter is entered. This allows the user to save $(S)$, modify $(M)$ or abort $(A)$ the modifications to the specification file. Selecting save will update the test parameter file only (ELM.TST).

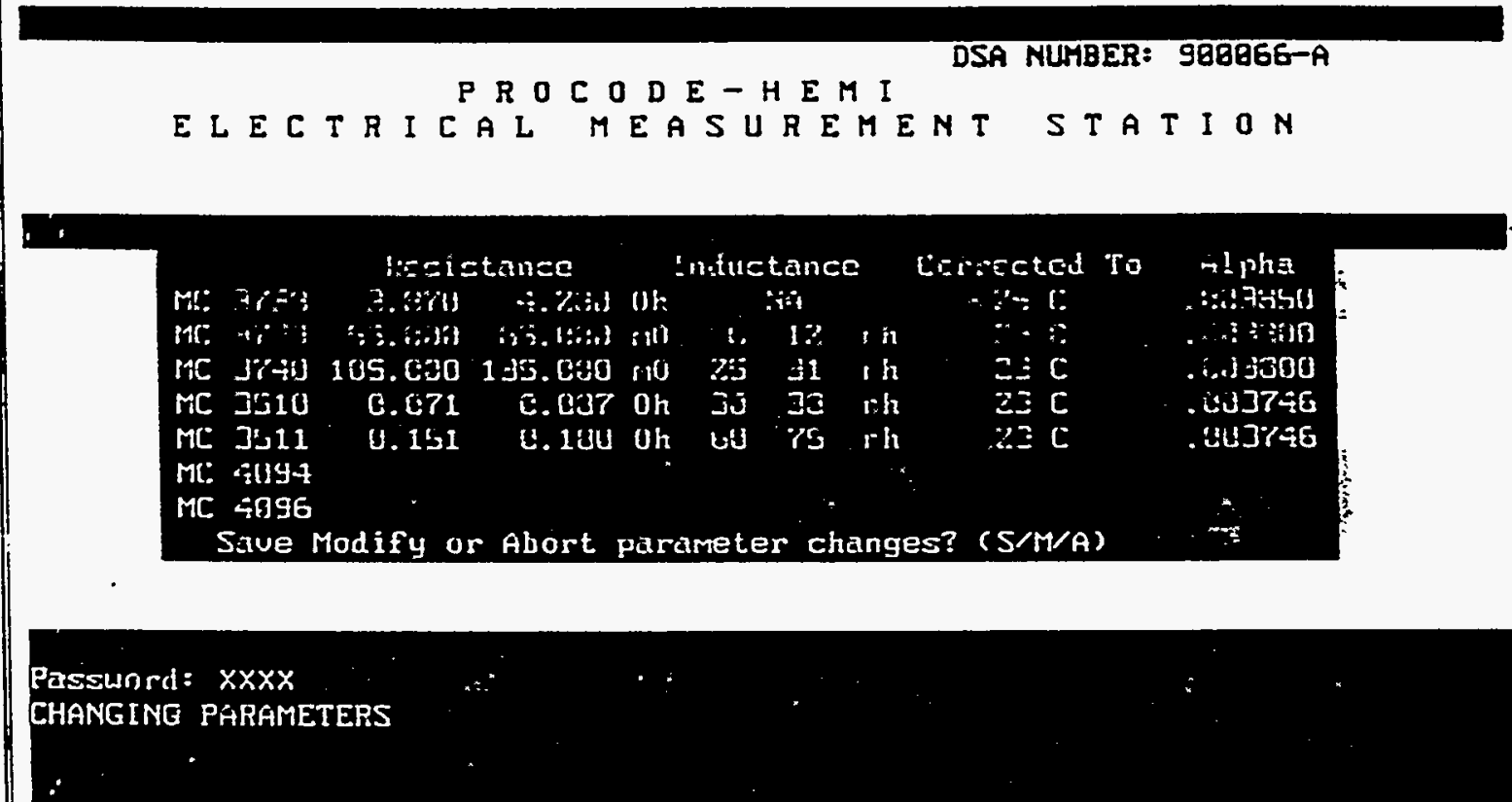

figure 7. Parameter Modification Screen.

\subsection{EXAMPLE RECORDS}

The following are examples of record whicn would be sent to the Cell Supervisor.

\subsubsection{SYSTEM START-UP}

1757,HDR,PROD,A04236.

i757.HDR.LOT.LO0123.

:757.HDR.HP.5370.

: 757.HDR.GRPNAM.PCRN.

1757.HDR.GRPVAL.C12346. 
1757,DETAILOPERATION,PROCESSED

1757,DETAIL *UPPER_RESIST(Ohms),\#\#\#\#\#\#.

,1757,DETAIL *LOWER_RESIST(OhmS),\#\#\#\#\#.

,1757,DETAIL_UPPER_INDUCT(nH),\#\#\#\#\#\#,

,1757,DETAIL_LOWER_INDUCT(nH),\#\#\#\#\#\#.

,1757,DETAIL_UPPER_TEMP(Deg C),\#\#\#\#,

,1757,DETAIL_LOWER_TEMP(Deg C),\#\#\#\#,

1757,HDR,COMPLETE,0,

\subsubsection{DURING THE TESTING OPERATION}

,1757,HDR,PROD.A04236,

.1757,HDR,LOT,L00123,

,1757,HDR,HP,5370,

,1757,HDR,GRPNAM,PCRN,

1757,HDR,GRPVALC12346,

,1757,SN 12345,UNCORR_RESIST(Ohms),\#\#\#\#\#\#,

1757,SN 12345,INDUCTANCE(nH), \#\#\#\#\#\#,

1757.SN 12345,CORR_RESIST(Ohms),\#\#\#\#\#,

,1757.SN 12345,ROOM_TEMP(Deg C),\#\#\#\#\#\#.

or (For rejected parts)

1757,SN 12345,REJECT CODE,RC 1234,

,1757.SN 12345,UNCORR_RESIST(Ohms),\#\#\#\#\#,

.1757,SN 12345,INDUCTANCE(nH),\#\#\#\#\#,

.1757,SN 12345,CORR_RESIST(Ohms),\#\#\#\#\#.

, 1757.SN 12345.ROOM_TEMP(Deg C),\#\#\#\#\#,

1757,HDR,COMPLETE,0,

\subsubsection{SYSTEM SHUTDOWN}

, 7557, HDR,PROD,A04236.

i 757,HDR.LOT.LO0123.

1757.HDR.HP.5370,

.1757. HDR,GRPNAM.PCRN,

1757.HDR.GRPVAL.C12346,

1757.HDR.COMM.\#\#\#\#\#\#\#\#\#\#\#\#\#\#\#\#\#\#\#\#\#\#\#\#\#\#\#\#\#\#\#\#, .1757,HDR,COMPLETE.0. 
EXHIBIT 5

Description

RGF Data Collection Program written in IRL
Page (s)

$70-80$ 
: Program Name Drawing \#

Issue

Created BY

Creation Date

Revised By

Revision Date
HEMI03.IRL

DSA 891081

C

Suzanne M. Crabtree

06-Jul-89

Suzanne M. Crabtree (ACO 900066MD)

01-Feb-90 - 4 digit reject codes

- add PVD run number prompt

- send record with cable SN/PVD Run association

- add Op 1862 (A04242) Head Handling

Revised By

Suzanne M. Crabtree (ACO 900282MD)

Revision Date : 18-Apr-90 - prompt for rejects on oper 1862

Description

: This operation will prompt the operator for the relati record of assembly information including product, lot, operation, HP\#, clean\# and comments

Numeric Registers ...

$\# 0$ - not used

$\# 1$ - used in. COMENT

$\# 2$ - not used

$\# 3$ - not used

$\# 4$ - not used

$\# 5$ - not used

$\# 6$ - not used

$\# 7$ - used in. SN to count \# of Header SN's entered

$\# 8$ - used in. SN to count \# of cable SN's entered

$\# 9$ - used in. REJN to count \# of rejects entered
File $D$ usage description...
$D(0)$ - Current Product
D( 1) - Current Lot
$D(2)$ - Current operation
$D(3)$ - Current HP \#
$D(4)$ - Current Prod/Lot/Oper
D( 5) - Current Clean.\#
$D(6)$ - DSA Number - Issue
D( 7$)$ - IRI Program Name
D $(8)-$ PVD Run \#

OD $(10,16)$

OR $(1000,10)$

: Open File For Product, Lot storage

$\begin{array}{ll}\text { OS }(1000,5) & : \text { file of entered cable serial numbers (bytes 1-5) } \\ \text { OT }(1000,5) & \text { : file of entered header serial numbers (bytes 1-5) }\end{array}$

$D D(\sigma)=$ "DSA891081-C" : Define DSA Number and Issue of this progra

$D D(7)=$ "HEMI03"

: Define Name of this program

: $S$. CONFIG

START

D $\# 7=0$
$D=1=0$
$D=49=0$

: Define number of $S N$ entered to zero

HP

: Define number of rejects entered to zero

$D S O=D(6)+"$ "

D $\$ 0=\$ O+D(7)$

$\mathrm{D} \$ 0=\$ 0+"$ Scan HP"

$P$ \$O

D $\$ 0=" 1 "$

:prompt for verification of 


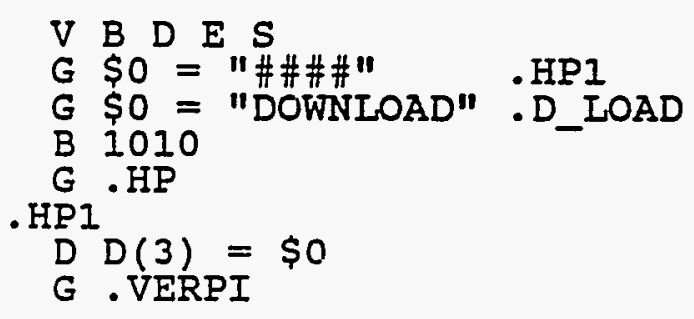

.VERPI

$D \$ 0=$ "Does " $+D(6)$

D $\$ 0=\$ 0+$ Match PI? $(Y / N)$ ".

P $\$ 0$

D $\$ 0=" n$

A

$G \$ O=$ "Y .VERPIEN

:prompt for verification of

$G \$ O=$ "Y" VERPIEN

G $\$ 0=$ "EXIT" .VERPI01

$G \$ O=$ "BACK" . HP

B 000

' $\mathrm{P}$ "*** Consult $* * * * * *$ Manual $* * *$ "

$S$.WAIT

G .START

- VERPIOI

$S$.EXIT H

$G \$ O=\pi Y "$.START

G $\$ 0=" N "$.VERPI

$P$ "Error In . VERPI contact PC\&DA "

G.ERROR

- VERPIEN

G . OPER

. OPER

P "Scan Operation \#From Menu "

D $\$ 0=$

$G$ \$O = "OI160" .OPEREN

G $\$ 0=$ "O1862" .OPEREN

$G \$ O=$ "EXIT" .OPEROI

$G$ $\$ O=$ "BACK" .VERPI

B 1010

$G$.OPER

. OPER01

. S .EXITH

$\mathrm{G}$ \$O $=\pi_{\mathrm{Y}} "$.START

$G \$ O=" N "$.OPER

p "Error In . OPER Contact PC\&DA " G .ERROR

. OPEREN

$D D(2)=\$ 0 R 4$

G.PRLOT

. PRLOT

P "Scan Product LotFrom Label

:swage pin and inspect

: program's drawing\#-issue

$U$ E D W

$G \$ O=$ "A04235e\#\#\#\#\#".PRLOT02

$\mathrm{G} \$ 0=$ "A04236e\#\#\#\#". PRLOT02

G $\$ 0=$ "A04242e\#\#\#\#\#".PRIOT02

G $\$ 0=$ "EXIT" .PRLOTOI

$G \$ O=$ "BACK" .OPER

B 1010

G. PRLOT

- PRLOTOI

$\mathrm{S}$. EXIT $\mathrm{H}$

G $\$ 0=\pi Y "$.START

G $\$ O=" \mathrm{~N} "$. PRLOT

P "Error In . PRLOT contact PC\&DA "

G. ERROR 
$D D(0)=\$ 0$ I 6

$D D(I)=\$ 0 R 6$

$D(4)=\$ 0+D(2)$

$G D(4)=$ "A04235e\#\#\#\#1160". PRLOT03

G $D(4)=$ "A04236 e\#\#\#\#\#1160". .PRLOT03

G $D(4)=$ "A04242 E\#\#\#\#\#1862". .PRLOTO3

B 000

D $\$ O=$ "Cannot Perform Oper\# " + D(2)

D $\$ 0=\$ 0+"$ Here"

$P$ \$O

$S$. WAIT

G.PRIOT

. PRLOTO3

$\mathrm{D} \$ 3=$ =HDR, PROD," $+\mathrm{D}(0)$

S . SEND

$\mathrm{D} \$ 3=$ "HDR, LOT, " $\quad+D(1)$

S . SEND

$\mathrm{D} \$ 3=$ "HDR, HP," $\mathrm{H}(3)$

$S$.SEND

$G \dot{D}(0)=" A 04242 "$.GPVD

G . PCNUM

- PCNUM

P "Scan Clean Run \#From Label "

$\mathrm{D} \$ \mathrm{O}=\| "$

U $\mathrm{D} W$

$G \$ O=$ "C\#\#\#\#\#" . PCNUM3

$G \$ O=$ "EXIT" .PCNUM2

$\mathrm{G} \$ 0=$ "BACK" $\quad$.PCNUMI

B 1010

G . PCNUM

- PCNUMI

$\mathrm{D} \# 2=3$

$S$. BACK

G.PRLOT

- PCNUM2

$S$ EXIT

$G \dot{\$} O=$ "Y" .START

$G \$ O=" N "$. PCNUM

$P$ "Error In . PCNUM contact PC\&DA "

G . ERROR

. PCNUM3

$D D(5)=\$ 0$

$D \$ 3=$ "HDR, GRPVAL, " + D(5)

: Valid product, lot, oper scanne

: send product record

: send lot record

: send HP record

: goto PVD prompt

$S$.SEND

: Do operation sequence check here someday

D $\$ 3=$ "HDR, GRPNAM, PCRN"

$S$.SEND

G . MAIN

.GPVD

P "Scan PVD Run \# From Label."

$\mathrm{D} \$ 0=\| "$

U E D W

$G \$ O=" \# \# \# \# "$.GPVD2

$\mathrm{G} \$ 0=$ "EXIT" .GPVDI

B 1010

G.GPVD

. GPVDI

$S$.EXIT

$G$ SO = "Y" .START

$G \$ 0=" N "$.GPVD

$P$ "Error In . GPVD contact PC\&DA " G . ERROR

$D D(8)=\$ 0$

D $\$ 3=$ "HDR, GRPVAL, " + D(8)

: Save Product code

: Save Iot Number

: Save Prod/Lot/Oper 


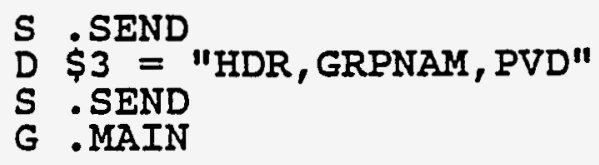

- MAIN

$G D(4)=$ "A04235e\#\#\#\#\#160". MAINI

$G D(4)=" A 04236$ e\#\#\#\#1160".MAINI

$G D(4)=$ "A04242E\#\#\#\#\#1862" .MAINEND

$P$ "PRODUCT CODE ERROR-GET HEIP" G . ERROR

- MAINI

S. .02706

$S$.PVD

S . SNOO

G MAINEND

- MAINEND

$S$. 4SREJ

$S$. COMENT

$S$. OPERPRO

G . END

. $Q C 2706$

$D \$ 0=" 1 "$

$P$ "ADHESIVE A04381 Scan QC\#"

A

G $\$ 0=" \# \# \# \#-? ? " .0 C 2706 \mathrm{~A}$

$G$ \$O = "EXIT" .QC2706B

B 1010

G . QC2706

. QC2706A

$\mathrm{D} \$ 3=$ "PN A04381, ADHESIVE,QC\#"+\$O

S . SEND

Q

. QC2 2706B

$S$. EXIT

G $\$ 0=$ "Y" .START

$G \$ 0=" N " . Q C 2706$

$P$ "Error In .QC2706Contact PC \& DA"

G . ERROR

- PVD

$P$ "Scan PVD Run \# From Label"

$D \$ 0=" 1$

U $D W$

$G$ \$O = "\#\#\#\#\#".PVD2

$G \$ 0=" E X I T " \quad$.PVD1

B 1010

G .PVD

. PVDI

$S$. EXIT

G $\$ O=$ "Y" .START

$G \$ O=" N "$. PVD

$P$ "Error In . PVD contact PC\&DA " G. ERROR

- PVD2

$D D(8)=\$ 0$

D $\$ 3=$ "DETAIL, PVD RUN\#," + D (8)

: save PVD \# in $D(8)$

$S$.SEND

Q

. SNOO

$\mathrm{D} \$ 0="$
$\mathrm{D} \$ 0=\$ 0+"$ Scan Cable $\mathrm{SN} "$

P $\$ 0$

SNOI

D $\$ 0=" 1$

. A 


$$
\begin{aligned}
& \text { G } \$ 0=\text { = \#\#\#\#". SNO3 } \\
& G \text { } \$ O=\text { "DONE" .SNEND } \\
& G \text { \$O }=\| " \text {.SNEND } \\
& \mathrm{G} \$ 0=\text { "EXIT" .SNO2 } \\
& G \$ 0=" P " 1 \text {.SN13 } \\
& \text { B } 1010 \\
& \text { G.SNOO }
\end{aligned}
$$

.SNO2

$S$.EXIT

$G \$ O=$ "Y" .START

$\mathrm{G} \$ 0=$ "N" .SNOO

$P$ i Error In.SN Contact PC\&DA "

G . ERROR

. SNO3

$\mathrm{D} \$ 2=" 1 "$

D $\$ 2=" S N "+\$ 0$

D $\# 8=\# 8+1$

$\mathrm{D} S(\# 8)=\$ 2 \mathrm{R} 5$

. SNO4

D $\$ 0=$ "Cable SN $"+s(\# 8)$

D $\$ 0=\$ 0+"$ Scan Header SN"

. SNO5

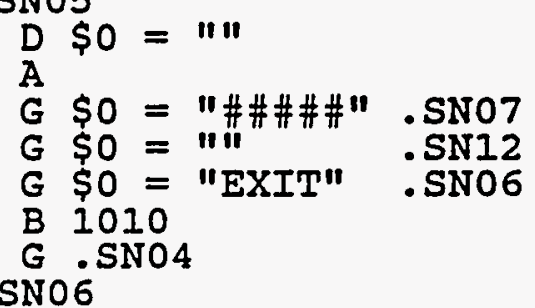

. SN06

$S$. EXIT

- G $\$ O=" Y "$.START

G $\$ 0=" N "$. . SNO4

$P$ " Error In .SN Contact PC\&DA "

G . ERROR

SN07

$\mathrm{D} \$ 2=" 1 "$

$\mathrm{D} \$ 2=" \mathrm{SN} "+\$ 0$

. SNO8

$D \# 7=\# 7+1$

SNO9

$D \$ 0=" C "+S(\# 8)$

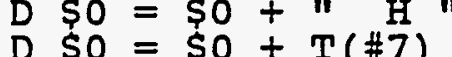

$\mathrm{D} \$ 0=\$ 0+"$ "Yes or No"

$P \$ 0$

D $\$ 0=\| "$

A

G $\$ 0=$ "Y" . SNIO

G $\$ 0=" N "$.SNII

B 1010

G . SNO9

SN10

D $\$ 3=" S N "+S(\# 8)$

D $\$ 3=\$ 3+", * A C C E P T$, INITIAI, $"$

$S$. SEND

D $\$ 3=" 11$

$\mathrm{D} \$ 3=" \mathrm{SN} "+\mathrm{S}(\# 8)$

D $\$ 2=\$ 3$

D $\$ 3=\$ 3+"$ HEADER SN,"

D $\$ 3=\$ 3+"$ SN "

$D \$ 3=\$ 3+T(\# 7)$

$P$ " SENDING CABIE \& HEADER SN's"

$S$.WAIT

S . SEND

D $\dot{\$} 3=\$ 2+"$, PVD RUN\#,"

:build the dbase file with good :cable serial numbers : save cable $\mathrm{SN}$ in $\$ 2$ for 2 nd record

:send the cable/header SN relationship :send the cable SN/PVD Run relationship 


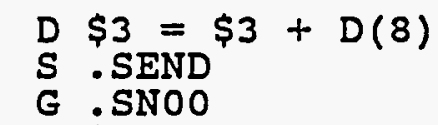

.SN11

$D$ SO = "DELETING $C "+S(\# 8)$

D $\$ 0=\$ O+"$ \& $\mathrm{H} "$

$D \$ 0=\$ 0+T(\# 7)$

$P \$ 0$

$S$.WAIT

$\mathrm{D} S(\# 8)=" \|$

D $\# 8=\# 8-1$

D $T(\# 7)=" 1 "$

D $\# 7=\# 7-1$

: delete the last cable and header : serial numbers located in files

:S (cables) and T (headers)

G . SNOO

: serial numbers were never sent to CS . SN12

D \$O = $" * * *$ DELETING $* * *$ Cable SN "

D $\$ 0=\$ 0+S(\# 8)$

P $\$ 0$

$S$.WAIT

D $S(\# 8)=" 11$

$D \# 8=\# 8-1$

G. $\mathrm{SNOO}$

. SN13

$S$. PVD

G. SNOO

- SNEND

$Q$

.4SREJ : enter serialized rejects using 4 digit reject codes

D
$P$ "AnY Rejects ?

A

G $\$ 0=$ "Y". 4SREJOI

G $\$ 0=$ "Y" . 4 SREJOI

G $\$ O=" N "$. ISREJEN

G $\$ O=" n "$. 4SREJEN

B 1010

G . 4SREJ

. 4SREJ0I

$G \# 9<1.4$ SREJ0 8

C $\$ 0=\# 9$

$G \# 0=0.4$ SREJ02

B 1010

.P "Bad Convert in .4SREJ get help"

G . 4SREJ01

. 4SREJ02

$D \# 0=[\$ 0]$

$G \# 0=1.4$ SREJ05

$G \# 0=2.4$ SREJO6

$G \# 0=3 \cdot$. $\#$ SREJ07

$G \# 0>2$. 4SREJ03

G $\# 0=0.4$ SREJO4

. 4SREJ03

B 1010

P "Too Many Rejects get help "

skip last SN stuff if first SN \#9 is number of rejects entered : see if \#9 converts properly to $\$ 0$ G . 4SREJO2

. 4 SREJ0 4

B 1010

$P$ "Bad Length in .SN get help" G . 4SREJ02

. 4SREJ05

$D \$ 0=" 0 "+\$ 0$

. 4SREJ06

$\mathrm{D} \$ 0=" 0 "+\$ 0$

. 4SREJ07

$\mathrm{D} \$ 0=\$ 0+" 1$

$\mathrm{D} \$ 0=\$ 0+R(\# 9)$ L 6

$D \$ 0=\$ 0+" 1 "$ "

: length $=1$

: get length of \# rejected integer

$D \$ 0=\$ 0+R(\# 9) R 4$

: complain if > 999 rejects

: 1000 rejects is probably too many

: except maybe for Tape Processing

: check for reasonableness length $=1$

: length $=2$

: prepend 0

: \$o is \# of rejects $\mathrm{w} /$ length $=3$

: add last SN scanned

: add last reject code scanned 75 
G . 4SREJ09

. 4SREJ08

$D \$ 0=" 1$

11

G . 4SREJ09

. 4SREJO9

D $\$ 0=\$ 0+"$ Scan Reject SN"

$\mathrm{P} \$ 0$

D $\$ 0=\| " 1$

A

G $\$ 0=$ = "\#\#\#\#" .4SREJ13

G $\$ O=$ "DONE" . .SREJEN

G $\$ 0=" \|$.4SREJEN

$G \$ O=$ "EXIT" .4SREJIO

G $\$ O=$ "BACK" . ASREJII

B 1010

G . 4SREJOI

. 4SREJ 10

$S$. EXIT

$\mathrm{G} \dot{\$} O=$ "Y" .START

G $\$ 0=$ "N" . 4SREJ01

$P$ "Error In . 4SREJ contact PC\&DA"

G. ERROR

. 4SREJ11

$G \# 9>0.4$ SREJ 12

B 1010

P "No Rejects - Cannot BACK"

$S$. WAIT

G . 4SREJ01

. 4SREJ 12

$D \# 2=1$

S. $\mathrm{BACK}$

B 000

$\mathrm{D} \$ 0=\| * * *$ DELETING $* * *$ SN $n+\mathrm{R}(\# 9)$ I 6

$D \$ 0=\$ 0+" R C "$

$D \$ 0=\$ 0+R(\# 9) R 4$

$p$ \$0

S .WAIT

$\mathrm{D} R(\# 9) \cdot=" 1$

D $\# 9=\# 9-1$

G .4SREJOI

. 4SREJ13

$D \$ 2=" S N "+\$ 0$

: format SN (SN 123456)

4SREJ14

$D \$ 0=" S c a n$ Reject Codefor:" + $\$ 2 \mathrm{R} 6$
$D \$ 0=\$ 0+. "$ "

$P \$ 0$

D $\$ 0=" 1$

A

$G$ SO = "\#\#\#" .4SREJ16

G $\$ 0=$ "BACK" .4SREJOI

$G$ $\$ O=$ "EXIT" .4SREJ15

B 1010

: only back if REJECTS have been en

G . 4SREJ14

. 4SREJI5

$S$.EXIT

G $\$ 0=$ "Y". START

G $\$ 0=" N " .4$ SREJI4

P "Error In . 4SREJ Contact PC\&DA "

G . ERROR

. 4SREJ16

$D \# 9=\# 9+1$

$\mathrm{D} R(\# 9)=\$ 2 \mathrm{R} 6+\$ 0$

D $\$ 3=\$ 1+\$ 2$

D $\$ 3=\$ 3+$ i, REJECT CODE, RC "

$\mathrm{D} \$ 3=\$ 3+\$ 0$

$S$. SEND

G . 4SREJOI

4SREJEN

$Q$

: increment file $R$ pointer

: save serial \# w/o prefix + Re

: serial \# with "SN " prefix 
. OPERPRO

D $\$ 3=$ "DETAIL, OPERATION, PROCESSED"

$S$.SEND

Q

. COMENT

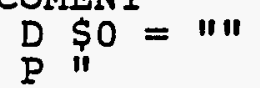

Comments or DONE"

A

$D \# 0=[\$ 0]$

G \#0<33. COMENT2

P "Coment Too Long Re-Enter "

- COMENT1

B 1010

S . WAIT

G. COMENT

. COMENT2

$G \$ O=" \|$. COMENT8

$G$ SO = "DONE" . COMENT8

$D \$ 2=\$ 0$

D $\$ 0=" \|$

$D I=0$

. COMENT3

$\mathrm{G} \$ 2=" 1$. COMENT6

D $\$ 3=\$ 2$ I I

G $\$ 3="$ " . COMENT4

D $\$ 0=\$ 0+\$ 3$

G $\$ 3=$ = ". COMENT5

$D \# 1=1$

G . COMENTS

. COMENT4

$D \$ 0=\$ 0+" "$

. COMENT5

$D \$ 2=\$ 2 M 128,2$

G . COMENT3

. COMENT6

G $\# I=I$. COMENT7 : test valid characters found flag

p "Invalia comment Re-Enter"

G. COMENTI

. COMENT7

$\mathrm{D} \$ 3=$ "HDR, COMM," + \$O

$S$.SEND

G . COMENT

. COMENT8

$Q$

- CLEARD

$D \# 5=0$

: flag to check if spaces only entered

: test left most character

: look for comma's

: no comma, use character

: set characters found flag to true

: replace commas with spaces

: strip left most character off

CLEARD1

$Q D(\# 5)=" 11$

$\mathrm{D} D(\# 5)=\| 1 "$

$D \# 5=\# 5+1$

G . CLEARD1

- CLEARR

D $\# 9=0$

. CLEARRI

Q R (\#9) = "I"

$D \# 9=\# 9+1$

G . CLEARRI

.SEND

D $\$ 3=", "+\$ 3$

$D \$ 3=D^{\prime}(2)+\$ 3$

$D \$ 3=", "+\$ 3$

$D \$ 3=\$ 3+1$,"

: clear data in file D

$\mathrm{X} M \mathrm{M}, \$ 3$

: clear data in file $\mathrm{R}$

: prepend operation number

: xmit to concentrator 
.WAIT

W 4

Q

- BACK

C $\$ 3=\# 2$

$\mathrm{D} \$ 3=$ "HDR, DELETE," + $\$ 3$

$S$.SEND

$Q$

. EXIT H

$D$
$P$ "Are You sure YouWant To EXIT? "

A

$G \$ O=~ " Y "$.EXIT HI

$G$ \$O $=$ "Y" .EXIT"HI

$\mathrm{G} \$ 0=" \mathrm{~N} "$.EXIT $\mathrm{H} 2$

$G \$ O=$ "n" .EXIT_H2

B 1010

G.EXIT_H

.EXIT HI

$\mathrm{D} \$ \overline{0}=$ "Y"

B 000

P $\| * *$ OPERATION $* * * *$ ABORTED $* * \|$

$S$.WAIT

$G$.EXITHEN

. EXIT H2

$D \$ \overline{0}=" N "$

$G$.EXITHEN

- EXITHEN

Q

-EXIT

D $\$$ "Are = "You Sure YouWant To EXIT? "

A

$G \$ 0=" Y "$.EXITI

$G \$ 0=$ "Y" .EXITI

$G$ \$O $=$ "N" .EXIT2

$\mathrm{G} \$ 0=" n "$.EXIT2

B 1010

G.EXIT

-EXITI

$D \$ 0=" Y "$

D $\$ 3=$ "HDR, EXIT, ALI"

$S$.SEND

B 000

$\mathrm{P} \| * *$ OPERATION $* * * *$ ABORTED $* * \|$

$S$.WAIT

$G$. EXITEN

- EXIT2

$D \$ 0=" N "$

G .EXITEN

- EXITEN

$Q$

. ERROR

$D \$ O=" "$

A

$G \$ O=$ "ABORT" .START

G.ERROR

. END

$D \$ 3=$ "HDR, COMPLETE, $0 "$

$S$.SEND

$\mathrm{P}$ "operation

$S$.WÃT
Completed.

It
: Subroutine to back up

: exit during header prompts
: in case " $n$ " was entered
: build exit record

: in case " $n$ " was entered 
G .START

. CONFIG

$\mathrm{Z} " \$+B V 7 \$-"$

: execute reader options with $\mathrm{z}$ command

B 11

: Loudest Level Beep

P "Setting PROCODE Standard Parms"

: Communication Parameters...

$\begin{array}{ll}F & 1000 \\ Z & \text { \$+PA3\$-" } \\ F & 0100 \\ Z & \text { \$+IA6\$-" } \\ F & 0010 \\ Z & \text { "\$+IB1\$-" } \\ \text { F } & 0001 \\ Z & \text { "\$+ICI\$-" } \\ \text { F } & 1000 \\ Z & \text { "\$+II7\$-" }\end{array}$

: play with the status lights

: Enable Multi-Drop Protocol

: 9600 Baud

: Even parity

: 1 stop bit

: 7 data bit word

: Bar Code Parameters...

\begin{tabular}{|c|}
\hline $\begin{array}{l}0100 \\
" \$+C A 6 \$-" 1 \\
0010 \\
" \$+C B 10 \$-" 1 \\
0001 \\
" \$+R B 0 \$-" \\
1000 \\
" \$+C C 000 \$-" \\
0100 \\
" \$+C D 00 \$-" 1 \\
0010 \\
" \$+C E 0000 \$-" 1 \\
0001 \\
" \$+C G 0 \$-" \\
1000 \\
\text { "\$+CFO } \$-" \\
0100\end{array}$ \\
\hline
\end{tabular}

: play with the status lights

: Enable Interleaved 2-of-5 ( 6 character length)

: Enable code 3-of-9 Symbology

: Disable code 3-of-9 Full Ascii option

: Disable 2 of 5

: Disable Codabar symbology

: Disable All UPC Symbologies

: Disable code 11 symbology

: Disable Code 93 symbology

: Reader Operating Parameters...

$$
\begin{aligned}
& \text { F } 0010 \\
& \text {.Z "\$+ODO\$-" } \\
& \text { F } 0001 \\
& 2 \text { "\$+DXO\$-" } \\
& \text { F } 1000 \\
& \text { Z "\$+PBO\$-" } \\
& \text { F } 0100 \\
& \text { Z "\$+OAOS-" } \\
& \text { F } 0010 \\
& 2 \text { "\$+SAO\$-" } \\
& \text { F } 0001 \\
& \text { Z "\$+SBO\$-" } \\
& \text { F } 1000 \\
& 2 \text { "\$+SCO\$-" } \\
& \text { F } 0100 \\
& 2 \text { "\$+PBO\$-" } \\
& \text { F } 0010 \\
& \text { Z "\$+DEO\$-" } \\
& \text { F } 0001 \\
& \text { Z "\$+XGI\$-" } \\
& \text { F } 1000 \\
& \mathrm{~F} \times \mathrm{XxX} \\
& \text { B } 00
\end{aligned}
$$

: Buffered Display Mode

: US Ascii Character set

: Computer Response Not Required

: Preamble A Not Required

: Scanner Timeout - None

: scanner operation - one shot

: Trigger Event - Level

: Computer Response Not Required

: Append Time - Disabled

: Resume IRI (on Power Up) - Enabled

: status lights default settings 


\section{B 1}

$\mathrm{Z} " \$+B V 1 \$-"$

B 0

$\mathrm{Z} " \$+B V 7 \$-"$

P "Connect Drop

D $\$ 0=\| "$

$\mathrm{V}$ B D E K S; 200

$\mathrm{G} \# 0=0$. CONFIG2

G . CONFIG3

. CONFIG2

P $" * *$ Scan Badge $* \star \star \star *$ To continue $* \|$

$\mathrm{V} B \mathrm{DEK}$ S; 200

$G \# 0=0$. CONFIGI

G . CONFIG4

. CONFIG3

$G \# 0=6$. CONFIG5

G . CONFIG2

. CONFIG4

$G \# 0=6$. CONFIG6

G . CONFIGI

: Loudest Level Beep

Remove Laptop!"

: look for timeout

CONFIG5

$G \$ 0=" \# \# \# "$.CFGEND : Accept HP format only

G. CONFIG2

. CONFIG6

$G \$ 0=" \# \# \# "$.CFGEND : Accept HP format only

G. CONFIGI

. CFGEND

$Q$

- D LOAD

$\overline{\mathrm{Z}}$ "\$+PA2\$-"

$\mathrm{Z} " \$+B V 3 \$-"$

: Enable Polling Mode D Protocol for laptop download

B 1

Z "\$+BVI\$-"

B 0

F 1000

F 1100

P "Remove Drop Wireconnect Laptop!"

F 1110

F 1111

V B D E K S; 200

F 1110

P $\| * * * * *$ Scan $* * * * * * * *$ EXIT IRL $* * \|$

F 1100

F 1000

F 0000

V B D E K S; 200

$G$. D_LOAD 


\section{EXHIBIT 6}

Description

A portion of the MDS Tape User's Guide

- instructions for the TM Operator
Page (s)

$82-86$ 
- DENOTES CHANGE

PROGRAM: MDS-TAPE USER'S GUIDE OPERATION TITIE: General Operation
MANUAL NO. MD-70591

OPERATION: 01 ISSUE NO: 3 SHEET 1 OF 2

ECN(S) INCORPORATED: $890957 \mathrm{MD}-\mathrm{C}$

APPROVED. BY:

J. A. Thomes, 5-22-89

APPROVED BY:

D. R. Reed, 5-22-89

EFFECTIVITY: See Publication Record

\section{GENERAI OPERATION OF THE TRANSACTION MANAGER.}

1. TURNING ON THE TRANSACTION MANAGER.

* 1.1. If the display is blank, depress the "power" button to turn on the Transaction Manager. The red "POWER" light will come on. The first program prompt will display the Drawing number and Issue of the IRI program and ask for verification "SCAN HP". If this prompt does not appear, contact your supervisor.

1.2. If the Transaction Manager is displaying the Drawing number prompt, then it is available for use and does not need to be rebooted (turned on).

1.3. If the Transaction Manager is displaying anything but the Drawing number prompt, it is already in use and can not be used until the current operation is completed.

2. SCANNING BAR CODES WITH THE WAND OR LASER GUN.

2.1. When prompted to scan data into the Transaction Manager, either the wand or laser gun may be used.

2.2. A single beep after a scan indicates a good read. If multiple beeps are heard, an entry error has occured. In this case the user should examine the prompt and scan the appropriate code.

* 2.3. An operation may be aborted at any time by scanning the "ERASE" bar code. Scanning this bar code (or typing "EXIT" and pressing <Enter> from the keyboard) will abort all data scanned for this log-on of the operation. 
-DENOTES CHANGE

PROGRAM: MDS-TAPE USER'S GUIDE

OPERATION TITLE: General Operation

MANUAL NO. MD-70591

OPERATION: 01 . ISSUE NO: 3

SHEET 2 OF 2

3. ENTERING DATA THROUGH THE KEYBOARD.

3.1. Make sure the "CAPS" lock is turned on. If the red light on the "CAPS" key (far left side of keyboard) is not illuminated, then depress it. Having "CAPS" on capitalizes all letters that are entered through the keyboard.

3.2. Always press the <Enter> key after the appropriate data has been typed in. For example, if you are prompted to enter the "Quantity of Parts Processed", you would type a number (for example: "123") and then press the <Enter> key.

3.3. If a typing error is made before the <Enter> key has been pressed, the error may be corrected by pressing either the "clr" key (top row) to clear all data entry, or by using the back arrow key (top row) to delete one character at a time.

3.4. Special characters (in white, above keys) may be typed by holding down the <Alt> key and at the same time depressing the required key from the keyboard. For example to type a hyphen, hold down the <Alt> key and depress the letter "U" (notice the "-" above the "U" key). 


\section{- DENOTES CHANGE}

PROGRAM: MDS-TAPE USER'S GUIDE OPERATION TITLE: TaPE01

MANUAL NO. MD-70591

OPERATION: 10 ISSUE NO: 6 SHEET 1 OF 3

ECN(S) INCORPORATED: 890957MD-C

APPROVED BY: J. A. Thomes, 5-22-89

APPROVED BY: $\quad$ D. R. Reed, 5-22-89

EFFECTIVITY: See Publication Record

PROGRAM: TAPEOI (STATION 1)

* 1. DSA871817, Tape 01.

* 1.1. The first program prompt will display the Drawing number and Issue number of the program along with "SCAN HP". If this prompt is not on the display, see "TURNING ON THE TRANSACTION MANAGER" in the "GENERAL OPERATION OF THE TRANSACTION MANAGER" section.

* 1.2. Scan the bar code on the back of your employee badge if the correct program name and Drawing No. are displayed. Your four digit HP\# must be scanned with a wand or laser gun, and cannot be entered from the keyboard. If either the name and;or Drawing No. are incorrect, inform your supervisor of the discrepancy.

* 2. Does DSA871817, Match PI? (Y/N).

* 2.1. Verify that the drawing number and issue displayed on the screen matches the drawing number and issue listed on the PI for this operation. Scan the "Y" bar code from the bar code menu if this is correct. If either the drawing number and/or the issue are incorrect, scan the "N" bar code and inform your supervisor of the discrepancy.

NOTE: You may also type "Y" or "N" from the keyboard, then press the <Enter> key. 
- DENOTES CHANGE

PROGRAM: MDS-TAPE USER'S GUIDE

MANUAL NO. MD-70591

OPERATION TITLE: TapEO 1

* 3. Scan Operation \# from Menu.

* 3.1. Scan the appropriate operation Number bar code from the bar code menu. The Operation Number must be of the format "Onnnn", where " $n$ " is any number.

* 4. Scan Product Lot from Reel Label.

* 4.1. Scan the Product/Lot bar code from the label located on the reel. The bar code must be of the format "AnnnnnnLnnnnn", or

"AnnnnnEnnnnn" where " $n$ " is any number.

* 5. Scan Reel \# from Reel Label.

5.1. Scan the Reel \# bar code located on the reel. The Reel \# must be of the format "Rnnn-nn", where " $n$ " is any number.

6. Scan QC \# or Tool \# as Prompted.

6.1. For all LAMINATE/RESIST operations, scan the appropriate eC \# bar code for the displayed part number (AInnnn). QC \# must be of the format "nnnnn-an", where " $n$ " is any number and " $a$ " is any letter.

NOTE: You may also type the QC \# from the keyboard, then press the <Enter> key.

6.2. For all EXPOSE operations, scan the appropriate TOOL No. bar codes as prompted. Photo-Tool numbers must be preceded by the letters "PT" and Tool-Report numbers must be preceded by the letters "TR". (Examples: PT123-B; TR54321)

NOTE: You may also type the PT No. or TR No. from the keyboard, then press the <Enter> key. 